\title{
PETROLOGIA DO MACIÇO ALCALINO DE ACAHAY, PARAGUAY ORIENTAL
}

\section{PIETRO COMIN-CHIARAMONTI*, CELSO DE BARROS GOMES**, ENZO MICHELE PICCIRILLO****, GIULIANO BELLIENI****, ANA MARIA CLERICI CASTILLO******, GABRIELLA DEMARCHI***, PASQUALE GALLO* e JUAN CARLOS VELAZQUEZ******} \begin{abstract}
PETROLOGY OF THE ALKALINE MASSIF OF ACAHAY, EASTERN
PARAGUAY. The alkaline massif of Acahay, subcircular in shape and covering an area of about $17 \mathrm{~km}^{2}$, intrudes into Silurian sandstones belonging to the Caacupé Formation. It is located at the intersection of the NW-trending fault system of Ypacarai and the Acahay lineament. The massif is mainly made up by intrusive rock-types forming two distinctive groups, alkali gabbros-syenogabbros-syenodiorites-syenites and essexitic gabbros-essexites, and, subordinately, by volcanic material represented by the sequence trachybasalts-trachyandesites-trachytes. Feldspars (plagioclases and alkali feldspar) and clinopyroxenes are their more abundant minerals, while nepheline, biotite, amphibole and olivine occur in minor proportions. Accessories phases include opaques (titanian magnetite and ilmenite), apatite, titanite and zircon. A potassic affinity clearly characterizes the $\mathrm{w}$ hole set of rocks and major and trace elements $v s . \mathrm{MgO}$ plots show significant negative correlations for $\mathrm{SiO}_{2}, \mathrm{Al}_{2} \mathrm{O}_{3}, \mathrm{Na}_{2} \mathrm{O}, \mathrm{K}_{2} \mathrm{O}, \mathrm{Ba}, \mathrm{Rb}$ and $\mathrm{Nb}$ and positive ones for $\mathrm{CaO}$, $\mathrm{TiO}_{2}, \mathrm{FeO}, \mathrm{P}_{2} \mathrm{O} 5, \mathrm{Cr}$ and $\mathrm{Ni}$. Chemical (minerals and rocks) and petrographic evidences suggest for the Acahay rocks an origin related to crystal fractionation processes. On the basis of mass balance calculations it is possible to derive, within each lithological group, the more evolved rock-types from the less evolved material by the removal of different amounts of solid phases. Also numerical values are consistent with a common derivation from the alkali gabbros for the trachybasalts and essexitic gabbros. Geochemical (e.g. $\mathrm{La} / \mathrm{Y})$ and isotopic $(\mathrm{Sr})$ data indicate that the Acahay alkali gabbros are probably originated from a lithospheric mantle source, of garnet peridotite type, assuming $4 \%-7 \%$ of melting degree.
\end{abstract}

Keywords: Alkaline massif, petrology, Acahay, Eastern Paraguay.

RESUMO $O$ maciço alcalino de Acahay tem forma subcircular, cobre área aproximada de $17 \mathrm{~km}^{2}$ e se acha encaixado em arenitos silurianos da Formação Caacupé. Ele está localizado na intersecção do sistema de falhas de Ypacaraí, de direcão NW-SE, com o lineamento de Acahay. O maciço é constituído, em sua maior parte, de rochas intrusivas que formam dois grupos distintos - gabros alcalinos-sienogabros-sienodioritos-sienitos e gabros essexfticos-essexitos - e, subordinadamente, de tipos extrusivos representados pela seqüência traquibasaltos-traquiandesitos-traquitos. Feldspatos (plagioclásios e feldspato alcalino) e piroxênios são os minerais mais abundantes, ocorrendo também nefelina, biotita, anfibólios e olivina, em menor proporção. Ás fases acessórias incluem opacos (magnetita com Ti e ilmenita), apatita, titanita e zircâb. Dados químicos testemunham o caráter medianamente potássico do conjunto de rochas do maciço. Gráficos que relacionam elementos principais e traços com $\mathrm{MgO}$ mostram boa correlação negativa para $\mathrm{SiO}_{2}, \mathrm{Al}_{2} \mathrm{O}_{3}$, $\mathrm{Na}_{2} \mathrm{O}, \mathrm{K}_{2} \mathrm{O}, \mathrm{Ba}, \mathrm{Rb}$ e Nb e positiva para $\mathrm{CaO}, \mathrm{TiO}_{2}, \mathrm{FeO}, \mathrm{P}_{2} \mathrm{O}_{5}, \mathrm{Cr}$ e Ni. Evidências químicas (minerais e rochas) e petrográficas são indicativas da formação das rochas de Acahay por processos de cristalização fracionada. Cálculos de balanço de massa confirmam a possibilidade de derivar, dentro de cada agrupamento litológico e mediante a remoção de fases minerais em proporções as mais diversas, os termos mais evolúídos a partir do material menos evoluído. Da mesma forma, demonstram a viabilidade de uma derivação comum para os traquibasaltos e gabros essexíticos a partir dos gabros alcalinos. Dados geoquímicos (e.g. La/Y) e isotópicos $(\mathrm{Sr}$ ) sugerem que os gabros alcalinos de Acahay foram provavelmente originados de uma fonte litosférica, do tipo peridotito com granada, com grau de fusão da ordem de $4 \%-7 \%$.

Palavras-chaves: Maciço alcalino, petrologia, Acahay, Paraguai Oriental.

INTRODUÇÃO A exemplo do sucedido na borda oriental da Bacia do Paraná, o magmatismo alcalino também se manifestou na sua porção ocidental, como evidenciado por dezenas de corpos intrusivos que se estendem por amplo intervalo de tempo (Permiano Superior-Oligoceno, $240 \mathrm{Ma}$ - 36Ma: Amaral et al. 1967, Comte \& Hasui 1971, Palmieri 1973, Palmieri \& Arribas 1975, Stormer et al. 1975, Bitschene \& Lippplt 1984, Eby \& Mariano 1986, Bitschene 1987). Eles são vistos como pertencentes a uma única província - Paraguai Oriental - com as rochas ocupando duas regiões geográficas distintas do país, central e norte (Almeida 1983), ou como distribuídos segundo três províncias perfeitamente individualizadas: Alto Paraguai, Amambay e Central (Livieres \& Quade 1987).

Informações gerais demonstram que essas intrusões acham-se tectonicamente relacionadas às grandes feições es- truturais características daquele país: 1 . Arco Central do Paraguai (Putzer 1962), também conhecido na literatura como Arco de Assunção (Northfleet et al. 1969, Almeida 1983), uma unidade contínua de direção geral NS, à qual se associam abundantes falhas e fraturas menores. Mais recentemente, esse conjunto vem sendo referido como formado, em realidade, de duas estruturas orientadas para NW-SE - os chamados anticlinais do Apa (parte norte do Paraguai) e de Assunção, com o Sinclinal de São Pedro se dispondo entre elas (Livieres $\&$ Quade 1987). 2. Diversas estruturas em anticlinal, alinhadas para NE-SW (Ponta-Porã, Capitán Bado, Igatímí, Caaguazú), representando antigas zonas de fraqueza pré-cambrianas reativadas no Mesozóico (Petri \& Fúlfaro 1983) e lineamentos isolados orientados seja para NE, seja para NW. Na figura 1 , em parte extraída de Livieres \& Quade (1987), é possível observar claramente que os vários corpos alcalinos acham-se

* Instituto de Mineralogia, Petrografia e Geoquímica, Universidade de Palermo, Via Archiraffi 52,90100 Palermo, Itália
** Instituto de Mineralogia e Petrografia, Universidade de Trieste, Piazzale Europa 1, 34100 Trieste, Itália. Endereço permanente: Instituto de Geociências, Universidade de São Paulo, Caixa Postal 20899, CEP 01498, São Paulo, SP, Brasil

*** Instituto de Mineralogia e Petrografia, Universidade de Trieste, Piazzale Europa 1, 34100 Trieste, Itália

**** Departamento de Mineralogia e Petrologia, Universidade de Pádua, Corso Garibaldi 36,35100 Pádua, Itália

***** Instituto de Ciências Básicas, Universidade Nacional de Assunção, Cidade Universitária de São Lourenço, Assunção, Paraguai 
localizados ao longo dos grandes traços estruturais mencionados ou no cruzamento de duas direções preferenciais.

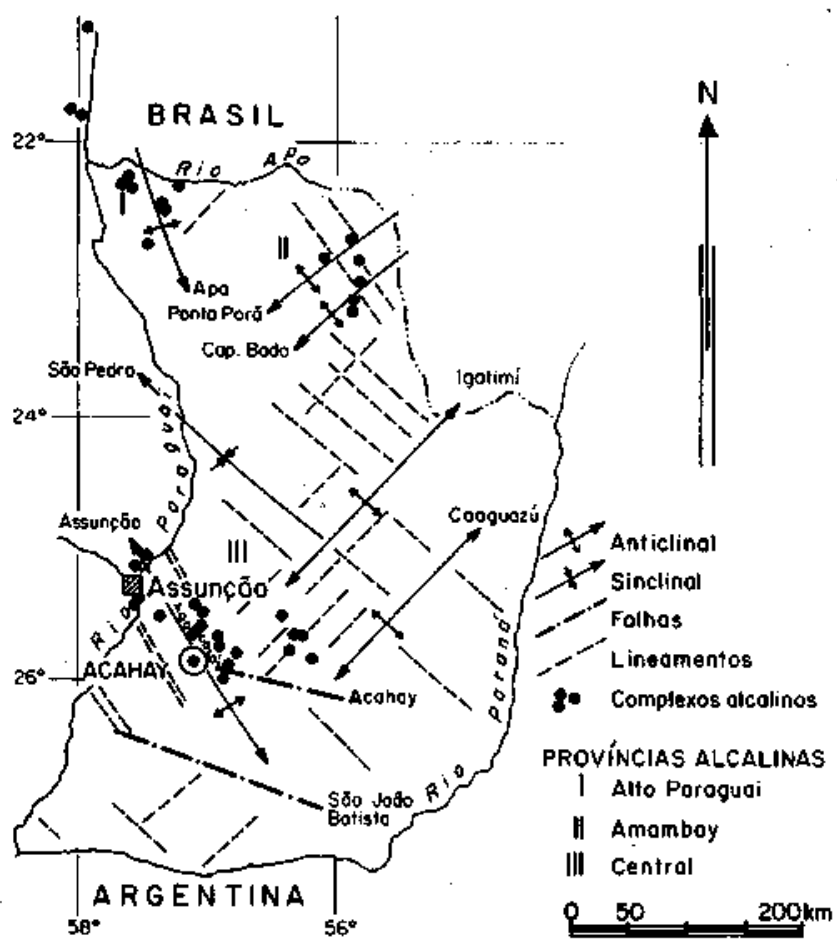

Figura 1 - Dismibuiça geral das ocorréncias alcalinas do Paraguai

Figure 1 - General distribution of alkaline oceurrences of Paraguay

Embora a citação sobre a existência de abundantes intrusões alcalinas no Paraguai já conste da literatura há muito (Harrington 1950, Eckel 1959, Putzer 1962, Putzer \& van den Boom 1962), esse magmatismo é ainda pouco conhecido no seu todo, posto que apenas algumas ocorrências foram alvo de investigações mais minuciosas, com a correspondente divulgação dos dados coligidos (e.g., Sapukai \& Palmieri 1973, Palmieri \& Arribas 1975). Uma caracterização sucinta, reunindo os principais tipos de rochas e modos de ocorrência, que se faz acompanhar das coordenadas de localização e da literatura pertinente, é dada por Livieres \& Quade (1987) para os 32 corpos presentemente conhecidos. E de se ressaltar a ampla diversidade litológica e de jazimento, bem como o fato de a presença de carbonatitos achar-se aparentemente restrita à Província de Amambay (Cerro Chiriguelo = Cerro Cora: Berbert 1973, Herbert \& Triguis 1973, Eby \& Mariano 1986, Censi et al. 1989; Cerro Sarambi: Palmieri et al. 1974, Eby \& Mariano 1986). Das três províncias reconhecidas, a do Alto Paraguai é a menos conhecida geologicamente, possuindo uma documentação em geral escassa e fragmentária. Por outro lado, a Central, reunindo maior número de intrusões e cobrindo amplo espectro de idade, com os valores de K/Ar apontando para dois grandes pólos de atividade magmática (Mesozóico, $184 \mathrm{Ma}-100 \mathrm{Ma}$, e Terciário, $61 \mathrm{Ma}-36 \mathrm{Ma}$ ), nos quais as relações magmatismo e tectonismo mostram-se melhor definidas, é a que tem sido objeto de mais atenção e que, conseqüentemente, conta com maior contingente de dados. Nos últimos anos, à vista da potencialidade econômica das ocorrências de carbonatitos, a Província de Amambay passou a receber tratamento especial e, como resultado, vem sendo pesquisada de forma intensa e sistemática.

O presente trabalho trata do estudo mineralógico, petrológico e geoquímico do maciço alcalino de Acahay, localizado na Província Central, e até então somente objeto de referências breves e muito gerais na literatura geológica do Paraguai. Informações mais pormenorizadas sobre alguns aspectos deste trabalho, particularmente o quimismo de minerais e rochas são encontradas em Gallo (1988).

GEOLOGIA LOCAL O maciço alcalino de Acahay, ocupando área aproximada de $17 \mathrm{~km}^{2}$, possui forma subcircular e acha-se encaixado em arenitos silurianos pertencentes à Formação Caacupé da Série Cordillera (Palmieri \& Arribas 1975). Localmente, as encaixantes foram afetadas pela massa intrusiva, como evidenciado por feições texturais, dando lugar à formação de pequena aureóla de metamorfismo. $\mathrm{O}$ maciço destaca-se prontamente do ponto de vista morfológico, com as suas bordas chegando a atingir altura pouco superior a 500 $\mathrm{m}$; a área interna mostra-se deprimida ao nível de $350 \mathrm{~m}$ e uma pequena elevação central alcança a cota de $450 \mathrm{~m}$.

Como é vísivel na figura 1 , o maciço situa-se na intersecção de duas grandes feições estruturais, entre o sistema de falhas escalonadas de Ypacaraí, de direção NW-SE, e a falha transversal de Acahay, sendo a sua colocação fortemente influenciada por aquele elemento.

Até o momento não se dispõe de determinações radiométricas, para as rochas de Acahay, com as relações estratigráficas sugerindo formação pós-süuriana. Muito provavelmente elas façam parte do mesmo evento magmático mesozóico de natureza alcalina representado em outros pontos da Província Central e para o qual as idades K/Ar disponíveis, ainda pouco numerosas, indicam valores entre $100 \mathrm{Ma}$ e $184 \mathrm{Ma}$ (Cerro Aguapety: Bitschene 1987; Cerro Santo Tomás: Conte \& Hasui 1971, Palmieri \& Arribas 1975; Cordiüera Ybyturuzú: Bitschene 1987; Sapukai: Comte \& Hasui 1971, Palmieri \& Arribas 1975; valores deste último trabalho recalculados por Sonoki \& Garda 1988, usando as constantes de decaimento recomendadas por Steiger \& Jãger 1978). Contudo, as rochas alcalinas, distantes apenas poucas dezenas de quilômetros e que guardam características petrográficas similares (Cerro Santo Tomás, Sapukai), apresentam idades compreendidas num intervalo bem menor - desde que excluído o dado aparentemente anômalo de 184 Ma obtido para a primeira ocorrência, e os valores de cerca de $179 \pm 10 \mathrm{Ma}$ relativos a Sapukai ( $c f$. Comte \& Hasui 1971) que são passíveis de questionamento (Palmieri \& Arribas 1975) -, respectivamente, 126 $\mathrm{Ma}$ - $137 \mathrm{Ma}$ e $100 \mathrm{Ma}$ - $136 \mathrm{Ma}$.

O maciço acha-se constituído dominantemente de rochas intrusivas, dispostas ao longo das suas bordas ou ocupando grande extensão da porção central; de modo subordinado, aparecem variedades extrusivas que ocorrem internamente em quatro áreas distintas e de forma irregular (Fig. 2). A localização das amostras investigadas é mostrada na figura 3. A atividade filoniana parece ter sido inexpressiva, com os poucos diques reconhecidos, verticais e de possança centimétrica a decimétrica, dirigidos para NW-SE e EW.

PETROGRAFIA E QUÍMICA MINERAL Petrograficamente, a fácies intrusiva do maciço acha-se representada por rochas de afinidade gábrica, sendo a textura, em geral, granular hipidiomórfica, como ligeira tendência para porfíritica (plagioclásios e piroxênios com fenocristais) junto às amostras de composição mais essexítica. Por outro lado, as variedades sieníticas, correspondentes aos poucos diques encontrados na área, exibem caráter alotriomórfico e têm no feldspato alcalino a sua fase mais importante. A fácies vulcânica é caracteristicamente porfirítica, com fenocristais de dimensões submilimétricas a milimétricas, em sua maior parte de plagioclásios e de piroxênios, imersos em massa fundamental afanítica apenas parcialmente cristalina. A sua composição é variável, passando de traquibasaltos a traquitos. É de salientar que as rochas desta última fácies, que ocupam as partes mais altas do maciço, adquirem textura granoblástica quando em 
contato com as anteriores, além de novos minerais (anfibólio de natureza kaersutítica), como observado em amostra de traquiandesito.

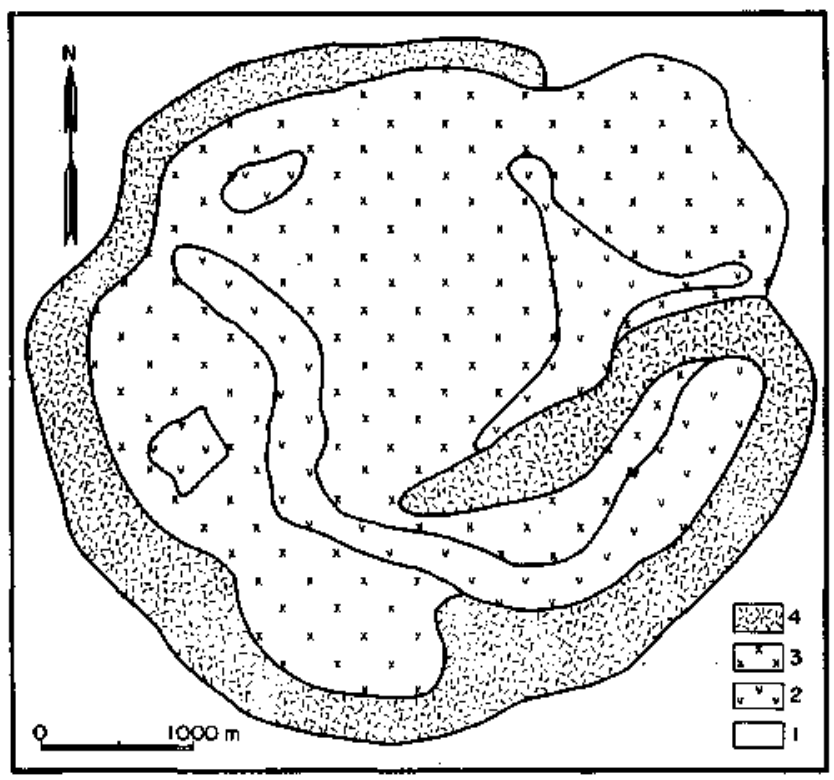

Figura 2 - Geologia esquemática do complexo de Acahay (Gallo 1988). Legendas: 1. Arenitos siluríanos; J. Traquibasaltos, traquiandesitos, traquitos; 3. Teralitos, gabros essexüicos, sienogabros; 4. Essexitos, sienodioritos Figure 2 - Schematic geology of the Acahay complex (Gallo 1988). Legend: 1. Silurian sandstones; 2. Trachybasalts, trachyandesites, trachytes; 3 . Theralites, essexitic gabbros, syenogabbros; 4. Essexites, syenodiorites

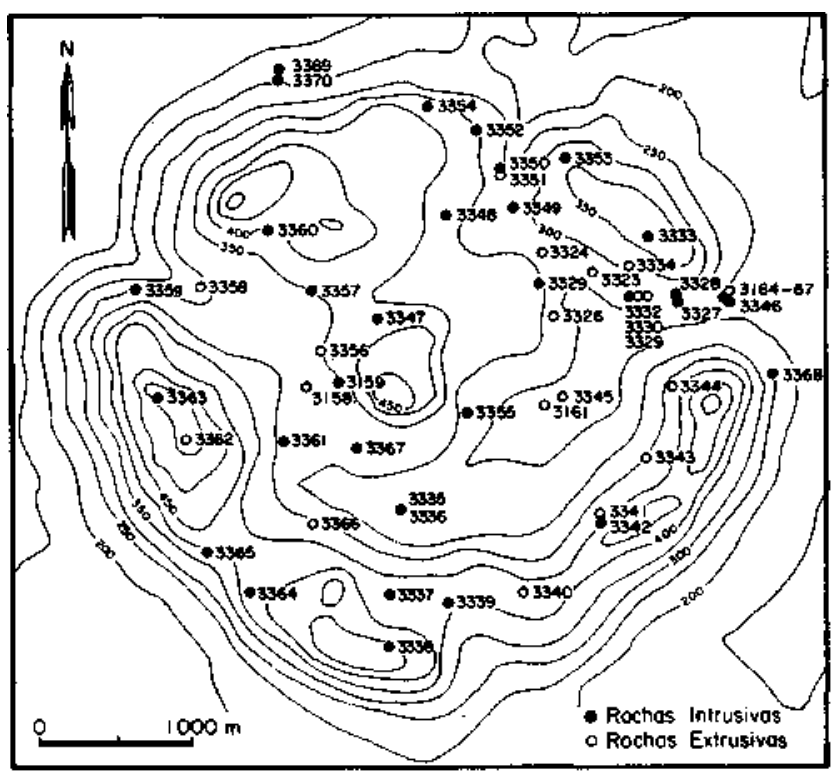

Figura 3-Mapa de localização das amostras investigadas Figure 3 - Topographic map showing the analyzed samples. Symbols as in figure 11

Do ponto de vista mineralógico, a suíte intrusiva de afinidade gábrica consiste de plagioclásios e piroxênios (ocasionalmente zonados, quando na condição de fenocristais), aparecendo, de forma subordinada, nefelina, biotita, anfibólios, feldspato alcalino (de ocorrência intersticial ou ocupando as bordas dos cristais de plagioclásio) e, mais raramente, olivina; como acessórios reconhecem-se opacos, apatita, titanita e zircão. A composição dos plagioclásios cobre o intervalo labradorita-oligoclásio, e o feldspato alcalino parece corresponder a sanidínio e a anortoclásio. Por sua vez, os piroxênios são de natureza salítica e podem conter inclusões aciculares de rutílo; perifericamente, alteram-se em anfibólio marrom e/ou biotita. Nas variedades mais sienfticas, o feldspato alcalino, guardando o mesmo intervalo composicional anterior, assume maior expressão volumétrica; adicionalmente, tem-se titanita como acessório. Ao lado de plagioclásios e piroxênios, como fenocristais e parte integrante da massa fundamental, a suíte vulcânica contém ainda olivina, biotita, nefelina, feldspato alcalino, vidro e, como acessórios, opacos, apatita e zircão. Os plagioclásios, por vezes zonados, são em geral mais cálcicos que os anteriores. Já os piroxênios possuem características similares, a principal diferença residindo no caráter zonado, com tendência egirínica em direção às bordas, exibido pelos cristais de algumas rochas.

Quando colocados no diagrama de classificação química de De La Roche et al. (1980) (Fig. 4), os tipos intrusivos (38 análises) distribuem-se segundo os campos dos teralitos, gabros alcalinos, gabros essexíticos, sienogabros, essexitos e sienodioritos, com as três amostras de dique apresentando natureza sienítica. Os extrusivos (20 análises) ocupam os campos dos traquibasaltos, traquiandesitos e traquitos, e apenas uma única amostra no campo dos fonotefritos. Em termos percentuais (cf. Gallo 1988), a primeira fácies possui distribuição marcadamente bimodal - os gabros essexíticos e sienodioritos são as classes mais abundantes. A efusiva é unimodal e tem nos traquiandesitos o seu tipo petrográfico mais representativo.

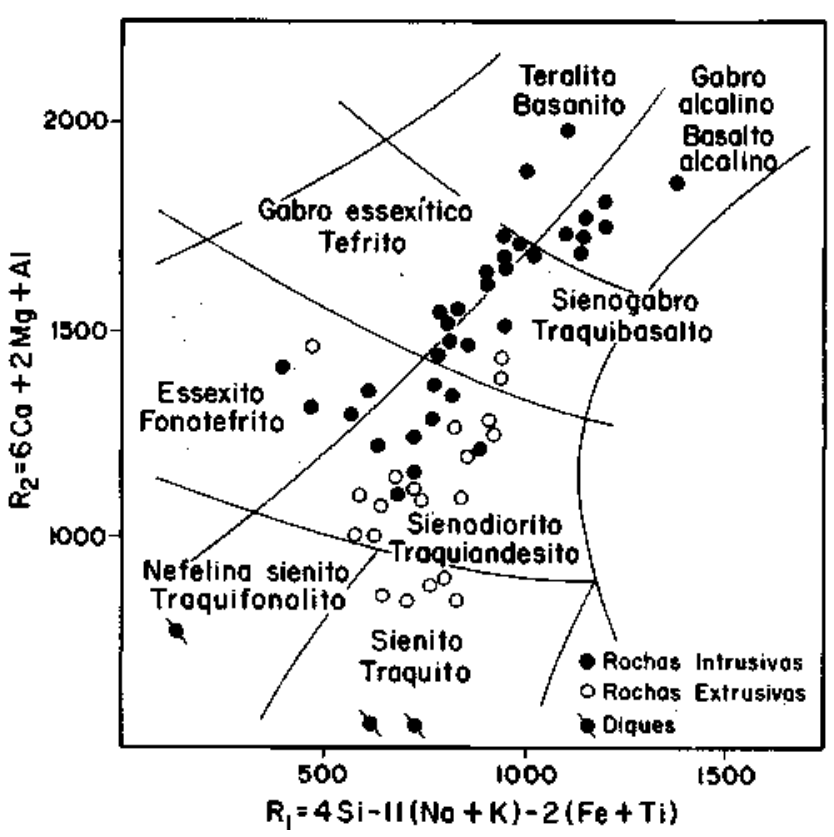

Figura 4 - Projeção das rochas analisadas no diagrama de classificação química R1-R2 de De la Roche et al. (7950;

Figure 4 - Plot of the analyzed rocks in the R 1-R2 chemical classificative diagram (after De La Roche et al. 1980)

O quimismo das fases minerais, perfazendo um total 250 análises completas, foi determinado com uma microssonda ARL, modelo SEMQ, operando a $15 \mathrm{kV}$ e $20 \mathrm{nA}$. Foram empregadas substâncias naturais como padrões, e os dados analíticos corrigidos com auxílio de programa de uso interno (Magic). Para os valores de $\mathrm{Fe} 2+\mathrm{e} \mathrm{Fe} 3+$ junto a piroxênios, anfibólios e opacos, foram utilizados, respectivamente, os cálculos de Papike et al. (1974) e Carmichael (1967). 
Feldspatos e Nefelina Análises representativas de plagioclásios, feldspato alcalino e nefelina são fornecidas na tabela 1. Or, Ab e An, e Ne, Ks e Qz foram recalculados para representação nos diagramas ternários, respectivamente, dos feldspatos e da nefelina (Fig. 5).

O zoneamento normal dos plagioclásios e a sua grande variação composicional ( $\mathrm{An}_{76-14}$, extrusiva; $\mathrm{An}_{78-17}$, intrusiva) devem ser notadas; o feldspato alcalino apresenta maior dispersão nas variedades intrusivas (Fig. 5). Ainda quanto a esta suíte, os últimos minerais mostram nítida diminuição do conteúdo de Or com o grau de evolução da rocha. A nefelina (Fig. 5) concentra-se preferencialmente no intervalo $\mathrm{Ne} e$ possui em geral baixo Qz, com os dois valores mais altos obtidos (Tab. 1) sujeitos a restrições.

As temperaturas médias $\left(\mathrm{T}^{\circ} \mathrm{C}\right)$ obtidas para os plagioclásios com o geotermômetro de Mathez (1973) - condições anidras para as rochas efusivas e $\mathrm{PH}_{2} \mathrm{O}=1 \mathrm{kbar}$ para as intrusivas -, são as seguintes: traquibasaltos, 1089; traquiandesitos, 1137; traquitos, 854; teralitos, 1024; gabros alcalinos, 1039; sienogabros, 1004; sienodioritos, 1088; sienitos, 903; gabros essexíticos, 974; e essexitos, 998 .

Os cálculos feitos para as fases coexistentes plagioclásio feldspato alcalino com o geotermômetro de Powell \& Powe (1977) fornecem valores de cerca de $800^{\circ} \mathrm{C}$ até menos de $400^{\circ} \mathrm{C}$, indicando temperaturas de reequilíbrio em condições subsólidas.
Piroxênios Os dados químicos relativos aos piroxênios (Tab. 2) apontam para vísivel concentração no campo da salita (cf. Poldervaart \& Hess 1951), como evidenciado no diagrama Ca-Mg-( $\left.\mathrm{Fe}^{2+}+\mathrm{Fe}^{3+}+\mathrm{Mn}\right)$ (Fig. 6). Seja na suíte extrusiva, seja na intrusiva, é observável a tendência no sentido de algum enriquecimento em $\mathrm{Ca}$ e, de forma mais acentuada, em $\mathrm{Fe}$, sem contudo atingir o campo da ferrossalita. Na base do conteúdo em titânio, esses minerais podem, em quase sua totalidade, ser definidos como salita titanífera $(0,025$ - 0,050 átomos de Ti por fórmula estrutural), pela nomenclatura proposta por Rock (1982).

$\mathrm{Na}$ série efusiva (traquibasaltos e traquitos), o valor de $\mathrm{mg}$ $(\mathrm{mg}=\mathrm{Mg} / \mathrm{Mg}+\mathrm{Fe} 2+)$ decresce de 0,888 a 0,793 , enquanto na intrusiva (gabros alcalinos a sienitos), de 0,863 a 0,720 . Variações químicas marcantes dentro da mesma amostra, encontradas nos dois conjuntos e em diversos tipos de rochas, têm como ponto comum a formação de fases de cristalização posterior, invariavelmente mais enriquecidas no componente acmítico.

Quando os dados são projetados no diagrama convencional $\mathrm{Na}-\mathrm{Mg}-(\mathrm{Fe} 2++\mathrm{Fe} 3++\mathrm{Mn}-\mathrm{Na})$ (Fig. 7), nota-se claramente o pequeno papel desempenhado pela molécula de egirina na formação desses minerais. Ainda que o seu crescimento seja indiscutível para as duas suítes, a seqüência evolutiva dos piroxênios de Acahay apresenta caráter apenas moderadamente alcalino, uma vez confrontada com a de outras ocor-

Tabela 1 - Teores (em \%) de Or, Ab e An em feldspatos e de Ne, Ks e Qz em nefelina, das rochas de Acahay, calculados a partir de análises químicas dos mesmos minerais. Legendas, igualmente aplicáveis às demais tabelas: Y.fenocristais (0,5 mm -1,0 mm); MF. megafenocristais (>2,0 mm); Mc. macrocristais (1,0 mm - 2,0 mm); $\mathbf{m F}$. microfenocrisíais (0,2 mm - 0,5 mm); M. massa fundamental $(<0,2 \mathrm{~mm}) ; \mathrm{m}$. micrólitos $(>0,2 \mathrm{~mm}) ; \mathrm{N}$. núcleo dos cristais; I. região intermediária; B. borda

Table 1 - Or, $\mathrm{Ab}$ and An contents in feldspars and $\mathrm{Ne}, \mathrm{Ks}$ and Qz contents in nepheline from the Acahay rocks, calculated as from chemical analysis of the same minerals (captions equally applicable to other tables: F. phenocrysts $(0.5 \mathrm{~mm}-1.0 \mathrm{~mm})$; MF. megaphenocrysts $(2.0 \mathrm{~mm})$; Me. macrocrysts $(1.0 \mathrm{~mm}-2.0 \mathrm{~mm}) ; \mathbf{~ m F}$. microphenocrysts $(0.2 \mathrm{~mm}-0.5 \mathrm{~mm})$; M. groundmass $(<0.2 \mathrm{~mm}) ;$ m. microlites $(<0.2 \mathrm{~mm})$; N. core; I. intermediate region; B. rim

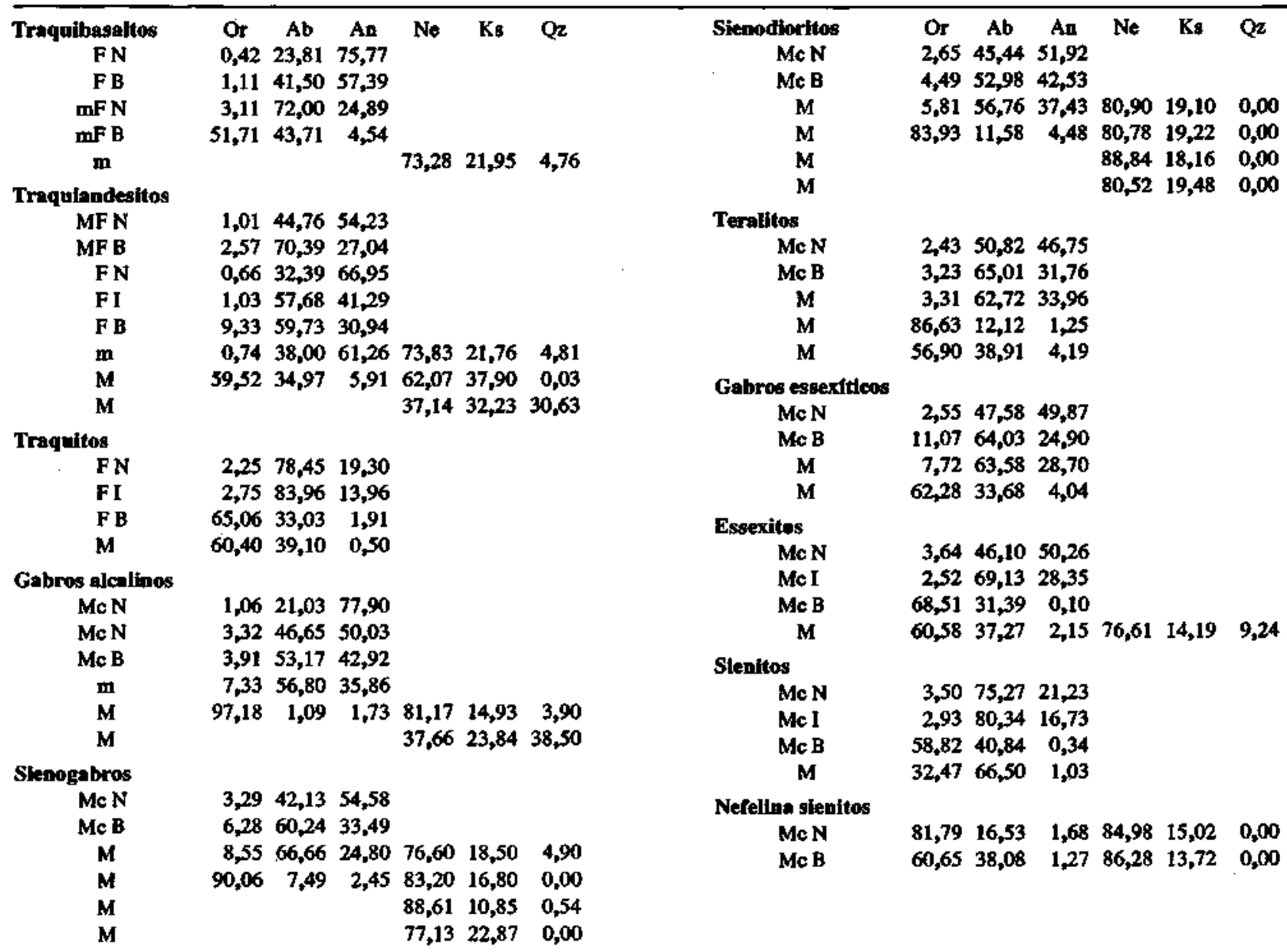




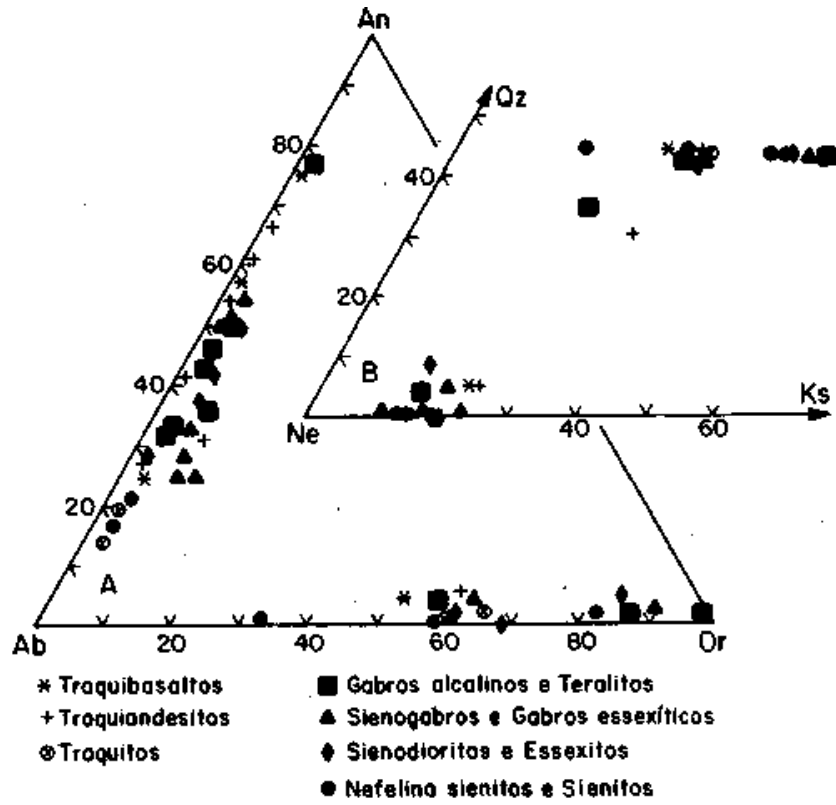

Figura 5-Composição de feldspatos e de nefelina expressa, respectivamente, nos diagramas ternários $\mathrm{Or}-\mathrm{Ab}-\mathrm{An}$ (A) e Ne$K s-Q z(B)$

Figure 5 - Feldspar and nepheline composition in the ternary diagrams Or-Ab-An (A) e Ne-Ks-Qz (B), respectively

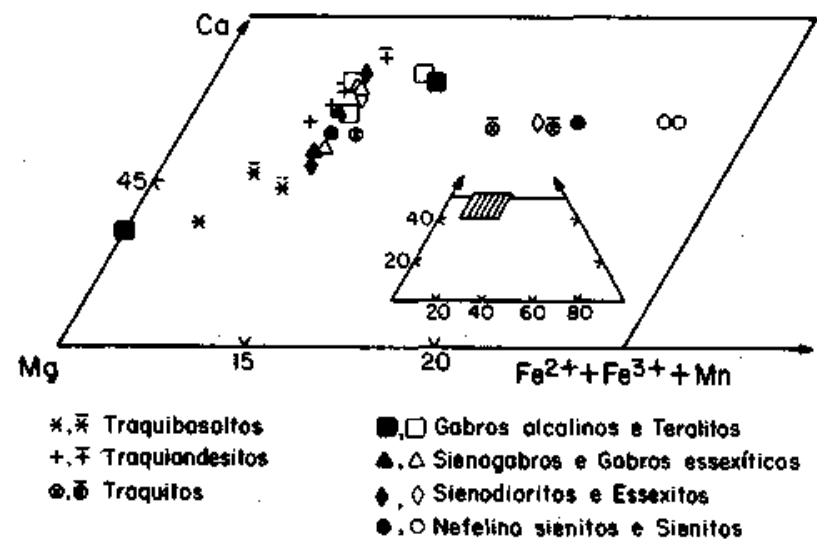

Retpetctivamente, para os diversos litologios, cristalizoçăo inicial te tardia

Figura 6 - Compostço dos piroxenios no diagrama convencional $\mathrm{Ca}-\mathrm{Mg}-\left(\mathrm{Fe}^{2+}+\mathrm{Fe}^{3+}+\mathrm{Mn}\right)$. Stmbolos cono as da figura 5, exceto para as fases de cristalizaça tardia

Figuro 6 - Pyroxens composition in the conventional dingram $\mathrm{Ca}-\mathrm{Mg}-\left(\mathrm{Fe}^{2+}+\mathrm{Fe}^{3+}+\mathrm{Mn}\right)$. Symbols 2 in in figuro 5, except for the hate cryatallization pheses

rências, notadamente as brasileiras (Gomes et al. 1987). O traçado dos pontos assemelha-se, em linhas gerais, ao da parte inicial das curvas obtidas para o maciço do Banhadão (Ruberti 1984) e para aqueles da porção oriental do Estado do Rio de Janeiro (Valença 1980), caracterizada por um brusco e progressivo empobrecimento em $\mathrm{Mg}$ e concomitante enriquecimento nos outros dois termos.

Anfibólios Análises químicas representantivas de anfibólios são apresentados na tabela 3. Pelo esquema de nomenclatura de Leake (1978), é possível enquadrá-los no grupo dos anfibólios cálcicos $\left[(\mathrm{Ca}+\mathrm{Na})_{\mathrm{B}} \geq 1, .34 ; \mathrm{Na}_{\mathrm{B}}<0,67 ;(\mathrm{Na}+\right.$ $\mathrm{K}) \geq 0,50]$. Com base na distribuição de Si, Ti $(<0,50), \mathrm{Al}$ e Fe (fig. 8), é verificável que eles caem em dois agrupa-

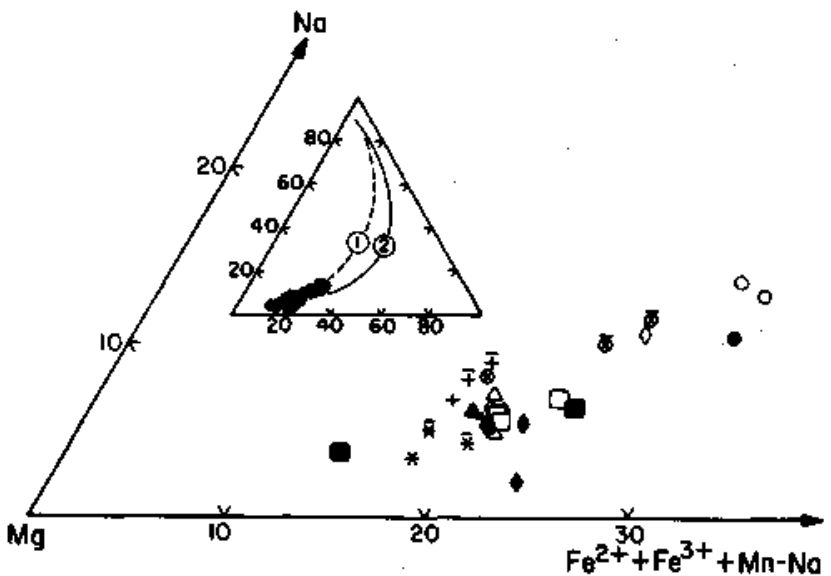

Figura 7 - Composição dos piroxênios no diagrama convencional $\mathrm{Na}-\mathrm{Mg}-\left(\mathrm{Fe}^{2+}+\mathrm{Fe}^{3+}+\mathrm{Na}\right)$. Na parte interna, curvas de cristalização de piroxênios: 1. Banhadão (Ruberti 1984) e 2. Maciços da porção oriental do Estado do Rio de Janeiro: Tanguá - Rio Bonito - Itaúna - Morro de São João (Valença 1980). Símbolos como os da figura 6

Figure 6 - Pyroxene composition in the conventional diagram $\mathrm{Na}-\mathrm{Mg}-\left(\mathrm{Fe}^{2+}+\mathrm{Fe}^{3+}+\mathrm{Na}\right)$. Inset, pyroxene crystallization trends: 1 . Banhadão (Ruberti 1984) and 2. Easterly Rio de Janeiro State massifs: Tanguá - Rio Bonito - Itadna - Mono de São João (Valença 1980). Symbols as in figure 6

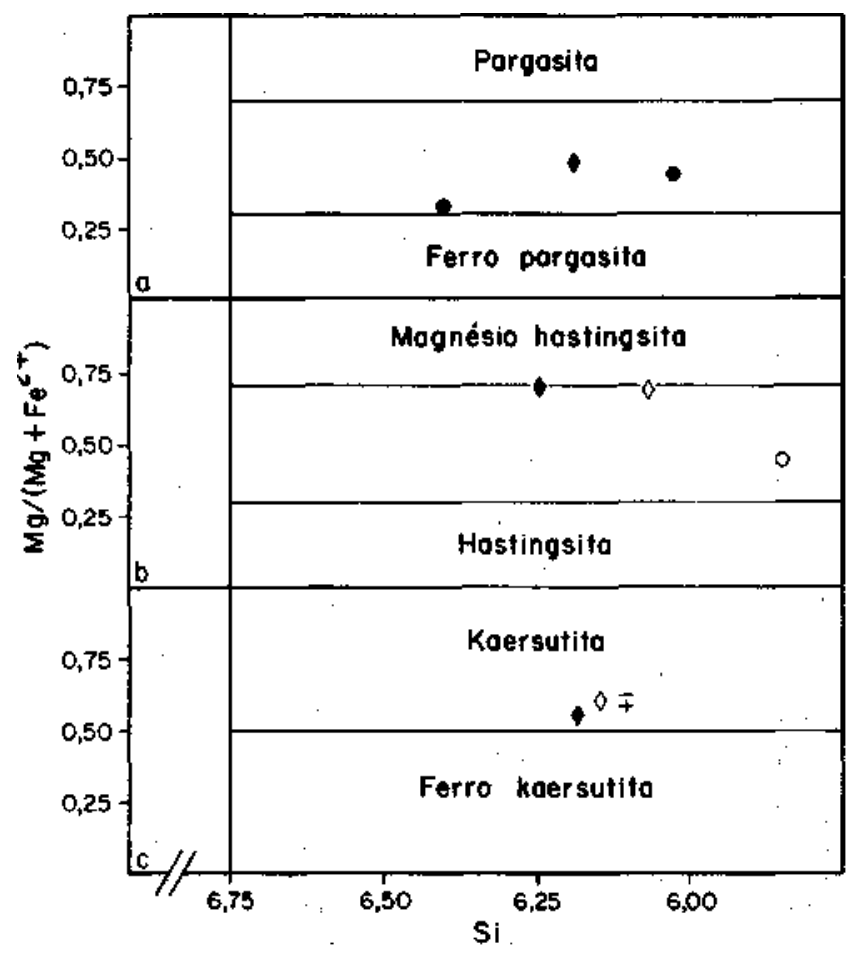

Figura 8 - Projeção dos anfibólios calcios $\left[(\mathrm{Ca}+\mathrm{Na})_{B} \geq 1,34\right.$; $N a_{B}<0,67 ;(N a+K)_{A} 0,507$ no diagrama de nomenclatura de Leake (1978). Em a. e b. Ti<0,50, além de, respectivamente $\mathrm{Fe}^{3+} \leq A l^{\mathrm{VI}}$ e $\mathrm{Fe}^{3+} \geq A l^{V I}$; em c. Ti>0,50. Símbolos como na figura 6

Figure 8- Calcic amphiboles plot $\left[(\mathrm{Ca}+\mathrm{Na})_{\mathrm{B}} \geq 1.34 ; \mathrm{Na}_{\mathrm{B}}<0.67 ;(\mathrm{Na}+\right.$ $\mathrm{K})_{\mathrm{A}} \geq 0.50$ ] in the nomenclature diagram by Leake (1978). In a. and b. Ti $\triangleleft 0.50$, and $\mathrm{Fe}^{3+} \leq \mathrm{Al}^{\mathrm{V}}, \quad \mathrm{Fe}^{3+} \geq \mathrm{Al}^{\mathrm{V}}$; respectively in c. Ti $>0.50$. Symbols as in figure 6 
Tabela 2 - Analises qufmicas representativas de piroxétios das rochas de Acahay. *. Fe calculado cono Fe ${ }_{2} \mathrm{O}_{3}$ segundo $P$ apike et al. $(1974) ; *$. Fe $=F e^{2+}+F e^{3 *}+M n ; * * . m g=M g /\left(M g+F e^{2+}\right)$

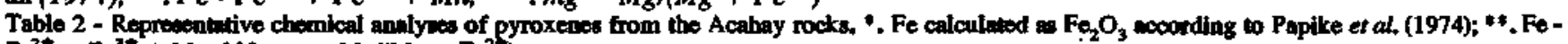
$\left.\mathrm{Fe}^{2+}+\mathrm{Fe}^{3+}+\mathrm{Mn} ;{ }^{* * *} \mathrm{mg}=\mathrm{Mg} / \mathrm{Mg}+\mathrm{Fe}^{2+}\right)$

\begin{tabular}{|c|c|c|c|c|c|c|c|c|c|c|}
\hline & \multicolumn{3}{|c|}{ Traquibasaltos } & \multicolumn{4}{|c|}{ Traquiandesitos } & \multicolumn{3}{|c|}{ Traquitos } \\
\hline & $\mathbf{F}$ & $\mathrm{mF}$ & $\mathbf{M}$ & MF & $\mathbf{F}$ & $\mathrm{mF}$ & $\mathbf{M}$ & $\mathbf{F}$ & $\mathbf{m F}$ & $\mathbf{M}$ \\
\hline $\begin{array}{l}\mathrm{SiO}_{2} \\
\mathrm{TiO}_{2} \\
\mathrm{Al}_{2} \mathrm{O}_{3} \\
\mathrm{FeOt} \\
\mathrm{MnO} \\
\mathrm{MgO} \\
\mathrm{CaO} \\
\mathrm{Na}_{2} \mathrm{O} \\
\mathrm{Cr}_{2} \mathrm{O}_{3}\end{array}$ & $\begin{array}{r}50,92 \\
1,33 \\
3,03 \\
7,09 \\
0,29 \\
15,43 \\
21,24 \\
0,54 \\
0,08\end{array}$ & $\begin{array}{r}49,98 \\
1,25 \\
3,74 \\
7,28 \\
0,39 \\
14,54 \\
21,73 \\
0,75 \\
0,05\end{array}$ & $\begin{array}{r}49,73 \\
1,53 \\
3,96 \\
8,00 \\
0,35 \\
14,12 \\
21,70 \\
0,65 \\
0,05\end{array}$ & $\begin{array}{r}49,60 \\
1,71 \\
4,58 \\
7,81 \\
0,31 \\
13,23 \\
22,17 \\
0,78 \\
0,03\end{array}$ & $\begin{array}{r}50,85 \\
1,27 \\
3,56 \\
7,58 \\
0,35 \\
13,51 \\
21,92 \\
0,93 \\
0,04\end{array}$ & $\begin{array}{r}50,30 \\
1,45 \\
3,99 \\
7,65 \\
0,43 \\
12,94 \\
22,29 \\
1,08 \\
0,02\end{array}$ & $\begin{array}{r}50,68 \\
1,19 \\
3,27 \\
7,91 \\
0,41 \\
12,16 \\
22,33 \\
1,15 \\
0,08\end{array}$ & $\begin{array}{r}51,35 \\
1,21 \\
2,71 \\
8,42 \\
0,40 \\
13,26 \\
21,93 \\
1,13 \\
0,03\end{array}$ & $\begin{array}{r}49,18 \\
0,95 \\
2,90 \\
10,09 \\
0,57 \\
11,63 \\
21,42 \\
1,35 \\
0,00\end{array}$ & $\begin{array}{r}50,02 \\
0,88 \\
2,90 \\
11,05 \\
0,67 \\
11,23 \\
21,62 \\
1,56 \\
0,00\end{array}$ \\
\hline Total & 99,99 & 99,71 & 100,09 & 100,22 & 100,01 & 100,15 & 99,18 & 100,44 & 98,09 & 99,93 \\
\hline $\mathrm{Fe}_{2} \mathrm{a}_{3} *$ & 2,73 & 4,46 & 4,67 & 3,19 & 2,74 & 3,63 & 2,52 & 3,67 & 6,04 & 6,75 \\
\hline $\begin{array}{l}\text { Si } \\
\text { A! IV } \\
\text { Total }\end{array}$ & $\begin{array}{l}1,877 \\
0,123 \\
2,000\end{array}$ & $\begin{array}{l}1,848 \\
0,152 \\
2,000\end{array}$ & $\begin{array}{l}1,830 \\
0,170 \\
2,000\end{array}$ & $\begin{array}{l}1,836 \\
0,164 \\
2,000\end{array}$ & $\begin{array}{l}1,882 \\
0,118 \\
2,000\end{array}$ & $\begin{array}{l}1,861 \\
0,139 \\
2,000\end{array}$ & $\begin{array}{l}1,899 \\
0,101 \\
2,000\end{array}$ & $\begin{array}{l}1,896 \\
0,104 \\
2,000\end{array}$ & $\begin{array}{l}1,871 \\
0,129 \\
2,000\end{array}$ & $\begin{array}{l}1,873 \\
0,127 \\
2,000\end{array}$ \\
\hline $\begin{array}{l}\mathrm{Al}^{2+} \\
\mathrm{Fe}^{2+} \\
\mathrm{Fe}^{3+} \\
\mathrm{Cr} \\
\mathrm{Mg} \\
\mathrm{Mn} \\
\mathrm{Ti} \\
\mathrm{Ca} \\
\mathrm{Na} \\
\text { Total }\end{array}$ & $\begin{array}{l}0,009 \\
0,142 \\
0,076 \\
0,002 \\
0,847 \\
0,009 \\
0,037 \\
0,838 \\
0,039 \\
1,999\end{array}$ & $\begin{array}{l}0,011 \\
0,101 \\
0,124 \\
0,001 \\
0,801 \\
0,012 \\
0,035 \\
0,861 \\
0,054 \\
2,000\end{array}$ & $\begin{array}{l}0,001 \\
0,117 \\
0,129 \\
0,001 \\
0,796 \\
0,011 \\
0,042 \\
0,855 \\
0,046 \\
1,998\end{array}$ & $\begin{array}{l}0,035 \\
0,153 \\
0,089 \\
0,001 \\
0,730 \\
0,010 \\
0,048 \\
0,879 \\
0,056 \\
2,001\end{array}$ & $\begin{array}{l}0,037 \\
0,158 \\
0,076 \\
0,001 \\
0,745 \\
0,011 \\
0,035 \\
0,869 \\
0,067 \\
1,999\end{array}$ & $\begin{array}{l}0,035 \\
0,136 \\
0,101 \\
0,001 \\
0,713 \\
0,013 \\
0,040 \\
0,883 \\
0,077 \\
1,999\end{array}$ & $\begin{array}{l}0,044 \\
0,177 \\
0,071 \\
0,002 \\
0,679 \\
0,013 \\
0,034 \\
0,897 \\
0,084 \\
2,001\end{array}$ & $\begin{array}{l}0,014 \\
0,158 \\
0,102 \\
0,001 \\
0,730 \\
0,013 \\
0,034 \\
0,868 \\
0,081 \\
2,001\end{array}$ & $\begin{array}{l}0,001 \\
0,148 \\
0,173 \\
0,000 \\
0,659 \\
0,018 \\
0,027 \\
0,873 \\
0,100 \\
1,999\end{array}$ & $\begin{array}{l}0,001 \\
0,156 \\
0,190 \\
0,000 \\
0,627 \\
0,021 \\
0,025 \\
0,867 \\
0,113 \\
2,000\end{array}$ \\
\hline $\begin{array}{l}\mathrm{Ca} \\
\mathrm{Mg}^{* *}\end{array}$ & $\begin{array}{l}43,83 \\
44,28 \\
11,89\end{array}$ & $\begin{array}{l}45,32 \\
42,18 \\
12,49\end{array}$ & $\begin{array}{l}44,82 \\
41,71 \\
13,47\end{array}$ & $\begin{array}{l}47,26 \\
39,22 \\
13,52\end{array}$ & $\begin{array}{l}46,73 \\
40,06 \\
13,20\end{array}$ & $\begin{array}{l}47,83 \\
38,62 \\
13,54\end{array}$ & $\begin{array}{l}48,82 \\
36,98 \\
14,21\end{array}$ & $\begin{array}{l}46,40 \\
39,02 \\
14,57\end{array}$ & $\begin{array}{l}46,64 \\
35,22 \\
18,13\end{array}$ & $\begin{array}{l}46,60 \\
33,67 \\
19,73\end{array}$ \\
\hline \multirow[t]{3}{*}{$\mathbf{m g} * * *$} & 0,856 & 0,888 & 0,872 & 0,827 & 0,825 & 0,840 & 0,793 & 0,822 & 0,817 & 0,800 \\
\hline & \multicolumn{3}{|c|}{ Gabros essexiticos } & \multicolumn{2}{|c|}{ Essexitos } & \multicolumn{2}{|c|}{ Sienitos } & \multicolumn{3}{|c|}{ Nefelina sienitos } \\
\hline & $\mathbf{N}$ & \multicolumn{2}{|c|}{ B } & $\mathbf{N}$ & B & $\mathbf{N}$ & B & & $\mathbf{N}$ & $\mathbf{M}$ \\
\hline $\begin{array}{l}\mathrm{SiO}_{2} \\
\mathrm{TiO}_{2} \\
\mathrm{Al}_{3} \mathrm{O}_{3} \\
\mathrm{FeO} \\
\mathrm{MnO} \\
\mathrm{MgO} \\
\mathrm{CaO} \\
\mathrm{Na}_{2} \mathrm{O} \\
\mathrm{Cr}_{2} \mathrm{O}_{3}\end{array}$ & $\begin{array}{r}50,34 \\
1,27 \\
3,73 \\
7,95 \\
0,27 \\
13,15 \\
22,10 \\
0,76 \\
0,03\end{array}$ & \multicolumn{2}{|c|}{$\begin{array}{r}51,57 \\
0,78 \\
2,72 \\
8,12 \\
0,27 \\
12,80 \\
22,31 \\
0,93 \\
0,07\end{array}$} & $\begin{array}{r}50,34 \\
1,37 \\
3,61 \\
8,14 \\
0,31 \\
13,86 \\
21,61 \\
0,31 \\
0,03\end{array}$ & $\begin{array}{r}49,02 \\
1,15 \\
3,87 \\
10,91 \\
0,37 \\
11,15 \\
21,48 \\
1,43 \\
0,00\end{array}$ & $\begin{array}{r}49,49 \\
0,92 \\
2,82 \\
12,00 \\
0,64 \\
10,37 \\
21,32 \\
1,38 \\
0,02\end{array}$ & $\begin{array}{r}49,86 \\
0,68 \\
2,65 \\
12,32 \\
0,83 \\
9,98 \\
21,23 \\
1,80 \\
0,01\end{array}$ & \multicolumn{2}{|c|}{$\begin{array}{r}49,40 \\
1,26 \\
3,47 \\
8,10 \\
0,30 \\
13,40 \\
21,87 \\
.0,77 \\
0,03\end{array}$} & $\begin{array}{r}48,98 \\
0,90 \\
3,04 \\
12,59 \\
0,69 \\
9,75 \\
21,07 \\
1,68 \\
0,03\end{array}$ \\
\hline Total & 99,60 & \multicolumn{2}{|c|}{99,57} & 99,58 & 99,38 & 98,96 & 99,36 & \multicolumn{2}{|c|}{98,60} & 98,73 \\
\hline $\mathrm{Fe}_{2} \mathrm{O}_{3} *$ & 2,40 & \multicolumn{2}{|c|}{1,93} & 0,95 & 6,29 & 5,38 & 6,96 & \multicolumn{2}{|c|}{4,08} & 6,75 \\
\hline $\begin{array}{l}\mathrm{Si} \\
\text { Al IV } \\
\text { Total }\end{array}$ & $\begin{array}{l}1,876 \\
0,124 \\
2,000\end{array}$ & \multicolumn{2}{|c|}{$\begin{array}{l}1,924 \\
0,076 \\
2,000\end{array}$} & $\begin{array}{l}1,880 \\
0,120 \\
2,000\end{array}$ & $\begin{array}{c}1,845 \\
0,155 \\
2,000\end{array}$ & $\begin{array}{l}1,884 \\
0,116 \\
2,000\end{array}$ & $\begin{array}{l}1,888 \\
0,112 \\
2,000\end{array}$ & \multicolumn{2}{|c|}{$\begin{array}{l}1,857 \\
0,143 \\
2,000\end{array}$} & $\begin{array}{l}1,870 \\
0,130 \\
2,000\end{array}$ \\
\hline $\begin{array}{l}\mathrm{Al} \mathrm{VI} \\
\mathrm{Fe}^{2+} \\
\mathrm{Fe}^{3+} \\
\mathrm{Cr} \\
\mathrm{Mg} \\
\mathrm{Mz} \\
\mathrm{Ti} \\
\mathrm{Ca} \\
\mathrm{Na} \\
\text { Total }\end{array}$ & $\begin{array}{l}0,040 \\
0,180 \\
0,067 \\
0,001 \\
0,730 \\
0,009 \\
0,036 \\
0,882 \\
0,055 \\
2,000\end{array}$ & \multicolumn{2}{|c|}{$\begin{array}{l}0,043 \\
0,199 \\
0,054 \\
0,002 \\
0,712 \\
0,009 \\
0,022 \\
0,892 \\
0,067 \\
2,000\end{array}$} & $\begin{array}{l}0,038 \\
0,228 \\
0,027 \\
0,001 \\
0,771 \\
0,010 \\
0,038 \\
0,865 \\
0,022 \\
2,000\end{array}$ & $\begin{array}{l}0,016 \\
0,165 \\
0,178 \\
0,000 \\
0,625 \\
0,012 \\
0,033 \\
0,866 \\
0,104 \\
1,999\end{array}$ & $\begin{array}{l}0,011 \\
0,228 \\
0,154 \\
0,001 \\
0,588 \\
0,021 \\
0,026 \\
0,870 \\
0,102 \\
2,001\end{array}$ & $\begin{array}{l}0,007 \\
0,192 \\
0,198 \\
0,000 \\
0,563 \\
0,027 \\
0,019 \\
0,861 \\
0,132 \\
1,999\end{array}$ & \multicolumn{2}{|c|}{$\begin{array}{l}0,011 \\
0,139 \\
0,115 \\
0,001 \\
0,751 \\
0,010 \\
0,036 \\
0,881 \\
0,056 \\
2,000\end{array}$} & $\begin{array}{l}0,007 \\
0,208 \\
0,194 \\
0,001 \\
0,555 \\
0,022 \\
0,026 \\
0,862 \\
0,124 \\
1,999\end{array}$ \\
\hline $\begin{array}{l}\mathrm{Ca}_{\mathbf{m}} \\
\mathrm{Me}_{* *}\end{array}$ & $\begin{array}{l}47,21 \\
39,07 \\
13,71\end{array}$ & \multicolumn{2}{|c|}{$\begin{array}{l}47,81 \\
38,15 \\
14,04\end{array}$} & $\begin{array}{l}45,51 \\
40,60 \\
13,90\end{array}$ & $\begin{array}{l}46,90 \\
33,86 \\
19,23\end{array}$ & $\begin{array}{l}46,74 \\
31,62 \\
21,64\end{array}$ & $\begin{array}{l}46,78 \\
30,59 \\
22,63\end{array}$ & \multicolumn{2}{|c|}{$\begin{array}{l}46,47 \\
29,60 \\
13,94\end{array}$} & $\begin{array}{l}46,82 \\
30,13 \\
23,05\end{array}$ \\
\hline$m g^{* * *}$ & 0,802 & \multicolumn{2}{|c|}{0,785} & 0,772 & 0,791 & 0,720 & 0,745 & & 0,844 & 0,727 \\
\hline
\end{tabular}


Tabela 2 - Continuaçato

Table 2-Conthues

$\begin{array}{llll}\text { Gabros alcalinos } & \text { Sienogabros } & \text { Sienodioritos } & \text { Teralitos }\end{array}$

\begin{tabular}{|c|c|c|c|c|c|c|c|c|c|c|}
\hline & $\mathbf{N}$ & B & $\mathbf{N}$ & B & $\mathbf{N}$ & B. & a & $\mathbf{N}$ & B & a \\
\hline $\begin{array}{l}\mathrm{SiO}_{2} \\
\mathrm{TiO}_{2} \\
\mathrm{Al}_{2} \mathrm{O}_{3} \\
\mathrm{FeOt} \\
\mathrm{MnO} \\
\mathrm{MgO} \\
\mathrm{CaO} \\
\mathrm{Na}_{2} \mathrm{O} \\
\mathrm{Cr}_{2} \mathrm{O}_{3}\end{array}$ & $\begin{array}{r}52,75 \\
0,88 \\
1,42 \\
6,07 \\
0,17 \\
16,39 \\
21,34 \\
0,57 \\
0,38\end{array}$ & $\begin{array}{r}50,58 \\
1,20 \\
3,49 \\
8,13 \\
0,26 \\
13,06 \\
22,10 \\
0,75 \\
0,05\end{array}$ & $\begin{array}{r}50,96 \\
1,20 \\
3,08 \\
8,03 \\
0,32 \\
13,72 \\
21,75 \\
0,85 \\
0,02\end{array}$ & $\begin{array}{r}51,12 \\
1,18 \\
3,06 \\
8,08 \\
0,33 \\
13,46 \\
21,91 \\
0,70 \\
0,01\end{array}$ & $\begin{array}{r}\mathbf{4 8 , 2 9} \\
1,28 \\
\mathbf{3 , 9 0} \\
7,90 \\
0,38 \\
12,57 \\
\mathbf{2 2 , 5 8} \\
0,73 \\
0,01\end{array}$ & $\begin{array}{r}47,87 \\
1,59 \\
4,35 \\
7,91 \\
0,38 \\
12,67 \\
22,14 \\
0,81 \\
0,06\end{array}$ & $\begin{array}{r}49,45 \\
1,05 \\
3,33 \\
7,77 \\
0,48 \\
12,83 \\
22,37 \\
0,87 \\
0,03\end{array}$ & $\begin{array}{r}51,43 \\
0,72 \\
2,99 \\
9,08 \\
0,37 \\
12,07 \\
22,43 \\
0,84 \\
0,03\end{array}$ & $\begin{array}{r}50,97 \\
0,98 \\
3,68 \\
7,85 \\
0,33 \\
12,80 \\
22,39 \\
0,81 \\
0,03\end{array}$ & $\begin{array}{r}51,11 \\
-0,68 \\
3,19 \\
8,84 \\
0,35 \\
12,05 \\
22,31 . \\
0,90 \\
0,00\end{array}$ \\
\hline Total & 99,97 & 99,62 & 99,93 & 99,85 & 97,64 & 97,78 & 98,18 & 99,96 & 99,84 & 99,43 \\
\hline $\mathrm{Fe}_{2} \mathrm{O}_{3} *$ & 1,53 & 2,11 & 2,89 & 1,70 & 4,56 & 4,81 & 4,16 & 1,62 & 1,79 & 1,89 \\
\hline $\begin{array}{l}\text { Si } \\
\text { Al IV } \\
\text { Total }\end{array}$ & $\begin{array}{l}1,937 \\
0,061 \\
1,998\end{array}$ & $\begin{array}{l}1,886 \\
0,114 \\
2,000\end{array}$ & $\begin{array}{l}1,889 \\
0,111 \\
2,000\end{array}$ & $\begin{array}{l}1,901 \\
0,099 \\
2,000\end{array}$ & $\begin{array}{l}1,837 \\
0,163 \\
2,000\end{array}$ & $\begin{array}{l}1,817 \\
0,183 \\
2,000\end{array}$ & $\begin{array}{l}1,868 \\
0,132 \\
2,000\end{array}$ & $\begin{array}{l}1,921 \\
0,079 \\
2,000\end{array}$ & $\begin{array}{l}1,896 \\
0,104 \\
2,000\end{array}$ & $\begin{array}{l}1,916 \\
0,084 \\
2,000\end{array}$ \\
\hline $\begin{array}{l}\mathrm{Al} \mathrm{VI} \\
\mathrm{Fe}^{2+} \\
\mathrm{Fe}^{3+} \\
\mathrm{Cr}^{3+} \\
\mathbf{M g} \\
\mathbf{M n} \\
\mathbf{T i} \\
\mathrm{Ca} \\
\mathrm{Na} \\
\text { Total }\end{array}$ & $\begin{array}{l}0,000 \\
0,144 \\
0,042 \\
0,011 \\
0,897 \\
0,005 \\
0,024 \\
0,839 \\
0,041 \\
2,003\end{array}$ & $\begin{array}{l}0,040 \\
0,194 \\
0,059 \\
0,001 \\
0,726 \\
0,008 \\
0,034 \\
0,883 \\
0,054 \\
1,999\end{array}$ & $\begin{array}{c}0,024 \\
0,168 \\
0,081 \\
0,001 \\
0,758 \\
0,010 \\
0,033 \\
0,0864 \\
0,061 \\
2,000\end{array}$ & $\begin{array}{l}0,035 \\
0,204 \\
0,048 \\
0,000 \\
0,746 \\
0,010 \\
0,033 \\
0,873 \\
0,050 \\
1,999\end{array}$ & $\begin{array}{l}0,012 \\
0,121 \\
0,131 \\
0,000 \\
0,713 \\
0,012 \\
0,037 \\
0,921 \\
0,054 \\
2,001\end{array}$ & $\begin{array}{l}0,012 \\
0,114 \\
0,137 \\
0,002 \\
0,717 \\
0,012 \\
0,045 \\
0,901 \\
0,060 \\
2,000\end{array}$ & $\begin{array}{l}0,017 \\
0,127 \\
0,118 \\
0,001 \\
0,722 \\
0,015 \\
0,030 \\
0,906 \\
0,064 \\
2,000\end{array}$ & $\begin{array}{l}0,053 \\
0,238 \\
0,045 \\
0,001 \\
0,672 \\
0,012 \\
0,020 \\
0,898 \\
0,061 \\
2,000\end{array}$ & $\begin{array}{l}0,057 \\
0,194 \\
0,050 \\
0,001 \\
0,709 \\
0,010 \\
0,027 \\
0,892 \\
0,058 \\
1,998\end{array}$ & $\begin{array}{l}0,057 \\
0,224 \\
0,053 \\
0,000 \\
0,673 \\
0,011 \\
0,019 \\
0,896 \\
0,065 \\
1,998\end{array}$ \\
\hline $\begin{array}{l}\mathrm{Ca} \\
\mathrm{Mg} \\
\mathrm{Fe}^{* *}\end{array}$ & $\begin{array}{r}43,54 \\
46,52 \\
9,94\end{array}$ & $\begin{array}{l}47,21 \\
38,80 \\
13,99\end{array}$ & $\begin{array}{l}45,93 \\
40,30 \\
13,77\end{array}$ & $\begin{array}{l}46,42 \\
39,66 \\
13,91\end{array}$ & $\begin{array}{l}48,53 \\
37,57 \\
13,90\end{array}$ & $\begin{array}{l}47,88 \\
38,11 \\
14,00\end{array}$ & $\begin{array}{l}47,94 \\
38,25 \\
13,81\end{array}$ & $\begin{array}{l}48,14 \\
36,03 \\
15,84\end{array}$ & $\begin{array}{l}48,07 \\
38,22 \\
13,71\end{array}$ & $\begin{array}{l}48,24 \\
36,24 \\
15,52\end{array}$ \\
\hline $\mathbf{M g} * * *$ & 0,862 & 0,789 & 0,784 & 0,785 & 0,855 & 0,863 & 0,850 & 0,738 & 0,785 & 0,750 \\
\hline
\end{tabular}

mentos distintos: pargasita- ferro- pargasita $\left(\mathrm{Fe}^{3+} \leq \mathrm{A} 1^{\mathrm{VI}}\right)$ e magnésio - hastingsita-hastingsita $\left(\mathrm{Fe}^{3+} \wedge \mathrm{Al}^{\mathrm{vl}}\right)$. No primeiro caso, os dados indicam tratar-se de pargasita ferrosa; no segundo, de hastingsita magnesiana. Já as fases mais enriquecidas em Ti $(>0,50)$, que também se acham presentes na suíte extrusiva, situam-se no campo da kaersutita. $\mathrm{O}$ valor de $\mathrm{mg}$ varia de 0,678 a 0,274 , com os valores mais baixos caracterizando as variedades sieníticas.

Biotitas Análises químicas representativas de biotitas acham-se reunidas na tabela 4 , com os dados para $\mathrm{Al}, \mathrm{Mg}$ e $\mathrm{Fe}^{2+}$ projetados no gráfico composicional da figura 9. Apesar da grande variação na razão $\mathrm{Mg} / \mathrm{Fe}^{2+}$, esses minerais mantêm-se dentro do campo das biotitas magnesianas, sendo a fase presente nos sienitos, uma biotita com $\mathrm{Fe}$, a única exceção. $\mathrm{O}$ alto conteúdo em $\mathrm{TiO}_{2}(\mathrm{Ti}>0,25$ átomos por fórmula unitária) permite classificá-las como biotita com Ti seguindo a recomendação de Rock (1982). Seja para a suíte extrusiva, seja intrusiva, verifica-se diminuição dos valores de $\mathrm{Mg} / \mathrm{Fe}^{2+}$ $(\mathrm{mg}=0,708$ a 0,388 , traquibasaltos a traquitos; $\mathrm{mg}=0,706 \mathrm{a}$ 0,407 , termos gábricos a sieníticos) com o grau de evolução das rochas; concomitantemente, ocorre também, junto às primeiras, ligeiro aumento de Al. À exclusão do acentuado decréscimo de teor nas variedades sieníticas, Ti não apresenta variações sistemáticas. Zoneamento é por vezes observado, com o núcleo dos cristais mostrando-se aparentemente mais rico em $\mathrm{TiO}_{2}$ que as bordas.

Olivina A tabela 5 reúne análises representativas de olivinas para as duas séries. A exemplo dos constituintes máficos

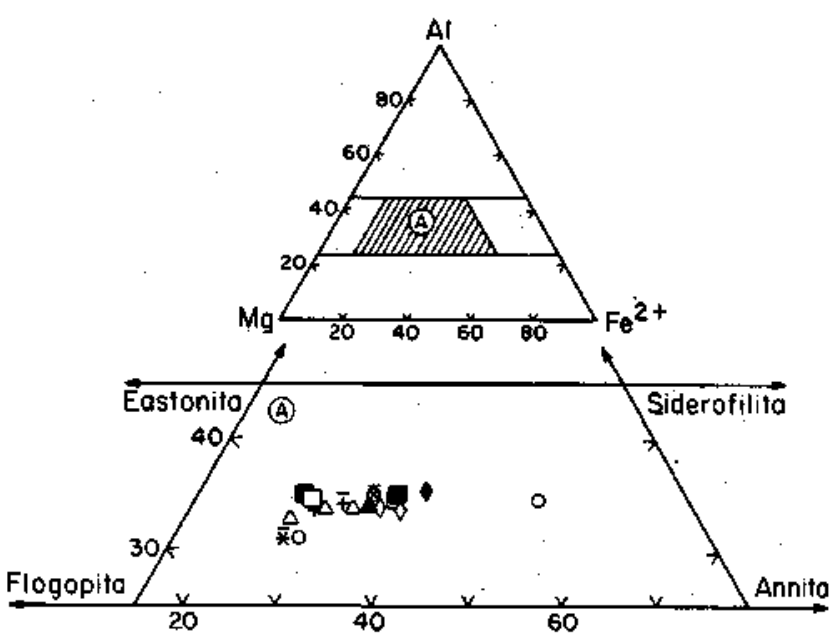

Figura 9 - Composição da biotita no diagrama composicional Al-Mg-Fe $e^{2}$. Stmbolos como na figura 6

Figure 9 - Biodte composition in the conventional diagram $\mathrm{AJ}-\mathrm{Mg}-\mathrm{Fe}^{2+}$, Symbols as in figure 6

precedentes, elas exibem mudanças composicionais, refletidas nos valores de mg $(0,807$ a 0,$612 ; 0,637$ a 0,444$)$, corn o grau de evolução das rochas. $\mathrm{O}$ aumento em $\mathrm{Fe}$ se faz acompanhar de um maior enriquecimento em $\mathrm{Mn}$, como também assinalado 
Tabela 3 - Análises químicas representativas de anfibólios das rochas de Acahay. Fórmula estrutural calculada na base de 23 átomos de oxigênio. *. Fe calculado estequiometricamente como $\mathrm{Fe}_{2} \mathrm{O}_{3}$; **. $\mathrm{Mg} /\left(\mathrm{Mg}+\mathrm{Fe}^{+}\right)$.

Table 3 - Representative chemical analyses of amphiboles from the Acahay rocks. Structural formula calculated on the basis of 23 atoms of oxygen. * $\mathrm{Fe}$ estequiometrically calculated as $\mathrm{Fe}_{2} \mathrm{O}_{3}$; **. $\mathrm{mg}=\mathrm{Mg} /\left(\mathrm{Mg}+\mathrm{Fe}^{2}\right)$

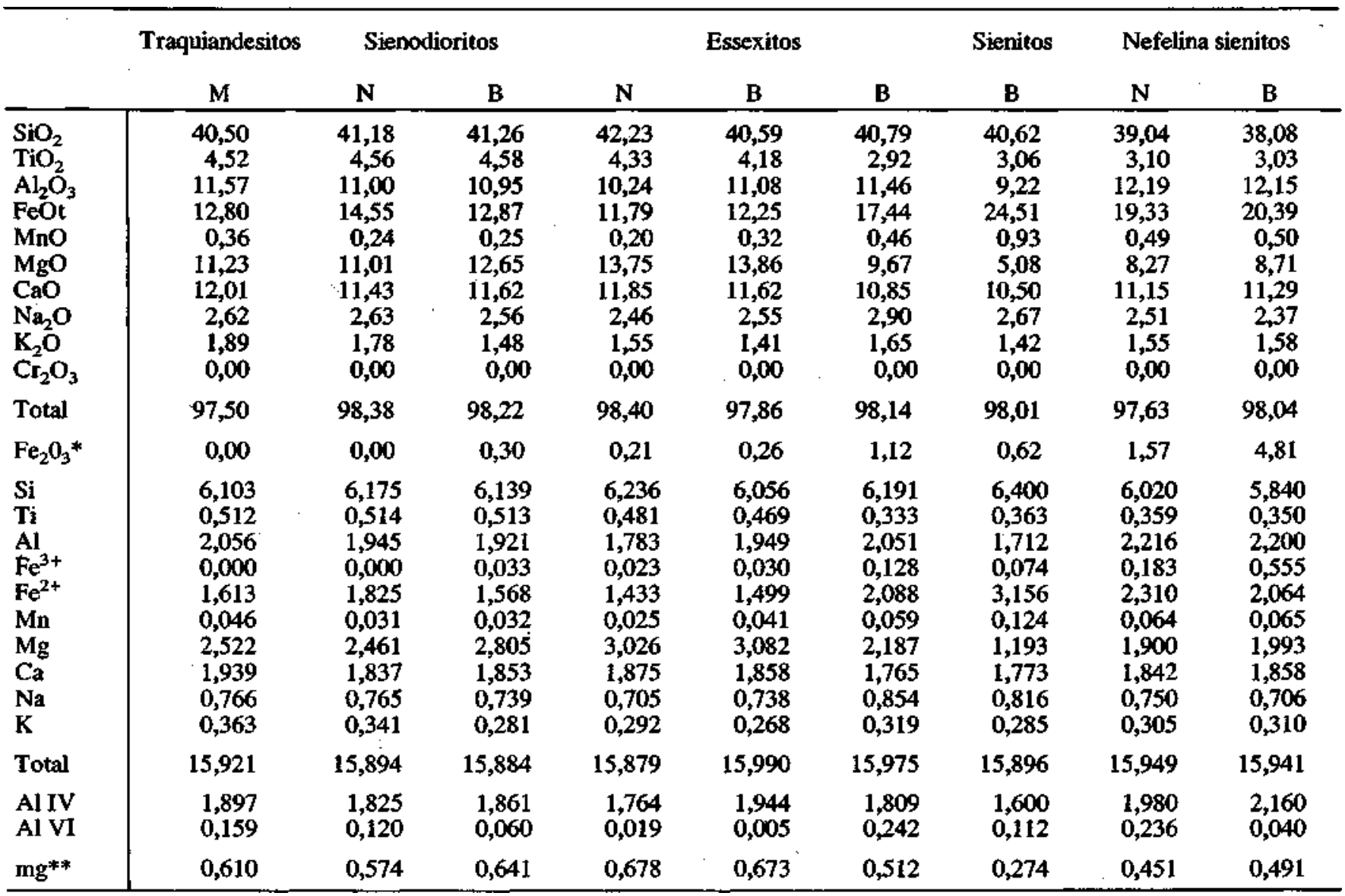

para outras ocorrências alcalinas (Stephenson 1974, Stephenson \& Upton 1982, Gomes et al. 1987). Aparentemente $\mathrm{Ca}$, um elemento menor que ocorre em concentração $(0,03 \%$ a $0,2 \% \mathrm{Ca}$ ) próxima ao limite "normal" de $0,1 \% \mathrm{Ca}$ proposto por Simkin \& Smith (1970) para olivinas plutônicas, comporta-se de modo similar.

Como mostrado na tabela 5, a composição das olivinas, excluída a amostra de traquibasalto, é mais ferrífera que a da olivina em equilíbrio - calculada a partir das composições das rochas hospedeiras $\left(\mathrm{K}_{\mathrm{D}}=0,30 ; \mathrm{Fe}_{2} \mathrm{O}_{3} / \mathrm{FeO}=0,20\right)$-, sugerindo, juntamente com as evidências petrográficas, que esses minerais representam um produto de cristalização tardia.

Opacos As fases opacas, comuns a todos os tipos petrográficos do maciço, acham-se representadas por titânio magnetita, com ilmenita exsolvida em graus diversos, e ilmenita. Análises químicas representativas das primeiras são fornecidas na tabela 6 , que também inclui valores para temperatura e fugacidade de oxigênio. Ao lado da grande variação composicional, as titânio magnetitas apresentam, como característica geral para as duas séries, um maior enriquecimento em Fe com o grau de evolução das rochas.

$\mathrm{Na}$ figura 10 os dados obtidos para temperatura e fugacidade situam-se entre os tampões FMQ (faialita-magnetitaquartzo) e $\mathrm{NNO}$ (Ni-NiO), com algumas amostras (traquito, gabro alcalino e gabro essexítico) demonstrando atividade de oxigênio muito elevada. Por outro lado, alguns valores de temperatura são demasiado baixos para serem interpretados como representativos de quenching, devendo, portanto, estar correlacionados às condições de equilíbrio subsólido. Além disso, somente em poucos casos (gabro alcalino, sienogabro e essexito) é verificada correspondência com as temperaturas obtidas para os plagioclásios.

\section{PETROQUíMICA E ASPECTOS PETROGENÉTICOS}

Análises químicas para elementos principais e traços dos diversos tipos litológicos do maciço fazem parte da tabela 7. Elas foram obtidas por fluorescência de raios X, sendo os dados corrigidos com o auxílio dos métodos de Franzini et al. (1975) e Leoni \& Saitta (1976). Maiores informações sobre a técnica empregada podem ser encontradas em Bellieni et al. (1983).

A natureza alcalina das rochas de Acahay acha-se bem evidenciada no diagrama $\mathrm{SiO}_{2}$ vs. $\mathrm{Na}_{2} \mathrm{O}+\mathrm{K}_{2} \mathrm{O}$ (Fig. 11), com os pontos dispostos nas imediações da linha que separa as variedades alcalinas das fortemente alcalinas, segundo Saggerson \& Williams (1964). Por outro lado, o caráter medianamente potássico de ambas as séries é visível no gráfico que relaciona $\mathrm{K}_{2} \mathrm{O}$ e $\mathrm{Na}_{2} \mathrm{O}$ (Fig. 12), inclusive com algumas poucas amostras colocando-se no campo das rochas mais ricas em K.

Quando projetadas no diagrama ternário AFM (fig. 13), os dados definem uma nítida tendência alcalina, bem como apontam para a inexistência de termos primitivos no maciço, aspecto este igualmente ressaltado pela baixa concentração de $\mathrm{Cr}$ e Ni. Os gráficos binaries, reunindo elementos principais e traços com o teor de $\mathrm{MgO}$ (Figs. 14 e 15), mostram boa correlação negativa para $\mathrm{SiO}_{2} \mathrm{Al}_{2} \mathrm{O}_{3}, \mathrm{Na}_{2} \mathrm{O}, \mathrm{K}_{2} \mathrm{O}, \mathrm{Ba}, \mathrm{Rb}$ e $\mathrm{Nb}$, além de positiva para $\mathrm{CaO}, \mathrm{TiO}_{2}, \mathrm{FeO}, \mathrm{P}_{2} \mathrm{O}_{5}, \mathrm{Cr}$ e Ni. Menos evidentes são o comportamento negativo de $\mathrm{Zr}$ e o positivo do Sr. 
Tabela 4 - Análises químicas representativas de biotita das rochas de Acahay. Fórmula estrutural calculada na base de 22 átomos de oxigênio. *. $m g=\mathrm{MgO} /(\mathrm{MgO}+\mathrm{FeO})$

Table 4 - Representative chemical analyses of biotite from the Acahay rocks. Structural formula calculated on the basis of 22 atoms of oxygen. *. mg = $\mathrm{MgO} /(\mathrm{MgO}+\mathrm{FeO})$

\begin{tabular}{|c|c|c|c|c|c|c|c|c|}
\hline & \multirow{2}{*}{$\begin{array}{c}\text { Traquibasaltos } \\
\text { M }\end{array}$} & \multicolumn{2}{|c|}{ Traquiandesitos } & \multirow{2}{*}{$\begin{array}{c}\text { Traquitos } \\
\text { M }\end{array}$} & \multicolumn{2}{|c|}{ Gabros alcalinos } & \multicolumn{2}{|c|}{ Sienogabros } \\
\hline & & $\mathrm{mF}$ & $\mathbf{M}$ & & $\mathbf{N}$ & $\mathbf{B}$ & $\mathbf{N}$ & $\mathbf{B}$ \\
\hline $\begin{array}{l}\mathrm{SiO}_{2} \\
\mathrm{TiO}_{2} \\
\mathrm{AI}_{2} \mathrm{O}_{3} \\
\mathrm{FeO}_{3} \\
\mathrm{MnO} \\
\mathrm{MgO} \\
\mathrm{CaO} \\
\mathrm{Na}_{2} \mathrm{O} \\
\mathrm{K}_{2} \mathrm{O}\end{array}$ & $\begin{array}{r}38,87 \\
6,75 \\
13,45 \\
12,14 \\
0,20 \\
16,55 \\
0,00 \\
0,00 \\
8,92\end{array}$ & $\begin{array}{r}37,02 \\
7,65 \\
14,39 \\
12,50 \\
0,25 \\
14,96 \\
0,15 \\
0,26 \\
9,95\end{array}$ & $\begin{array}{r}37,26 \\
7,52 \\
14,35 \\
13,73 \\
0,28 \\
14,05 \\
0,05 \\
0,24 \\
10,04\end{array}$ & $\begin{array}{r}38,13 \\
6,56 \\
15,08 \\
15,24 \\
0,27 \\
13,49 \\
0,00 \\
0,00 \\
8,99\end{array}$ & $\begin{array}{r}36,82 \\
8,17 \\
14,98 \\
11,94 \\
0,09 \\
15,27 \\
0,00 \\
0,10 \\
10,15\end{array}$ & $\begin{array}{r}36,72 \\
7,75 \\
14,79 \\
12,42 \\
0,11 \\
15,07 \\
0,02 \\
0,16 \\
9,96\end{array}$ & $\begin{array}{r}37,75 \\
7,36 \\
14,00 \\
11,70 \\
0,11 \\
15,78 \\
0,01 \\
0,11 \\
10,20\end{array}$ & $\begin{array}{r}38,03 \\
7,55 \\
14,09 \\
12,88 \\
0,13 \\
14,49 \\
0,01 \\
0,14 \\
9,43\end{array}$ \\
\hline Total & 97,78 & 97,13 & 97,52 & 97,79 & 97,52 & 97,00 & 97,02 & 96,75 \\
\hline $\begin{array}{l}\mathrm{Si} \\
\mathrm{Al} \text { IV } \\
\mathrm{Al} \text { VI } \\
\mathrm{Ti} \\
\mathrm{Fe}^{2+} \\
\mathrm{Mn} \\
\mathrm{Mg} \\
\mathrm{Ca} \\
\mathrm{Na} \\
\mathrm{K}\end{array}$ & $\begin{array}{l}5,839 \\
2,161 \\
0,221 \\
0,763 \\
1,525 \\
0,025 \\
3,705 \\
0,000 \\
0,000 \\
1,710\end{array}$ & $\begin{array}{l}5,543 \\
2,457 \\
0,083 \\
0,861 \\
1,565 \\
0,032 \\
3,338 \\
0,024 \\
0,075 \\
1,901\end{array}$ & $\begin{array}{l}5,637 \\
2,363 \\
0,196 \\
0,856 \\
1,737 \\
0,036 \\
3,168 \\
0,008 \\
0,070 \\
1,938\end{array}$ & $\begin{array}{l}5,770 \\
2,230 \\
0,460 \\
0,747 \\
1,929 \\
0,035 \\
3,042 \\
0,000 \\
0,000 \\
1,620\end{array}$ & $\begin{array}{l}5,520 \\
2,480 \\
0,167 \\
0,921 \\
1,497 \\
0,011 \\
3,412 \\
0,000 \\
0,029 \\
1,941\end{array}$ & $\begin{array}{l}5,483 \\
2,517 \\
0,086 \\
0,870 \\
1,551 \\
0,014 \\
3,353 \\
0,003 \\
0,046 \\
1,897\end{array}$ & $\begin{array}{l}5,627 \\
2,373 \\
0,088 \\
0,825 \\
1,459 \\
0,014 \\
0,506 \\
0,002 \\
0,032 \\
1,940\end{array}$ & $\begin{array}{l}5,640 \\
2,360 \\
0,104 \\
0,842 \\
1,598 \\
0,016 \\
3,203 \\
0,002 \\
0,040 \\
1,784\end{array}$ \\
\hline Total & 15,949 & 15,879 & 16,009 & 15,833 & 15,978 & 15,820 & 15,866 & $15 ; 589$ \\
\hline $\begin{array}{l}\mathrm{Al} \\
\mathrm{Mg} \\
\mathrm{Fe}^{2+}\end{array}$ & $\begin{array}{l}31,29 \\
48,67 \\
20,04\end{array}$ & $\begin{array}{l}34,12 \\
44,85 \\
21,03\end{array}$ & $\begin{array}{l}34,29 \\
42,44 \\
23,27\end{array}$ & $\begin{array}{l}35,11 \\
39,71 \\
25,18\end{array}$ & $\begin{array}{l}35,03 \\
45,16 \\
19,81\end{array}$ & $\begin{array}{l}34,67 \\
44,67 \\
20,66\end{array}$ & $\begin{array}{l}33,14 \\
47,21 \\
19,65\end{array}$ & $\begin{array}{l}33,92 \\
44,08 \\
22,00\end{array}$ \\
\hline $\mathrm{Mg}^{*}$ & 0,708 & 0,681 & 0,646 & 0,388 & 0,695 & 0,684 & 0,706 & 0,667 \\
\hline
\end{tabular}

Sienodionitos

Teratitos

Gabros essexíticos

Essexitos Sienitos

Nefelina

sienitos

\begin{tabular}{|c|c|c|c|c|c|c|c|c|c|}
\hline & $\mathbf{N}$ & B & $\mathbf{N}$ & B & $\mathbf{N}$ & $\mathbf{B}$ & $\mathbf{N}$ & $\mathbf{N}$ & $\mathbf{N}$ \\
\hline $\begin{array}{l}\mathrm{SiO}_{2} \\
\mathrm{TiO}_{2} \\
\mathrm{Al}_{3} \mathrm{O}_{3} \\
\mathrm{FeO} \\
\mathrm{MnO} \\
\mathrm{MgO} \\
\mathrm{CaO} \\
\mathrm{Na}_{2} \mathrm{O} \\
\mathrm{K}_{2} \mathrm{O}\end{array}$ & $\begin{array}{r}35,05 \\
7,31 \\
15,22 \\
17,76 \\
0,42 \\
11,98 \\
0,04 \\
0,10 \\
9,92\end{array}$ & $\begin{array}{r}35,91 \\
4,59 \\
15,45 \\
16,73 \\
0,35 \\
14,22 \\
0,10 \\
0,06 \\
10,18\end{array}$ & $\begin{array}{r}36,13 \\
6,45 \\
15,24 \\
16,52 \\
0,19 \\
13,06 \\
0,00 \\
0,33 \\
9,94\end{array}$ & $\begin{array}{r}36,15 \\
6,41 \\
15,15 \\
16,51 \\
0,23 \\
13,19 \\
0,02 \\
0,30 \\
9,81\end{array}$ & $\begin{array}{r}36,98 \\
7,63 \\
14,25 \\
14,77 \\
0,15 \\
13,83 \\
0,01 \\
0,27 \\
9,95\end{array}$ & $\begin{array}{r}37,17 \\
6,97 \\
14,39 \\
14,52 \\
0,15 \\
14,20 \\
0,09 \\
0,10 \\
10,12\end{array}$ & $\begin{array}{r}37,35 \\
6,81 \\
14,17 \\
16,55 \\
0,27 \\
12,67 \\
0,00 \\
0,22 \\
8,87\end{array}$ & $\begin{array}{r}34,86 \\
4,64 \\
14,98 \\
23,70 \\
0,40 \\
9,13 \\
0,20 \\
0,00 \\
9,18\end{array}$ & $\begin{array}{r}37,66 \\
4,56 \\
14,15 \\
13,58 \\
0,27 \\
16,91 \\
0,04 \\
0,44 \\
9,76\end{array}$ \\
\hline Total & 97,80 & 97,59 & 97,86 & 97,77 & 97,84 & 97,71 & 96,91 & 97,09 & 97,37 \\
\hline $\begin{array}{l}\text { Si } \\
\text { Al IV } \\
\text { AJ VI } \\
\text { Ti } \\
\mathrm{Fe}^{2+} \\
\mathrm{Mn} \\
\mathrm{Mg} \\
\mathrm{Ca} \\
\mathrm{Na} \\
\mathrm{K}\end{array}$ & $\begin{array}{l}5,431 \\
2,569 \\
0,211 \\
0,852 \\
2,302 \\
0,055 \\
2,767 \\
0,007 \\
0,030 \\
1,961\end{array}$ & $\begin{array}{l}5,516 \\
2,484 \\
0,315 \\
0,530 \\
2,149 \\
0,046 \\
3,256 \\
0,016 \\
0,018 \\
1,995\end{array}$ & $\begin{array}{l}5,553 \\
2,447 \\
0,314 \\
0,746 \\
2,123 \\
0,025 \\
2,991 \\
0,000 \\
0,098 \\
1,949\end{array}$ & $\begin{array}{l}5,547 \\
2,453 \\
0,288 \\
0,740 \\
2,119 \\
0,030 \\
3,016 \\
0,003 \\
0,089 \\
1,921\end{array}$ & $\begin{array}{l}5,665 \\
2,335 \\
0,239 \\
0,879 \\
1,892 \\
0,019 \\
3,021 \\
0,002 \\
0,080 \\
1,945\end{array}$ & $\begin{array}{l}5,646 \\
2,354 \\
0,233 \\
0,796 \\
1,845 \\
0,019 \\
3,215 \\
0,015 \\
0,029 \\
1,961\end{array}$ & $\begin{array}{l}5,633 \\
2,367 \\
0,152 \\
0,772 \\
2,087 \\
0,034 \\
2,848 \\
0,000 \\
0,064 \\
1,707\end{array}$ & $\begin{array}{l}5,490 \\
2,510 \\
0,271 \\
0,550 \\
3,121 \\
0,053 \\
2,143 \\
0,403 \\
0,000 \\
1,844\end{array}$ & $\begin{array}{l}5,668 \\
2,332 \\
0,179 \\
0,516 \\
1,709 \\
0,034 \\
3,793 \\
0,006 \\
0,128 \\
1,874\end{array}$ \\
\hline Total & 16,185 & 16,325 & 16,246 & 16,203 & 16,077 & 16,103 & 15,664 & 16,016 & 16,239 \\
\hline $\begin{array}{l}\mathrm{Al} \\
\mathrm{Mg}^{2} \\
\mathrm{Fe}^{2+}\end{array}$ & $\begin{array}{l}35,42 \\
35,25 \\
29,33\end{array}$ & $\begin{array}{l}34,11 \\
39,70 \\
26,19\end{array}$ & $\begin{array}{l}35,06 \\
37,98 \\
26,96\end{array}$ & $\begin{array}{l}34,80 \\
38,29 \\
26,91\end{array}$ & $\begin{array}{l}34,38 \\
40,35 \\
25,27\end{array}$ & $\begin{array}{l}33,74 \\
42,10 \\
24,16\end{array}$ & $\begin{array}{l}33,79 \\
38,21 \\
28,00\end{array}$ & $\begin{array}{l}34,57 \\
26,64 \\
38,79\end{array}$ & $\begin{array}{l}31,34 \\
47,34 \\
21,32\end{array}$ \\
\hline mg* & 0,361 & 0,602 & 0,585 & 0,587 & 0,615 & 0,635 & 0,577 & 0,407 & 0,689 \\
\hline
\end{tabular}


Tabela 5 - Análises químicas representativas de olivinas das rochas de Acahay. *. $\mathrm{mg}=\mathrm{Mg} /\left(\mathrm{Mg}+\mathrm{Fe} \mathrm{e}^{+}\right)$da olivina; ** mg da olivina em equilibrio com o llquido $\left(K_{\mathrm{D}}=0,30, \mathrm{Fe}_{2} \mathrm{O} / \mathrm{FeO}=0,20\right)$

Table 5 - Representative chemical analyses of olivines from the Acahay rocks * $. \mathrm{mg}=\mathrm{Mg}\left(\mathrm{Mg}+\mathrm{Fe}^{2+}\right.$ ) of olivine; ** , mg of olivine in equilibrium with the liquid ( $\mathrm{K}_{\mathrm{D}}=0.30 ; \mathrm{Fe}_{2} \mathrm{O}_{3} / \mathrm{FeO}=0.20$ )

\begin{tabular}{|c|c|c|c|c|c|c|c|c|}
\hline & \multirow{2}{*}{$\begin{array}{c}\text { Traquibasaltos } \\
\mathbf{m F}\end{array}$} & \multirow{2}{*}{$\begin{array}{c}\text { Traquiandesitos } \\
\text { M }\end{array}$} & \multicolumn{2}{|c|}{ Gabros alcalinos } & \multicolumn{2}{|c|}{ Sienogabros } & \multirow{2}{*}{$\begin{array}{c}\text { Sienodioritos } \\
\text { M }\end{array}$} & \multirow{2}{*}{$\begin{array}{c}\text { Gabros } \\
\text { essexíticos } \\
\text { M }\end{array}$} \\
\hline & & & $\mathbf{M c} \mathbf{N}$ & $\mathbf{M}$ & $\mathbf{M c N}$ & $\mathbf{M}$ & & \\
\hline $\mathrm{SiO}_{2}$ & 39,28 & 36,60 & 36,87 & 36,89 & 35,72 & 35,77 & 34,04 & 35,28 \\
\hline $\mathrm{FeO}$ & 17,91 & 33,06 & 31,64 & 31,80 & 34,88 & 35,47 & 44,50 & 38,49 \\
\hline $\mathrm{MnO}$ & 0,65 & 1,54 & 0,91 & 1,14 & 1,13 & 1,15 & 1,81 & 1,41 \\
\hline $\mathrm{MgO}$ & 42,04 & 29,25 & 31,20 & 30,95 & 28,42 & 27,81 & 19,98 & 25,32 \\
\hline $\mathrm{CaO}$ & 0,05 & 0,15 & 0,14 & 0,12 & 0,23 & 0,19 & 0,28 & 0,28 \\
\hline Total & 99,93 & 100,60 & 100,76 & 100,90 & 100,38 & 100,39 & 100,61 & 100,78 \\
\hline $\mathbf{S i}$ & 1,002 & 1,003 & 0,999 & 1,000 & 0,991 & 0,995 & 0,995 & 0,994 \\
\hline $\mathrm{Fe}^{2+}$ & 0,382 & 0,758 & 0,717 & 0,721 & 0,809 & 0,825 & 1,087 & 0,907 \\
\hline Mn & 0,014 & 0,036 & 0,021 & 0,026 & 0,027 & 0,027 & 0,045 & 0,034 \\
\hline $\mathrm{Mg}$ & 1,598 & 1,195 & 1,260 & 1,250 & 1,175 & 1,153 & 0,870 & 1,063 \\
\hline $\mathrm{Ca}$ & 0,001 & 0,004 & 0,004 & 0,003 & 0,007 & 0,006 & 0,009 & 0,008 \\
\hline Total & 1,996 & 1,993 & 2,002 & 2,000 & 2,018 & 2,010 & 2,011 & 2,012 \\
\hline Fo & 80,08 & 59,96 & 62,94 & 62,49 & 58,23 & 57,33 & 43,26 & 52,84 \\
\hline $\mathrm{Fa}$ & 19,15 & 38,03 & 35,82 & 36,03 & 40,11 & 41,04 & 54,07 & 45,07 \\
\hline Tphr & 0,70 & 1,79 & 1,04 & 1,31 & 1,32 & 1,35 & 2,23 & 1,67 \\
\hline Lar & 0,07 & 0,22 & 0,20 & 0,17 & 0,34 & 0,28 & 0,44 & 0,42 \\
\hline $\mathrm{mg} *$ & 0,807 & 0,612 & 0,637 & 0,634 & 0,592 & 0,583 & 0,444 & 0,539 \\
\hline$m g^{* * *}$ & 0,815 & 0,749 & 0,845 & & 0,778 & & 0,755 & 0,814 \\
\hline
\end{tabular}

No todo, essas variações são compatíveis com a formação comum dessas rochas por cristalização fracionada. Contudo, a dispersão presente em boa parte dos diagramas relativos aos elementos principais e traços (Fig. 16) parece indicar um processo de maior complexidade. Assim, por exemplo, o comportamento dos álcalis (Figs, li e 12), nos quais se reconhece a presença de termos com grau variável de alcalinidade, é sugestivo da existência de mais de uma unha de evolução a partir de um ou mais líquidos geradores, estes não representados entre as rochas do maciço até agora identificadas.

Evidências químicas (minerais e rochas) e petrográficas são indicativas de que as rochas de Acahay - caracterizando duas suítes (extrusiva e intrusiva) e reunidas, em função de várias afinidades, em três grupos distintos: a. traquibasaltos-traquiandesitos-traquitos, b. gabros alcalinos-sienogabros-sienodioritos-sienitos (Qz e Ne normativos) e c. gabros essexíticos-essexitos - originaram-se possivelmente por mecanismos de cristalização fracionada. Por outro lado, as características químicas, notadamente os baixos conteúdos de $\mathrm{Cr}$ e Ni, aliadas às feições texturais, permitem atribuir para as rochas teralíticas, representadas apenas por duas amostras, uma formação dôsjiatureza cumulática.

Cálculos de balanço de massa (elementos principais, Wright \& Doberty 1970; traços, lei de Rayleigh) foram feitos para os três grupos litológicos, empregando-se as composições médias fornecidas na tabela 8 para as rochas e os coeficientes de partição dos minerais apresentados na tabela 9; composições usadas da olivina assumindo condições de equilíbrio a baixa pressão. Os resultados indicam que os termos extrusivos formam uma seqüência evolutiva, com os traquiandesitos podendo derivar-se dos traquibasaltos e, por sua vez, os traquitos dos traquiandesitos (Tab. 10). Na primeira etapa, as fases extraídas em clinopiroxênio, plagioclásio, olivina e magnetita, e, na segunda, apareceriam, adicionalmente, apatita, biotita $\mathrm{e} \pm$ nefelina. Da mesma forma, são perfeitamente plausíveis as transformações dos gabros alcalinos em sienodioritos e dos gabros essexíticos em essexitos (Tabs. 11 e 12) e representadas, juntamente com as da suíte anterior, pelas linhas de evolução mostradas na figura 17 . É interessante realçar que á passagem dos sienodioritos a sienitos (Tab. 11) é compatível com um processo de cristalização fracionada apenas no tocante ao comportamento dos elementos principais, uma vez que, para os traços, os valores calculados são em geral muito mais elevados que os observados (média calculado/observado $=3,8 \pm 2,2$ ). Este fato sugere que os sienitos, que correspondem aos únicos diques até agora encontrados no maciço, acham-se possivelmente relacionados a processos mais complexos de evolução, envolvendo o fracionamento de outras fases acessórias, como, por exemplo, titanita e zircão.

A afinidade genética entre os três agrupamentos foi também pesquisada por meio de cálculos de balanço de massa, com os resultados indicando, seja para os elementos principais ou para os traços, a possibilidade de uma derivação comum para os traquibasaltos e gabros essexíticos a partir dos gabros 
Tabela 6-Análises químicas representativas de opacos (magnetita com Ti) das rochas de Acahay. Dados para temperatura e fugacidade, calculados segundo Budding ton \& Lindsley (1964)

Table 6 - Representative chemical analysis of opaque (titanian magnetite) from the Acahay rocks. Data of temperature and fugacity calculated according to Buddington\& Lindsley (1964)

\begin{tabular}{|c|c|c|c|c|c|c|c|c|}
\hline & \multicolumn{2}{|c|}{ Traquibasaltos } & \multirow{2}{*}{$\begin{array}{c}\text { Traquiandesitos } \\
\mathbf{M} \\
\end{array}$} & \multirow{2}{*}{$\begin{array}{c}\text { Traquitos } \\
\mathbf{M} \\
\end{array}$} & \multicolumn{2}{|c|}{ Gabros alcalinos } & \multicolumn{2}{|c|}{ Sienogabros } \\
\hline & $\mathbf{m F}$ & $\mathbf{M}$ & & & Mc & $\mathbf{m}$ & Mc & $\mathbf{m}$ \\
\hline $\begin{array}{l}\mathrm{TiO}_{2} \\
\mathrm{Al}_{2} \mathrm{O}_{3} \\
\mathrm{FeOt} \\
\mathrm{MnO} \\
\mathrm{MgO} \\
\mathrm{CaO} \\
\mathrm{Cr}_{2} \mathrm{O}_{3}\end{array}$ & $\begin{array}{r}23,90 \\
2,78 \\
68,80 \\
1,09 \\
2,21 \\
0,00 \\
0,04\end{array}$ & $\begin{array}{r}18,66 \\
4,85 \\
69,64 \\
0,91 \\
3,09 \\
0,00 \\
0,17\end{array}$ & $\begin{array}{r}22,83 \\
2,32 \\
70,58 \\
1,10 \\
1,50 \\
0,00 \\
0,05\end{array}$ & $\begin{array}{r}9,37 \\
1,43 \\
82,43 \\
0,95 \\
0,57 \\
0,00 \\
0,02\end{array}$ & $\begin{array}{r}13,36 \\
3,68 \\
77,32 \\
0,66 \\
1,32 \\
0,00 \\
0,38\end{array}$ & $\begin{array}{r}14,80 \\
3,91 \\
74,23 \\
0,67 \\
1,80 \\
0,03 \\
0,27\end{array}$ & $\begin{array}{r}17,00 \\
2,85 \\
74,99 \\
0,87 \\
1,41 \\
0,02 \\
0,12\end{array}$ & $\begin{array}{r}21,75 \\
1,86 \\
72,38 \\
1,15 \\
0,52 \\
0,00 \\
0,04\end{array}$ \\
\hline Total & 98,82 & 97,32 & 98,39 & 94,77 & 96,72 & 95,71 & 97,24 & 97,70 \\
\hline $\begin{array}{l}\mathrm{FeO} \\
\mathrm{Fe}_{2} \mathrm{O}_{3}\end{array}$ & $\begin{array}{l}49,54 \\
21,40\end{array}$ & $\begin{array}{l}43,63 \\
28,90\end{array}$ & $\begin{array}{l}49,48 \\
23,45\end{array}$ & $\begin{array}{l}49,30 \\
38,07\end{array}$ & $\begin{array}{l}41,62 \\
39,67\end{array}$ & $\begin{array}{l}41,79 \\
36,05\end{array}$ & $\begin{array}{l}44,47 \\
33,91\end{array}$ & $\begin{array}{l}49,69 \\
25,21\end{array}$ \\
\hline \multirow[t]{2}{*}{ Ulvक } & 62,60 & 51,64 & 61,07 & 26,12 & 40,95 & 44,45 & 47,81 & 60,08 \\
\hline & $\mathbf{m}$ & & $\mathbf{m}$ & $\mathbf{m}$ & $\mathbf{m}$ & & $\mathbf{m}$ & \\
\hline $\begin{array}{l}\mathrm{TiO}_{2} \\
\mathrm{Al}_{3} \mathrm{O}_{3} \\
\mathrm{FeOt} \\
\mathrm{MnO} \\
\mathrm{MgO} \\
\mathrm{CaO} \\
\mathrm{Cr}_{2} \mathrm{O}_{3}\end{array}$ & $\begin{array}{r}50,30 \\
0,00 \\
44,84 \\
0,81 \\
2,78 \\
0,00 \\
0,00\end{array}$ & . & $\begin{array}{r}49,59 \\
0,00 \\
43,49 \\
2,68 \\
4,61 \\
0,00 \\
0,00\end{array}$ & $\begin{array}{r}37,00 \\
0,00 \\
58,17 \\
1,70 \\
2,34 \\
0,00 \\
0,00\end{array}$ & $\begin{array}{r}44,64 \\
0,00 \\
49,82 \\
1,87 \\
2,95 \\
0,00 \\
0,00\end{array}$ & & $\begin{array}{r}47,32 \\
0,07 \\
47,79 \\
1,23 \\
1,92 \\
0,02 \\
0,05\end{array}$ & \\
\hline Total & 98,73 & & 100,37 & 99,21 & 99,28 & & 98,40 & \\
\hline $\mathrm{Fe}_{2} \mathrm{O}_{3} \%$ & 5,98 & & 10,92 & 34,22 & 18,70 & & 11,04 & \\
\hline $\mathrm{T}^{\circ} \mathrm{C}$ & 865 & & 1022 & 1037 & 1023 & & 1027 & \\
\hline \multirow[t]{3}{*}{$-\log \mathrm{fO}_{2}$} & 13,6 & & 10,5 & 8,3 & 9,7 & & 10,4 & \\
\hline & \multicolumn{2}{|c|}{ Sienodioritos } & \multicolumn{2}{|c|}{ Teralitos } & $\begin{array}{c}\text { Gabros } \\
\text { essexíticos }\end{array}$ & Essexitos & Sienitos & $\begin{array}{c}\text { Nefelina } \\
\text { sienitos }\end{array}$ \\
\hline & $\mathrm{mC}$ & m & $\mathbf{M C}$ & $\mathbf{m}$ & $\mathrm{m}$ & $\mathbf{m}$ & $\mathbf{m}$ & $\mathbf{m}$ \\
\hline $\begin{array}{l}\mathrm{TiO}_{2} \\
\mathrm{Al}_{3} \mathrm{O}_{3} \\
\mathrm{FeOt} \\
\mathrm{MnO} \\
\mathrm{MgO} \\
\mathrm{CaO} \\
\mathrm{Cr}_{2} \mathrm{O}_{3}\end{array}$ & $\begin{array}{r}6,47 \\
2,24 \\
84,66 \\
1,56 \\
0,62 \\
0,00 \\
0,02\end{array}$ & $\begin{array}{r}7,50 \\
2,05 \\
84,50 \\
1,38 \\
0,31 \\
0,02 \\
0,00\end{array}$ & $\begin{array}{r}12,69 \\
2,79 \\
79,62 \\
0,98 \\
1,07 \\
0,00 \\
0,16\end{array}$ & $\begin{array}{r}11,58 \\
2,51 \\
78,65 \\
1,04 \\
0,43 \\
0,00 \\
0,05\end{array}$ & $\begin{array}{r}15,30 \\
2,77 \\
76,68 \\
0,94 \\
1,18 \\
0,01 \\
0,07\end{array}$ & $\begin{array}{r}20,21 \\
2,03 \\
72,78 \\
1,29 \\
0,70 \\
0,00 \\
0,08\end{array}$ & $\begin{array}{r}12,02 \\
0,73 \\
81,57 \\
1,24 \\
0,36 \\
0,03 \\
0,00\end{array}$ & $\begin{array}{c}5,00 \\
1,07 \\
85,98 \\
2,12 \\
0,63 \\
0,00 \\
0,09\end{array}$ \\
\hline Total & 95,57 & 95,76 & 97,31 & 94,26 & 96,95 & 97,09 & 95,95 & 94,89 \\
\hline $\begin{array}{l}\mathrm{FeO}_{\mathrm{Fe}_{2} \mathrm{O}_{3}} \\
\end{array}$ & $\begin{array}{l}35,24 \\
54,91\end{array}$ & $\begin{array}{l}36,80 \\
53,00\end{array}$ & $\begin{array}{l}41,18 \\
42,71\end{array}$ & $\begin{array}{c}438,91 \\
44,16\end{array}$ & $\begin{array}{l}43,18 \\
37,23\end{array}$ & $\begin{array}{l}47,77 \\
27,80\end{array}$ & $\begin{array}{l}40,65 \\
45,47\end{array}$ & $\begin{array}{l}33,00 \\
58,87\end{array}$ \\
\hline \multirow[t]{2}{*}{ Utv\% } & 17,59 & 20,89 & 36,45 & 30,41 & 43,41 & 55,58 & 31,19 & 9,57 \\
\hline & m & & & & $\mathbf{m}$ & $\mathbf{m}$ & $\mathbf{m}$ & $\mathbf{m}$ \\
\hline $\begin{array}{l}\mathrm{TiO}_{2} \\
\mathrm{Al}_{3} \mathrm{O}_{3} \\
\mathrm{FeOt} \\
\mathrm{MnO} \\
\mathrm{MgO} \\
\mathrm{CaO} \\
\mathrm{Cr}_{2} \mathrm{O}_{3}\end{array}$ & $\begin{array}{r}50,23 \\
0,01 \\
44,48 \\
2,45 \\
2,03 \\
0,00 \\
0,00\end{array}$ & & & & $\begin{array}{r}42,05 \\
0,00 \\
52,41 \\
1,98 \\
3,00 \\
0,00 \\
0,00\end{array}$ & $\begin{array}{r}48,90 \\
0,38 \\
46,56 \\
1,27 \\
1,66 \\
0,00 \\
0,00\end{array}$ & $\begin{array}{r}50,41 \\
0,00 \\
44,38 \\
3,74 \\
0,09 \\
0,01 \\
0,00\end{array}$ & $\begin{array}{r}50,73 \\
0,03 \\
44,05 \\
3,59 \\
0,48 \\
0,00 \\
0,00\end{array}$ \\
\hline Total & 99,20 & & & & 99,44 & 98,77 & 98,63 & 98,88 \\
\hline $\mathrm{Fe}_{2} \mathrm{O}_{3} \%$ & 6,01 & & & & 24,39 & 7,59 & 3,34 & 3,25 \\
\hline $\mathrm{T}^{\circ} \mathrm{C}$ & 676 & & & & 1089 & 939 & 699 & 549 \\
\hline$-\log \mathrm{fO}_{2}$ & 17,8 & & & & 8,5 & 11,9 & 18,1 & 22,4 \\
\hline
\end{tabular}


Tabela 7 - Análises químicas (elementos principais e traços) e norma CIPW para os diferentes tipos petrográficos do maciço de Acahay

Table 7 - Chemical analyses (major and trace elements, CIPW norms) for the different petrographyc types from the Acahay massif

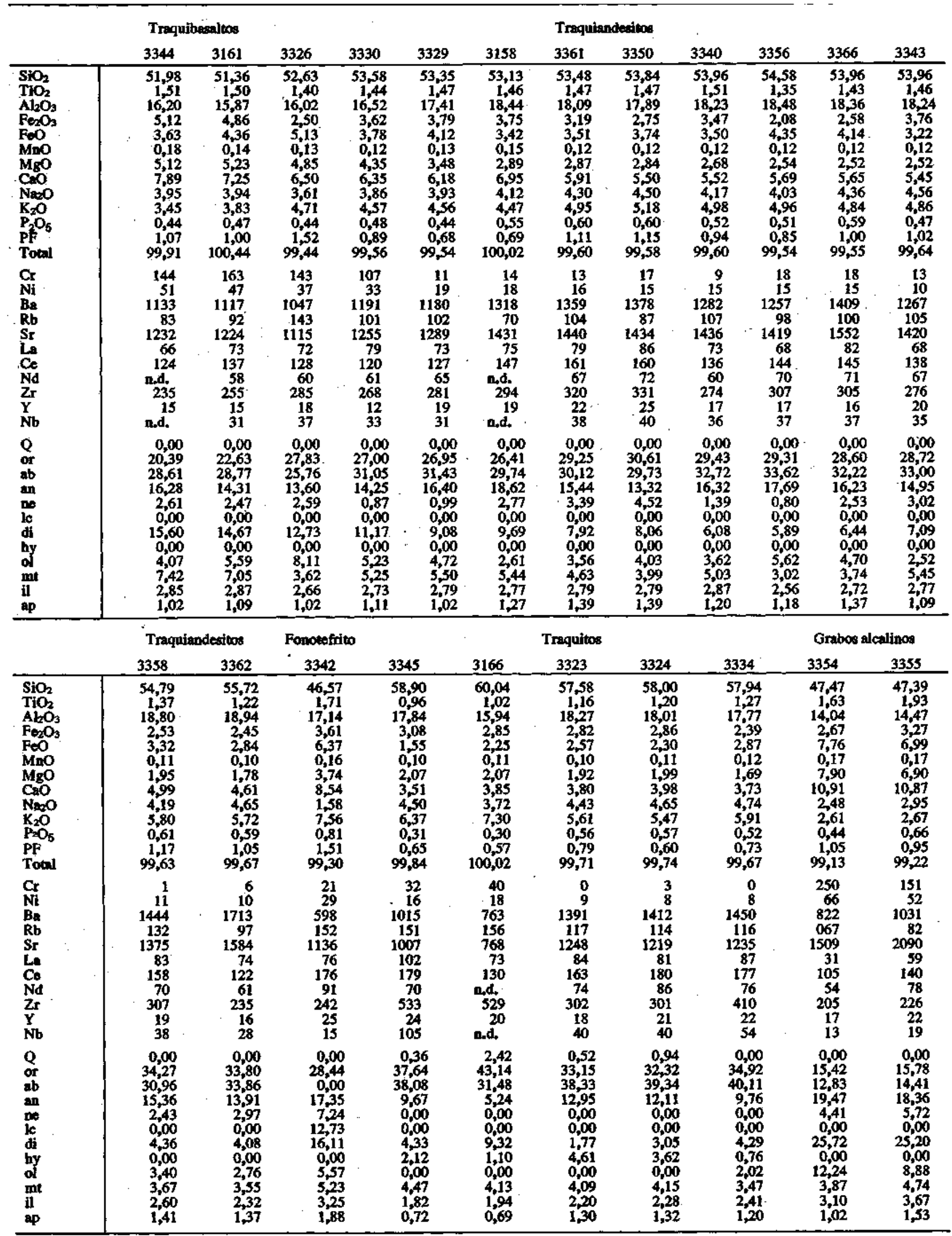


Tabela 7 - Continuaģa

Table 7-Continues

\begin{tabular}{|c|c|c|c|c|c|c|c|c|c|c|c|}
\hline & \multicolumn{4}{|c|}{ Gabroes alcalinos } & \multicolumn{7}{|c|}{ Sienogabros } \\
\hline & 3353 & 3333 & 3359 & 3341 & .3348 & 3325 & 3328 & 3346 & 3367 & 3159 & 3371 \\
\hline $\begin{array}{l}\mathrm{SiO}_{2} \\
\mathrm{ThO}_{2} \\
\mathrm{Al}_{2} \mathrm{O}_{3} \\
\mathrm{Fe}_{2} \mathrm{O}_{3} \\
\mathrm{FeO}^{\mathrm{MnO}} \\
\mathrm{MgO} \\
\mathrm{CHO} \\
\mathrm{Na}_{2} \mathrm{O} \\
\mathrm{K}_{2} \mathrm{O} \\
\mathrm{P}_{2} \mathrm{O}_{5} \\
\mathrm{PF} \\
\text { Total }\end{array}$ & $\begin{array}{r}48,26 \\
1,70 \\
14,58 \\
2,79 \\
7,31 \\
0,17 \\
6,60 \\
9,89 \\
3,05 \\
3,05 \\
0,58 \\
1,22 \\
99,20\end{array}$ & $\begin{array}{r}47,73 \\
1,72 \\
15,40 \\
2,76 \\
7,40 \\
0,16 \\
6,42 \\
10,11 \\
2,77 \\
3,28 \\
0,60 \\
0,82 \\
99,17\end{array}$ & $\begin{array}{r}46,49 \\
1,76 \\
16,30 \\
2,99 \\
7,59 \\
0,16 \\
6,35 \\
10,27 \\
2,45 \\
2,92 \\
0,72 \\
1,15 \\
99,15\end{array}$ & $\begin{array}{r}46,01 \\
2,02 \\
16,01 \\
3,64 \\
7,55 \\
0,19 \\
5,88 \\
10,51 \\
2,61 \\
2,88 \\
0,93 \\
0,94 \\
99,17\end{array}$ & $\begin{array}{r}47,55 \\
2,12 \\
14,75 \\
3,96 \\
6,52 \\
0,18 \\
5,54 \\
10,61 \\
2,85 \\
3,28 \\
0,80 \\
1,11 \\
99,27\end{array}$ & $\begin{array}{r}47,80 \\
2,05 \\
15,15 \\
3,72 \\
6,49 \\
0,17 \\
5,38 \\
10,26 \\
2,94 \\
3,51 \\
0,77 \\
1,04 \\
99,28\end{array}$ & $\begin{array}{r}49,77 \\
1,53 \\
16,80 \\
1,96 \\
6,77 \\
0,15 \\
4,79 \\
8,53 \\
3,69 \\
3,44 \\
0,71 \\
1,11 \\
99,25\end{array}$ & $\begin{array}{r}49,97 \\
1,62 \\
16,64 \\
2,16 \\
6,76 \\
0,15 \\
4,57 \\
8,20 \\
3,78 \\
3,64 \\
0,68 \\
1,08 \\
99,25\end{array}$ & $\begin{array}{r}49,01 \\
1,70 \\
17,62 \\
5,81 \\
5,23 \\
0,16 \\
4,11 \\
8,02 \\
3,08 \\
4,87 \\
0,74 \\
1,34 \\
101,69\end{array}$ & $\begin{array}{r}49,51 \\
1,75 \\
17,25 \\
4,01 \\
4,96 \\
0,19 \\
4,05 \\
8,47 \\
3,83 \\
3,71 \\
0,75 \\
1,47 \\
99,95\end{array}$ & $\begin{array}{r}50,81 \\
1,48 \\
17,00 \\
3,33 \\
5,05 \\
0,15 \\
4,24 \\
7,49 \\
4,04 \\
4,04 \\
0,58 \\
1,24 \\
99,45\end{array}$ \\
\hline $\begin{array}{l}\mathrm{Cr} \\
\mathrm{Nit} \\
\mathrm{Bt} \\
\mathrm{Rb} \\
\mathrm{Sr} \\
\mathrm{La} \\
\mathrm{Ce} \\
\mathrm{Nd} \\
\mathrm{Zr} \\
\mathrm{Y} \\
\mathrm{Nb}\end{array}$ & $\begin{array}{r}162 \\
39 \\
939 \\
60 \\
1579 \\
55 \\
130 \\
67 \\
251 \\
19 \\
21\end{array}$ & $\begin{array}{r}115 \\
48 \\
943 \\
99 \\
1716 \\
53 \\
117 \\
63 \\
216 \\
14 \\
18\end{array}$ & $\begin{array}{r}98 \\
44 \\
831 \\
78 \\
1814 \\
58 \\
111 \\
51 \\
174 \\
15 \\
12\end{array}$ & $\begin{array}{r}57 \\
33 \\
1003 \\
53 \\
2057 \\
81 \\
166 \\
87 \\
224 \\
23 \\
16\end{array}$ & $\begin{array}{r}71 \\
37 \\
1182 \\
80 \\
2054 \\
91 \\
170 \\
93 \\
282 \\
22 \\
20\end{array}$ & $\begin{array}{r}59 \\
33 \\
1139 \\
87 \\
1995 \\
84 \\
178 \\
88 \\
314 \\
28 \\
24\end{array}$ & $\begin{array}{r}94 \\
32 \\
1131 \\
78 \\
1725 \\
71 \\
141 \\
65 \\
238 \\
18 \\
23\end{array}$ & $\begin{array}{r}64 \\
27 \\
1189 \\
66 \\
1679 \\
84 \\
135 \\
63 \\
261 \\
23 \\
20\end{array}$ & $\begin{array}{r}29 \\
23 \\
1498 \\
103 \\
2108 \\
95 \\
128 \\
64 \\
270 \\
20 \\
26\end{array}$ & $\begin{array}{r}27 \\
26 \\
2178 \\
104 \\
2269 \\
83 \\
157 \\
\text { n,d. } \\
254 \\
17 \\
\text { nd. }\end{array}$ & $\begin{array}{r}72 \\
27 \\
1207 \\
78 \\
1537 \\
84 \\
145 \\
67 \\
295 \\
22 \\
30\end{array}$ \\
\hline \multirow[t]{3}{*}{$\begin{array}{l}Q \\
\text { or } \\
\text { ab } \\
\text { an } \\
\text { bo } \\
\text { le } \\
\text { dit } \\
\text { hy } \\
\text { of } \\
\text { mt } \\
\text { il } \\
\text { ap } \\
\end{array}$} & $\begin{array}{r}0,00 \\
18,02 \\
15,89 \\
17,08 \\
5,37 \\
0,00 \\
22,86 \\
0,00 \\
10,14 \\
4,05 \\
3,23 \\
1,34 \\
\end{array}$ & $\begin{array}{r}0,00 \\
19,38 \\
12,88 \\
19,90 \\
5,72 \\
0,00 \\
21,38 \\
0,00 \\
10,43 \\
4,00 \\
3,27 \\
1,39\end{array}$ & $\begin{array}{r}0,00 \\
17,25 \\
13,42 \\
24,85 \\
3,96 \\
0,00 \\
17,38 \\
0,00 \\
11,79 \\
4,34 \\
3,34 \\
1,67 \\
\end{array}$ & $\begin{array}{r}0,00 \\
17,02 \\
13,74 \\
23,46 \\
4,52 \\
0,00 \\
18,34 \\
0,00 \\
9,88 \\
5,28 \\
3,84 \\
2,15 \\
\end{array}$ & $\begin{array}{r}0,00 \\
19,38 \\
14,85 \\
17,77 \\
5,02 \\
0,00 \\
23,86 \\
0,00 \\
5,66 \\
5,74 \\
4,03 \\
1,85 \\
\end{array}$ & $\begin{array}{r}0,00 \\
20,74 \\
14,33 \\
17,77 \\
5,72 \\
0,00 \\
22,66 \\
0,00 \\
5,96 \\
: \quad 5,39 \\
\mathbf{3 , 8 9} \\
1,78\end{array}$ & $\begin{array}{r}0,00 \\
20,33 \\
21,08 \\
19,12 \\
5,49 \\
0,00 \\
15,19 \\
0,00 \\
9,54 \\
2,84 \\
2,91 \\
1,64 \\
\end{array}$ & $\begin{array}{r}0,00 \\
21,51 \\
21,35 \\
17,69 \\
5,76 \\
0,00 \\
15,19 \\
0,00 \\
8,89 \\
3,13 \\
3,08 \\
1,57 \\
\end{array}$ & $\begin{array}{r}0,00 \\
28,78 \\
16,04 \\
19,87 \\
5,43 \\
0,00 \\
11,99 \\
0,00 \\
4,88 \\
8,42 \\
3,23 \\
1,71 \\
\end{array}$ & $\begin{array}{r}0,00 \\
21,92 \\
21,95 \\
18,92 \\
5,66 \\
0,00 \\
14,58 \\
0,00 \\
4,57 \\
5,81 \\
3,32 \\
1,74 \\
\end{array}$ & $\begin{array}{r}0,00 \\
23,87 \\
23,55 \\
16,32 \\
5,76 \\
0,00 \\
13,73 \\
0,00 \\
5,99 \\
4,83 \\
2,81 \\
1,34 \\
\end{array}$ \\
\hline & & & \multicolumn{3}{|c|}{ Sienodiaritos } & \multicolumn{6}{|c|}{ Tertlitos } \\
\hline & 3370 & 3365 & 3374 & 3167 & 3368 & 3335 & 3339 & 3336 & 3357 & 3352 & 3363 \\
\hline $\begin{array}{l}\mathrm{SiO}_{2} \\
\mathrm{TjO}_{2} \\
\mathrm{Al}_{2} \mathrm{O}_{3} \\
\mathrm{Fe}_{3} \\
\mathrm{FeO} \\
\mathrm{MaO} \\
\mathrm{MgO} \\
\mathrm{CaO} \\
\mathrm{Na}_{2} \mathrm{O} \\
\mathrm{K}_{2} \mathrm{O} \\
\mathrm{P}_{2} \mathrm{O}_{5} \\
\mathrm{PF} \\
\text { Tonal }\end{array}$ & $\begin{array}{r}51,31 \\
1,50 \\
17,03 \\
1,76 \\
6,38 \\
0,14 \\
4,11 \\
7,25 \\
3,99 \\
4,07 \\
0,66 \\
1,08 \\
99,28\end{array}$ & $\begin{array}{r}52,07 \\
1,45 \\
17,45 \\
2,45 \\
5,01 \\
0,13 \\
3,93 \\
6,33 \\
4,39 \\
4,55 \\
0,59 \\
1,09 \\
99,44\end{array}$ & $\begin{array}{r}51,49 \\
1,54 \\
17,49 \\
2,21 \\
5,64 \\
0,13 \\
3,55 \\
6,93 \\
4,04 \\
4,31 \\
0,79 \\
1,26 \\
99,38\end{array}$ & $\begin{array}{r}52,59 \\
1,49 \\
17,20 \\
1,82 \\
5,70 \\
0,14 \\
3,43 \\
6,22 \\
3,83 \\
4,49 \\
0,50 \\
2,00 \\
99,38\end{array}$ & $\begin{array}{r}53,63 \\
1,61 \\
17,15 \\
2,66 \\
4,58 \\
0,13 \\
3,22 \\
5,65 \\
5,36 \\
4,83 \\
0,51 \\
1,15 \\
99,48\end{array}$ & $\begin{array}{r}51,52 \\
1,38 \\
19,80 \\
2,43 \\
3,57 \\
0,12 \\
2,65 \\
6,52 \\
3,01 \\
6,31 \\
0,69 \\
1,61 \\
99,61\end{array}$ & $\begin{array}{r}54,22 \\
1,36 \\
18,58 \\
2,75 \\
3,38 \\
0,11 \\
2,47 \\
5,94 \\
4,46 \\
4,83 \\
0,55 \\
0,97 \\
99,62\end{array}$ & $\begin{array}{r}43,40 \\
2,39 \\
12,97 \\
4,24 \\
8,60 \\
0,21 \\
8,46 \\
11,95 \\
2,63 \\
2,05 \\
1,00 \\
1,13 \\
99,03\end{array}$ & $\begin{array}{r}43,97 \\
2,47 \\
14,14 \\
4,93 \\
7,73 \\
0,21 \\
6,84 \\
11,99 \\
2,90 \\
1,75 \\
1,31 \\
0,90 \\
99,14\end{array}$ & $\begin{array}{r}47,56 \\
1,77 \\
14,07 \\
2,55 \\
7,87 \\
0,17 \\
7,34 \\
9,60 \\
3,09 \\
3,44 \\
0,64 \\
1,02 \\
99,12\end{array}$ & $\begin{array}{r}47,32 \\
1,77 \\
15,76 \\
2,48 \\
7,72 \\
0,16 \\
6,16 \\
9,25 \\
3,21 \\
3,45 \\
0,68 \\
1,18 \\
99,14\end{array}$ \\
\hline $\begin{array}{l}\mathrm{Cr} \\
\mathrm{Ni} \\
\mathrm{Ba} \\
\mathrm{Rb} \\
\mathrm{Sr} \\
\mathrm{La} \\
\mathrm{Ce} \\
\mathrm{Nd} \\
\mathrm{Zr} \\
\mathrm{Y} \\
\mathrm{Nb}\end{array}$ & $\begin{array}{r}56 \\
25 \\
1173 \\
94 \\
1504 \\
80 \\
132 \\
62 \\
275 \\
22 \\
31\end{array}$ & $\begin{array}{r}44 \\
21 \\
1241 \\
108 \\
1402 \\
80 \\
147 \\
70 \\
333 \\
18 \\
41\end{array}$ & $\begin{array}{r}41 \\
24 \\
1305 \\
114 \\
1601 \\
88 \\
160 \\
70 \\
291 \\
18 \\
33\end{array}$ & $\begin{array}{r}42 \\
12 \\
1153 \\
98 \\
1269 \\
67 \\
126 \\
12 d \\
193 \\
19 \\
28\end{array}$ & $\begin{array}{r}26 \\
19 \\
255 \\
107 \\
1280 \\
84 \\
154 \\
77 \\
373 \\
19 \\
43\end{array}$ & $\begin{array}{r}18 \\
16 \\
1796 \\
149 \\
3314 \\
70 \\
108 \\
50 \\
227 \\
14 \\
15\end{array}$ & $\begin{array}{r}9 \\
12 \\
1236 \\
99 \\
1383 \\
65 \\
125 \\
123 \\
281 \\
17 \\
34\end{array}$ & $\begin{array}{r}64 \\
38 \\
886 \\
38 \\
1514 \\
86 \\
166 \\
97 \\
270 \\
27 \\
20\end{array}$ & $\begin{array}{r}51 \\
33 \\
1006 \\
29 \\
2028 \\
83 \\
\mathbf{1 8 3} \\
107 \\
344 \\
30 \\
60\end{array}$ & $\begin{array}{r}212 \\
61 \\
1012 \\
62 \\
1268 \\
66 \\
152 \\
76 \\
273 \\
21 \\
28\end{array}$ & $\begin{array}{r}105 \\
39 \\
1001 \\
72 \\
1454 \\
76 \\
157 \\
72 \\
273 \\
22 \\
28\end{array}$ \\
\hline $\begin{array}{l}\text { Q } \\
\text { or } \\
\text { ab } \\
\text { an } \\
\text { ne } \\
\text { lc } \\
\text { di } \\
\text { hy } \\
\text { ol } \\
\text { mt } \\
\text { id } \\
\text { ap }\end{array}$ & $\begin{array}{r}0,00 \\
24,05 \\
24,14 \\
16,54 \\
5,21 \\
0,00 \\
12,41 \\
0,00 \\
8,92 \\
2,55 \\
2,85 \\
1,53\end{array}$ & $\begin{array}{r}0,00 \\
26,89 \\
25,29 \\
14,47 \\
6,42 \\
0,00 \\
10,60 \\
0,00 \\
7,01 \\
3,55 \\
2,75 \\
1,37\end{array}$ & $\begin{array}{r}0,00 \\
25,47 \\
25,78 \\
16,86 \\
4,55 \\
0,00 \\
10,11 \\
0,00 \\
7,39 \\
3,20 \\
2,92 \\
1,83\end{array}$ & $\begin{array}{r}0,00 \\
26,53 \\
28,71 \\
16,48 \\
2,00 \\
0,00 \\
9,13 \\
0,00 \\
7,96 \\
2,64 \\
2,77 \\
1,66\end{array}$ & $\begin{array}{r}0,00 \\
28,54 \\
30,62 \\
12,96 \\
3,40 \\
0,00 \\
9,49 \\
0,00 \\
5,23 \\
3,86 \\
3,06 \\
1,18\end{array}$ & $\begin{array}{r}0,00 \\
37,29 \\
16,62 \\
21,88 \\
4,80 \\
0,00 \\
4,79 \\
0,00 \\
4,89 \\
3,52 \\
2,62 \\
1,60\end{array}$ & $\begin{array}{r}0,00 \\
28,54 \\
32,00 \\
16,41 \\
3,11 \\
0,00 \\
7,57 \\
0,00 \\
3,18 \\
3,99 \\
2,58 \\
1,27\end{array}$ & $\begin{array}{r}0,00 \\
12,11 \\
6,94 \\
17,53 \\
8,29 \\
0,00 \\
28,38 \\
0,00 \\
11,64 \\
6,15 \\
4,54 \\
2,32\end{array}$ & $\begin{array}{r}0,00 \\
10,34 \\
13,94 \\
20,40 \\
5,74 \\
0,00 \\
25,54 \\
0,00 \\
8,41 \\
7,15 \\
4,69 \\
3,03\end{array}$ & $\begin{array}{r}0,00 \\
20,33 \\
11,11 \\
14,36 \\
8,14 \\
0,00 \\
23,59 \\
0,00 \\
12,02 \\
3,70 \\
\mathbf{3}, 36 \\
1,48\end{array}$ & $\begin{array}{r}0,00 \\
20,39 \\
12,50 \\
18,40 \\
7,94 \\
0,00 \\
18,77 \\
0,00 \\
11,42 \\
3,60 \\
3,36 \\
1,57\end{array}$ \\
\hline
\end{tabular}


Tabela 7 - Continuaçāo

Table 7-Coatinues

\begin{tabular}{|c|c|c|c|c|c|c|c|c|c|c|c|c|c|c|}
\hline & \multicolumn{7}{|c|}{ Gabros exestiticos } & \multicolumn{4}{|c|}{ Estexitios } & \multicolumn{2}{|c|}{ Sienitos } & \multirow{2}{*}{$\begin{array}{c}\begin{array}{c}\text { Nefelina } \\
\text { Sienilo }\end{array} \\
3164 \\
\end{array}$} \\
\hline & 3360 & 3338 & 3364 & 3349 & 3337 & 3347 & 3351 & 3327 & 3369 & 3165 & 3160 & 3331 & 3332 & \\
\hline $\begin{array}{l}\mathrm{SiO}_{2} \\
\mathrm{TiO}_{2} \\
\mathrm{Al}_{3} \mathrm{O}_{3} \\
\mathrm{Fo}_{2} \mathrm{O}_{3} \\
\mathrm{FoO} \\
\mathrm{MrO} \\
\mathrm{MgO} \\
\mathrm{C} \mathrm{O} \\
\mathrm{Na}_{4} \mathrm{O} \\
\mathrm{K}_{20} \\
\mathrm{P}_{2} \mathrm{O}_{5} \\
\mathrm{PF} \\
\text { Total }\end{array}$ & $\begin{array}{r}47,19 \\
1,82 \\
15,72 \\
2,81 \\
7,66 \\
0,17 \\
5,85 \\
9,69 \\
2,93 \\
3,56 \\
0,74 \\
1,01 \\
99,15\end{array}$ & $\begin{array}{r}49,20 \\
1,69 \\
15,82 \\
2,40 \\
6,53 \\
0,15 \\
5,66 \\
8,55 \\
3,74 \\
3,65 \\
0,66 \\
1,21 \\
99,26\end{array}$ & $\begin{array}{r}49,01 \\
1,61 \\
15,31 \\
2,32 \\
6,77 \\
0,15 \\
5,52 \\
8,58 \\
3,57 \\
3,96 \\
0,59 \\
1,86 \\
99,25\end{array}$ & $\begin{array}{r}46,97 \\
2,12 \\
14,90 \\
3,94 \\
6,84 \\
0,18 \\
5,46 \\
10,75 \\
3,45 \\
2,74 \\
0,89 \\
1,01 \\
99,25\end{array}$ & $\begin{array}{r}48,14 \\
1,64 \\
16,63 \\
2,02 \\
7,28 \\
0,16 \\
5,43 \\
9,22 \\
3,47 \\
3,37 \\
0,73 \\
1,11 \\
99,20\end{array}$ & $\begin{array}{r}49,09 \\
1,88 \\
16,20 \\
3,30 \\
5,96 \\
0,15 \\
5,41 \\
10,02 \\
3,71 \\
2,69 \\
0,66 \\
1,27 \\
99,34\end{array}$ & $\begin{array}{r}48,21 \\
1,80 \\
17,28 \\
3,57 \\
5,62 \\
0,16 \\
4,67 \\
8,63 \\
3,46 \\
3,86 \\
0,86 \\
1,27 \\
99,39\end{array}$ & $\begin{array}{r}50,96 \\
1,37 \\
17,47 \\
1,90 \\
5,58 \\
0,13 \\
4,49 \\
7,08 \\
4,38 \\
4,40 \\
0,55 \\
1,06 \\
99,37\end{array}$ & $\begin{array}{r}51,12 \\
1,50 \\
16,95 \\
1,68 \\
6,44 \\
0,15 \\
3,92 \\
6,94 \\
4,37 \\
4,46 \\
0,64 \\
1,13 \\
99,30\end{array}$ & $\begin{array}{r}48,77 \\
1,56 \\
16,51 \\
5,10 \\
4,48 \\
0,21 \\
3,85 \\
8,13 \\
4,31 \\
4,50 \\
0,65 \\
1,83 \\
99,90\end{array}$ & $\begin{array}{r}49,47 \\
1,70 \\
18,88 \\
3,93 \\
3,81 \\
0,18 \\
3,25 \\
7,09 \\
3,66 \\
5,59 \\
0,82 \\
1,58 \\
99,96\end{array}$ & $\begin{array}{r}63,25 \\
0,51 \\
18,27 \\
1,74 \\
0,70 \\
0,05 \\
0,58 \\
1,42 \\
4,68 \\
8,03 \\
0,14 \\
0,54 \\
99,91\end{array}$ & $\begin{array}{r}64,36 \\
0,39 \\
18,11 \\
1,34 \\
0,48 \\
0,05 \\
0,35 \\
1,37 \\
4,32 \\
8,54 \\
0,11 \\
0,53 \\
99,95\end{array}$ & $\begin{array}{r}57,56 \\
0,53 \\
20,06 \\
1,61 \\
1,42 \\
0,07 \\
0,83 \\
2,88 \\
5,08 \\
7,81 \\
0,19 \\
1,84 \\
99,88\end{array}$ \\
\hline $\begin{array}{l}\mathrm{Cr} \\
\mathbf{N i} \\
\mathbf{B a} \\
\mathrm{Rb} \\
\mathbf{S r} \\
\mathbf{L} \mathbf{} \\
\mathbf{C e} \\
\mathbf{N d} \\
\mathbf{Z r} \\
\mathbf{Y} \\
\mathbf{N b}\end{array}$ & $\begin{array}{r}65 \\
36 \\
984 \\
77 \\
1648 \\
52 \\
147 \\
64 \\
239 \\
16 \\
23\end{array}$ & $\begin{array}{r}108 \\
36 \\
1118 \\
76 \\
1622 \\
62 \\
1252 \\
75 \\
288 \\
20 \\
29\end{array}$ & $\begin{array}{r}129 \\
40 \\
1074 \\
78 \\
1419 \\
74 \\
149 \\
69 \\
303 \\
21 \\
30\end{array}$ & $\begin{array}{r}54 \\
31 \\
1199 \\
59 \\
2101 \\
94 \\
187 \\
106 \\
341 \\
28 \\
25\end{array}$ & $\begin{array}{r}83 \\
36 \\
1162 \\
55 \\
1638 \\
74 \\
119 \\
58 \\
236 \\
17 \\
24\end{array}$ & $\begin{array}{r}57 \\
29 \\
1261 \\
66 \\
2350 \\
79 \\
144 \\
77 \\
306 \\
20 \\
23\end{array}$ & $\begin{array}{r}26 \\
23 \\
1482 \\
103 \\
2244 \\
86 \\
171 \\
85 \\
285 \\
23 \\
35\end{array}$ & $\begin{array}{r}73 \\
26 \\
980 \\
92 \\
1489 \\
74 \\
128 \\
60 \\
388 \\
17 \\
25\end{array}$ & $\begin{array}{r}49 \\
25 \\
\mathbf{1 3 5 8} \\
\mathbf{8 1} \\
\mathbf{1 3 5 8} \\
\mathbf{8 7} \\
\mathbf{1 4 9} \\
\mathbf{8 0} \\
\mathbf{3 6 5} \\
\mathbf{2 2} \\
\mathbf{4 1}\end{array}$ & $\begin{array}{r}19 \\
22 \\
1284 \\
88 \\
1576 \\
96 \\
174 \\
n_{1} d_{4} \\
405 \\
21 \\
\text { n.d. }\end{array}$ & $\begin{array}{r}19 \\
20 \\
1396 \\
139 \\
2319 \\
78 \\
166 \\
\text { nd. } \\
272 \\
18 \\
\text { n.d. }\end{array}$ & $\begin{array}{r}0 \\
9 \\
276 \\
112 \\
273 \\
39 \\
63 \\
25 \\
93 \\
4 \\
12\end{array}$ & $\begin{array}{r}0 \\
6 \\
336 \\
120 \\
422 \\
48 \\
88 \\
40 \\
118 \\
9 \\
22\end{array}$ & $\begin{array}{r}6 \\
11 \\
1236 \\
158 \\
1582 \\
45 \\
74 \\
7, d_{.} \\
349 \\
11 \\
0, d .\end{array}$ \\
\hline $\begin{array}{l}Q \\
\text { or } \\
\text { ab } \\
\text { an } \\
\text { no } \\
\text { ic } \\
\text { di } \\
\text { hy } \\
\text { od } \\
\text { mt } \\
\text { il } \\
\text { ap }\end{array}$ & $\begin{array}{r}0,00 \\
21,04 \\
11,74 \\
19,23 \\
7,07 \\
0,00 \\
19,57 \\
0,00 \\
10,26 \\
4,07 \\
3,46 \\
1,71\end{array}$ & $\begin{array}{r}0,00 \\
21,57 \\
17,52 \\
15,60 \\
7,65 \\
0,00 \\
18,26 \\
0,00 \\
9,24 \\
3,48 \\
3,21 \\
1,51\end{array}$ & $\begin{array}{r}0,00 \\
23,40 \\
15,08 \\
14,05 \\
8,19 \\
0,00 \\
20,06 \\
0,00 \\
8,81 \\
3,36 \\
3,06 \\
1,37\end{array}$ & $\begin{array}{r}0,00 \\
16,19 \\
15,48 \\
17,08 \\
7,43 \\
0,00 \\
24,58 \\
0,00 \\
5,69 \\
5,71 \\
4,03 \\
2,06\end{array}$ & $\begin{array}{r}0,00 \\
19,91 \\
15,14 \\
19,85 \\
7,70 \\
0,00 \\
17,27 \\
0,00 \\
10,49 \\
2,93 \\
3,11 \\
1,69\end{array}$ & $\begin{array}{r}0,00 \\
15,90 \\
18,59 \\
19,61 \\
6,93 \\
0,60 \\
20,76 \\
0,00 \\
6,40 \\
4,78 \\
3,57 \\
1,53\end{array}$ & $\begin{array}{r}0,00 \\
22,81 \\
17,34 \\
20,22 \\
6,46 \\
0,00 \\
13,67 \\
0,00 \\
7,03 \\
5,18 \\
3,42 \\
1,99\end{array}$ & $\begin{array}{r}0,00 \\
26,00 \\
19,49 \\
15,01 \\
9,52 \\
0,00 \\
13,44 \\
0,00 \\
8,22 \\
2,75 \\
2,60 \\
1,27\end{array}$ & $\begin{array}{r}0,00 \\
26,35 \\
20,80 \\
13,46 \\
8,76 \\
0,00 \\
13,41 \\
0,00 \\
8,21 \\
2,44 \\
2,85 \\
1,48\end{array}$ & $\begin{array}{r}0,00 \\
26,59 \\
15,01 \\
12,41 \\
11,63 \\
0,00 \\
18,77 \\
0,00 \\
1,80 \\
7,39 \\
2,96 \\
1,51\end{array}$ & $\begin{array}{r}0,00 \\
33,03 \\
14,41 \\
18,58 \\
8,97 \\
0,00 \\
8,89 \\
0,00 \\
3,68 \\
5,70 \\
3,23 \\
1,90\end{array}$ & $\begin{array}{r}\mathbf{2 , 4 2} \\
\mathbf{4 7 , 4 5} \\
\mathbf{3 9 , 6 0} \\
5,13 \\
0,00 \\
0,00 \\
0,68 \\
0,28 \\
0,00 \\
2,52 \\
0,97 \\
0,32\end{array}$ & $\begin{array}{r}4,04 \\
50,46 \\
36,55 \\
4,80 \\
0,00 \\
0,00 \\
0,69 \\
0,09 \\
0,00 \\
1,94 \\
0,74 \\
0,25\end{array}$ & $\begin{array}{r}0,00 \\
46,15 \\
25,97 \\
8,97 \\
9,22 \\
0,00 \\
3,33 \\
0,00 \\
0,73 \\
2,33 \\
1,01 \\
0,44\end{array}$ \\
\hline
\end{tabular}

Tabela 8 - Composição média dos principais litotipos de Acahay utilizados para os cálculos de balanço de massa. TB. traquibasaltos; TA. traquiandesitos; T. traquitos; GA. gabros alcaUnos; SD. sienodioritos; S. sienitos; GE. gabros essexíticos; E. essexitos; número de amostras mostrado em parênteses. Dados normalizados para $100 \%$ e recalculados em base anidra, com os valores do desvio padrão indicados em parênteses

Table 8 - Average composition of the main lithotypes of Acahay samples used for mass balance calculations. TB. trachybasalts; TA. trachyandesites; T. trachytes; AG. alkali gabbros; SD. syenogabbros; S. syenites; GE. essexitic gabbris; E. essexites; number of samples are shown in brackets. Data normalized to $100 \%$ and recalculated on volatile free-basis with standard deviation values indicated

\begin{tabular}{|c|c|c|c|c|c|c|c|c|c|}
\hline & TB (2) & TA (12) & $\mathbf{T}(5)$ & GA (T) & SG (8) & SD (8) & $S(2)$ & GE (9) & $E$ (4) \\
\hline $\begin{array}{l}\mathrm{SiO}_{2} \\
\mathrm{TiO}_{2} \\
\mathrm{AL}_{2} \mathrm{O}_{3} \\
\mathrm{Fe}_{2} \mathrm{O}_{3} \\
\mathrm{FeO}_{3} \\
\mathrm{MnO} \\
\mathrm{MgO}_{\mathrm{gOO}} \\
\mathrm{CaO} \\
\mathrm{Na}_{2} \mathrm{O} \\
\mathrm{K}_{2} \mathrm{O} \\
\mathrm{P}_{2} \mathrm{O}_{5}\end{array}$ & $\begin{array}{r}52,48(0,52) \\
1,54(0,02) \\
16,26(0,25) \\
2,58(0,03) \\
5,89(0,17) \\
0,16(0,03) \\
5,25(0,08) \\
7,71(0,42) \\
3,99(0,03) \\
3,70(0,28) \\
0,47(0,02)\end{array}$ & $\begin{array}{r}54,72(0,83) \\
1,45(0,08) \\
18,17(0,88) \\
2,18(0,21) \\
4,66(0,53) \\
0,12(0,01) \\
2,97(0,91) \\
5,89(0,65) \\
4,23(0,31) \\
5,07(0,44) \\
0,54(0,06)\end{array}$ & $\begin{array}{r}59,07(0,89) \\
1,13(0,13) \\
17,71(0,95) \\
1,73(0,10) \\
3,34(0,23) \\
0,11(0,01) \\
1,97(0,16) \\
3,82(0,18) \\
4,46(0,42) \\
6,20(0,73) \\
0,45(0,14)\end{array}$ & $\begin{array}{r}48,14(0,79) \\
1,88(0,19) \\
15,32(0,86) \\
3,03(0,07) \\
7,67(0,30) \\
0,17(0,01) \\
6,62(0,77) \\
10,69(0,39) \\
2,77(0,24) \\
3,02(0,27) \\
0,69(0,17)\end{array}$ & $\begin{array}{r}50,11(0,88) \\
1,77(0,20) \\
16,96(0,96) \\
2,74(0,14) \\
6,55(0,48) \\
0,17(0,02) \\
4,65(0,55) \\
8,89(0,91) \\
3,51(0,43) \\
3,91(0,61) \\
0,75(0,04)\end{array}$ & $\begin{array}{r}53,18(1,18) \\
1,51(0,08) \\
17,99(0,98) \\
2,33(0,26) \\
5,18(0,67) \\
0,14(0,01) \\
3,51(0,66) \\
6,70(0,66) \\
4,06(0,47) \\
4,79(0,75) \\
0,62(0,10)\end{array}$ & $\begin{array}{r}64,24(0,76) \\
0,46(0,08) \\
18,29(0,12) \\
0,76(0,16) \\
1,31(0,28) \\
0,05(0,00) \\
0,47(0,16) \\
1,41(0,04) \\
4,52(0,25) \\
8,37(0,36) \\
0,13(0,02)\end{array}$ & $\begin{array}{r}49,81(0,87) \\
1,83(0,15) \\
16,01(0,95) \\
2,88(0,17) \\
7,11(0,55) \\
0,17(0,01) \\
5,82(0,74) \\
9,60(0,74) \\
3,45(0,28) \\
3,50(0,46) \\
0,73(0,10)\end{array}$ & $\begin{array}{r}51,01(1,05) \\
1,57(0,14) \\
17,75(1,04) \\
2,51(0,23) \\
5,83(0,64) \\
0,17(0,03) \\
3,95(0,51) \\
7,47(0,57) \\
4,25(0,35) \\
4,84(0,57) \\
0,68(0,11)\end{array}$ \\
\hline $\begin{array}{l}\mathrm{Cr} \\
\mathrm{Ni} \\
\mathrm{Ba} \\
\mathrm{Ce} \\
\mathrm{La} \\
\mathrm{Sr} \\
\mathrm{Zr} \\
\mathbf{R b} \\
\mathrm{Y} \\
\mathrm{Nb} \\
\mathrm{Nd}\end{array}$ & $\begin{array}{r}154(13) \\
49(3) \\
1125(11) \\
131(9) \\
70(5) \\
1228(6) \\
245(14) \\
88(6) \\
15(0) \\
31(0) \\
58(0)\end{array}$ & $\begin{array}{r}31(45) \\
18(9) \\
1320(166) \\
141(14) \\
76(6) \\
1396(127) \\
290(26) \\
104(19) \\
18(3) \\
35(4) \\
66(5)\end{array}$ & $\begin{array}{r}15(19) \\
12(5) \\
1206(304) \\
166(21) \\
85(11) \\
1095(208) \\
415(115) \\
131(21) \\
21(2) \\
60(31) \\
77(7)\end{array}$ & $\begin{array}{r}129(66) \\
46(11) \\
964(124) \\
134(26) \\
61(20) \\
1831(241) \\
225(34) \\
74(15) \\
19(4) \\
17(3) \\
70(16)\end{array}$ & $\begin{array}{r}55(28) \\
28(4) \\
1427(446) \\
148(20) \\
83(9) \\
1955(251) \\
267(29) \\
88(16) \\
21(4) \\
23(3) \\
70(12)\end{array}$ & $\begin{array}{r}39(20) \\
20(6) \\
1296(208) \\
137(17) \\
77(9) \\
1661(678) \\
284(56) \\
106(21) \\
19(3) \\
32(9) \\
74(23)\end{array}$ & $\begin{array}{r}0,3(0) \\
6(2) \\
306(42) \\
76(18) \\
44(6) \\
348(105) \\
106(18) \\
116(6) \\
7(4) \\
17(7) \\
33(11)\end{array}$ & $\begin{array}{r}93(55) \\
37(11) \\
1144(158) \\
153(19) \\
74(13) \\
1749(387) \\
283(33) \\
72(14) \\
21(3) \\
27(4) \\
76(14)\end{array}$ & $\begin{array}{r}40(26) \\
23(3) \\
1255(189) \\
154(20) \\
84(10) \\
1685(432) \\
358(59) \\
100(26) \\
20(2) \\
33(11) \\
70(14)\end{array}$ \\
\hline
\end{tabular}




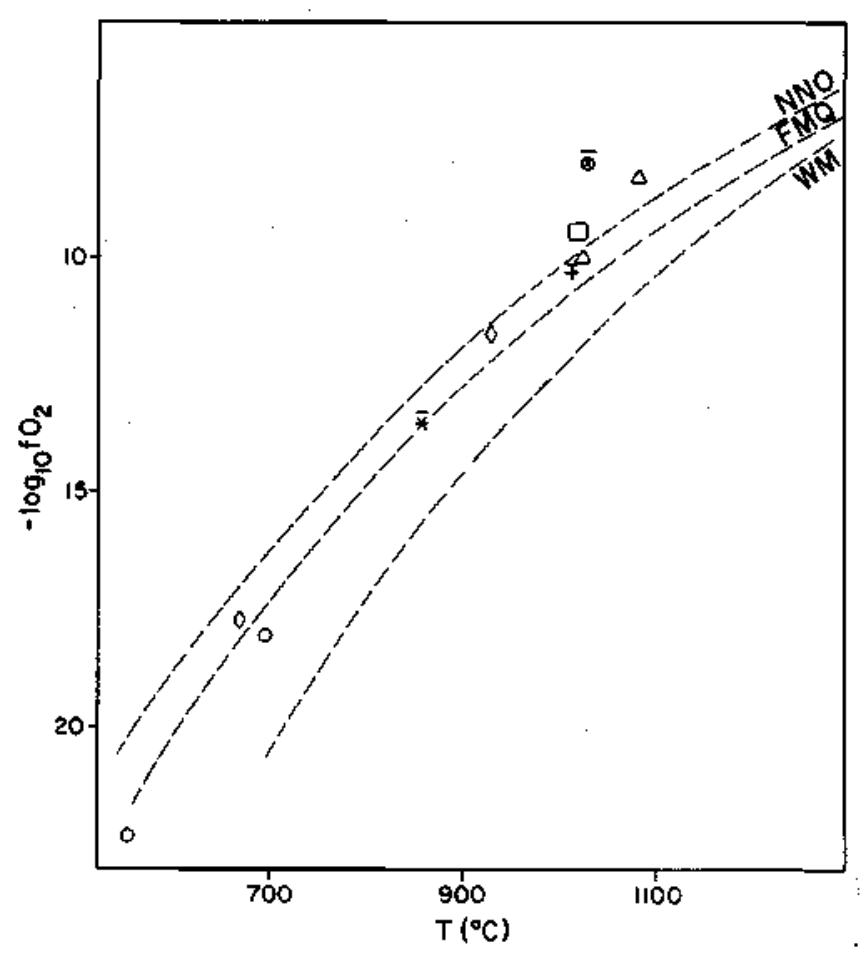

Figura 10 - Projeção dos valores de temperatura e fugacidade de oxigênio para os opacos de Acahay. Símbolos como na figurão

Figure 10 - Temperature and oxygen fugacity values for the opaques of Acahay. Symbols as in figure 6

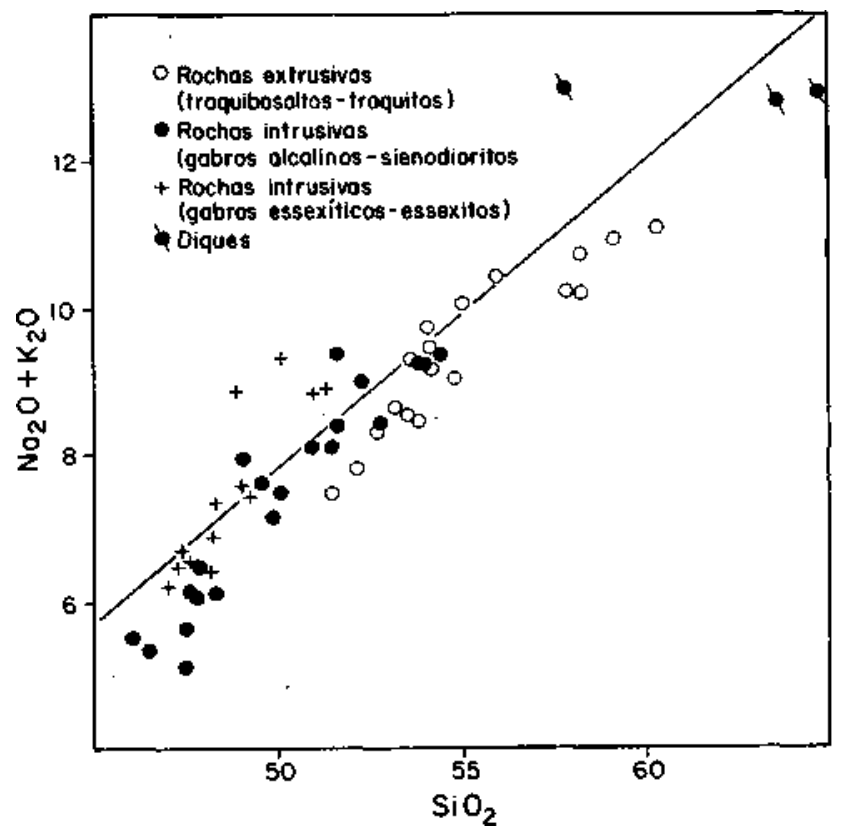

Figura 11 - Projeção das rochas de Acahay no diagrama $\mathrm{SiO}_{2}$ vs. $\mathrm{Na}_{2} \mathrm{O}+\mathrm{K}_{2} \mathrm{O}$ (\% em peso). Linha de referência segundo Saggerson \& Williams (1964)

Figure 11 - Plot of Acahay rocks in the diagram $\mathrm{SiO}_{2}$ vs. $\mathrm{Na}_{2} \mathrm{O}$ (in weight \%). Reference line according to Saggerson \& Williams (1964)

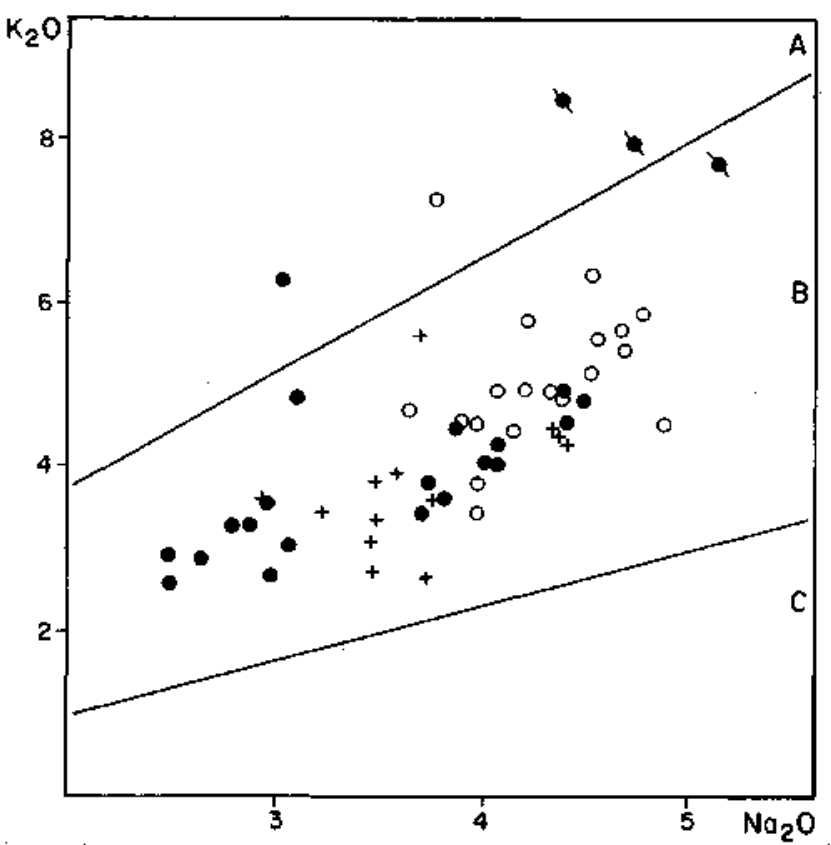

Figura 12 - Projeção das rochas de Acahay no diagrama $\mathrm{Na}_{2} \mathrm{O}$ vs. $\mathrm{K}_{2} \mathrm{O}$ (\% em peso). A. série rica em $\mathrm{K}$; B. série potássica; C. série sódica. Símbolos como na figura 11 Figure 12 - Plot of the Acahay rocks in the diagram $\mathrm{Na}_{2} \mathrm{O} / \mathrm{K}_{2} \mathrm{O}$ (in weight \%). Á. K-rich series; B. potássio series; C. sodic series. Symbols as in figure 11

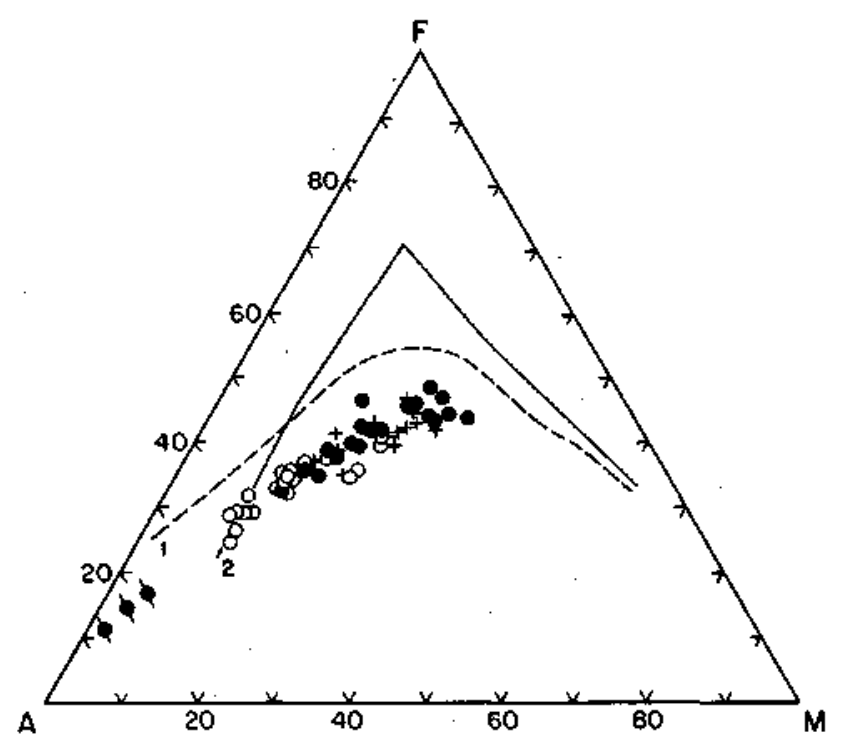

Figura 13 - Projeção das rochas de Acahay no diagrama A $\left(\mathrm{Na}_{2} \mathrm{O}+\mathrm{K}_{2} \mathrm{O}\right)-\mathrm{F}\left(\mathrm{FeO}+\mathrm{Fe}_{2} \mathrm{O}_{3} \times 0,9\right)-\mathrm{M}(\mathrm{MgO})$ (referências: 1. seqüência alcalina e 2. seqüência toleítica do Havai, cf. MacDonald \& Katsura 1964). Símbolos como na figura 11

Figure 13 - Plot of the Acahay rocks in the diagram A $\left(\mathrm{Nap}+\mathrm{K}_{2} \mathrm{O}\right)$ $\mathrm{F}\left(\mathrm{FeO}+\mathrm{Fe}_{2} \mathrm{O}_{3} x\right.$ 0.9) - $\mathrm{M}(\mathrm{MgO})$ (references: 1. Hav aiian alkaline sequence and 2. Hawaiian tholeiitic sequence, in accordance with MacDonald \& Katsura 1964). Symbols as in figure 11 
Tabela 9 - Coeficientes de partição das fases minerais empregadas na modelagem dos cálculos para elementos traços. Fonte: A. Ewart 1984 (comunicação pessoal)

Table 9 - The partition coeeficients of the mineral phases used in the melting model for trace elements. Source: A. Ewart 1984 (personal communication)

\begin{tabular}{|c|c|c|c|c|c|c|c|c|}
\hline & O] & Cp & PI & Mt & $\mathrm{Bi}$ & Anf & Ap & $\mathbf{F A}$ \\
\hline Cr & $1,5 t$ & 9,50 & 0,08 & 46,52 & 8,09 & 0,52 & 0,04 & 0,6 \\
\hline $\mathbf{N i}$ & 10,67 & 1,34 & 0,05 & 8,71 & 7,06 & 0,40 & 0,04 & 0,5 \\
\hline Bạ & 0,06 & 0,213 & 0,77 & 0,34 & 3,80 & 0,826 & 0,05 & 4,1 \\
\hline $\mathbf{K b}$ & 0,037 & 0,058 & 0,22 & 0,09 & 2,51 & 0,322 & 0,04 & 0,8 \\
\hline $\mathbf{S}_{\mathbf{r}}$ & 0,016 & 0,121 & 1,16 & 0,08 & 0,29 & 0,631 & 0,88 & 3,0 \\
\hline La & 0,03 & 0,119 & 0,18 & 0,26 & 0,19 & 0,289 & 8,2 & 0,25 \\
\hline $\mathrm{Ce}$ & 0,04 & 0,190 & 0,17 & 0,27 & 0,17 & 0,298 & 9,6 & 0,15 \\
\hline No' & 0,04 & 0,322 & 0,14 & 0,33 & 0,14 & 0,582 & 10,0 & 0,12 \\
\hline $\mathbf{Z r}$ & 0,045 & 0,46 & 0,085 & 0,3 & 0,34 & 0,47 & 0,3 & 0,15 \\
\hline $\mathbf{Y}$ & 0,09 & 0,61 & 0,066 & 0,35 & 0,54 & 0,672 & 18,2 & 0,01 \\
\hline Nb & 0,165 & 0,066 & $0 ; 051$ & 5,00 & 0,62 & 0,565 & 0,011 & 0,01 \\
\hline
\end{tabular}
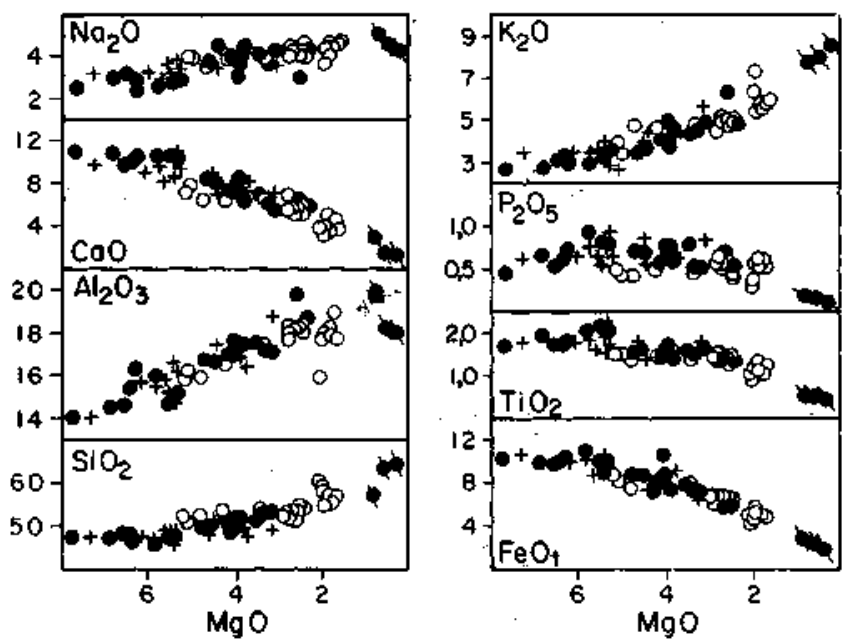

Figura 14 - Diagramas binários ( $\mathrm{SiO}_{2}, \mathrm{Al}_{2} \mathrm{O}_{3}, \mathrm{CaO}, \mathrm{Na}_{2} \mathrm{O}$, $\mathrm{FeO}$ total, $\mathrm{TiO}_{2}, \mathrm{P}_{2} \mathrm{O}$ e $\mathrm{K}_{2} \mathrm{O}$ vs. $\mathrm{MgO}$, valores em \%) para as rochas de Acahay. Símbolos como na figura 11 Figure 14 - Binary diagrams $\left(\mathrm{SiO}_{2}, \mathrm{Al}_{2} \mathrm{O}_{3}, \mathrm{CaO}, \mathrm{Na}_{2} \mathrm{O}, \mathrm{FeO}\right.$ total, $\mathrm{TiO}_{2}, \mathrm{P}_{2} \mathrm{O}$ e $\mathrm{K}_{2} \mathrm{O}$ vs. $\mathrm{MgO}$; in weight $\%$ ) for the Acahay rocks. Symbols as in figure 11

alcalinos (Tab. 11). Estas últimas rochas representam material menos evoluído do maciço $(\mathrm{mg} \sim 0,6)$ e que, com o acréscimo de pequena quantidade de olivina $(5 \%-10 \%)$, é obtido um Valor de mg próximo a 0,7 , típico de magmas primários.

Asssumindo os gabros alcalinos como magma parental das rochas do maciço, procurou-se verificar a sua provável correspondência: produto de fusão de um manto com granada ou de um manto com espinélio. Os valores elevados de La/Y (variação 1,82 - 9,75, média 4,04 $\pm 1,07$ ) indicam uma fonte possivelmente com granada, posto que as altas razões acham-se relacionadas à presença de granada no resíduo sólido. Os basal tos toleíticps da Bacia do Paraná possuem razoes $\mathrm{La} / \mathrm{Y}$ que variam de 0,5 a 1,4, com um valor médio de 0,9 $\pm 0,4$ (Piccirillo et al. 1989a). Considerando que estas rochas são originárias de grau de fusão superior a $10 \%$, os modelos de fusão indicam para os produtos alcalinos de Acahay valores bem inferiores, da ordem de $4-7 \%$.

Se, por um lado, os dados geoqufinicos dos magmas menos evoluídos poderiam ser vistos com sugestivos da sua origem a
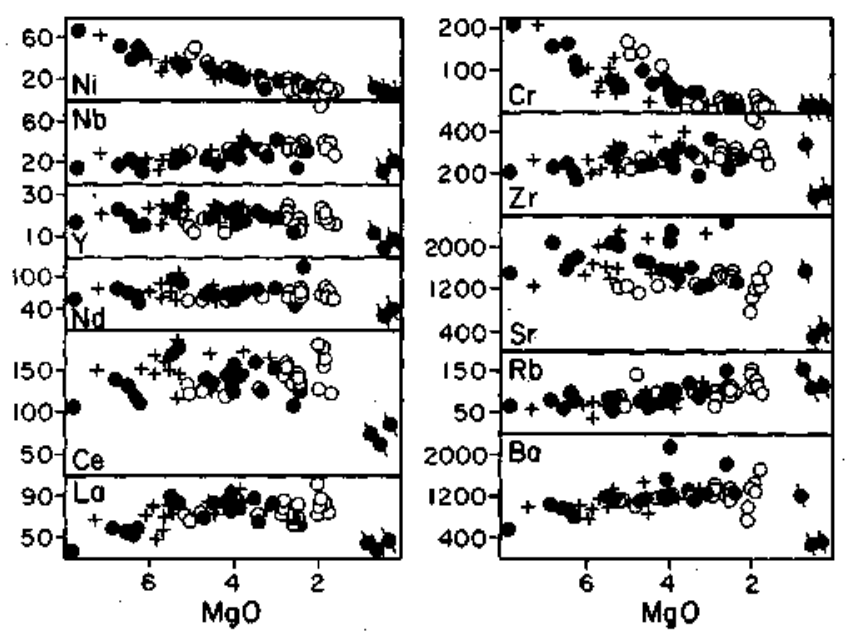

Figura I5 - Diagramas bindrios ( $L a, C e, N d, Y, N b, N i, B a$, $R b, S r, \mathrm{Zr}$ e Cr vs. $\mathrm{MgO}$, valores para os traços em ppm) para as rochas de Acahay. Sambolos como na figura $I I$

Figure 15 - Binsry diagrams ( $\mathrm{La}, \mathrm{Ce}, \mathrm{Nd}, \mathrm{Y}$, nb, Ni, Ba, Rb, Sr, Zr and $\mathrm{Cr}$ vo. $\mathrm{MgO}$; (rece elements in weight\%) for the Acahay rocks, Symbols as in figure 11
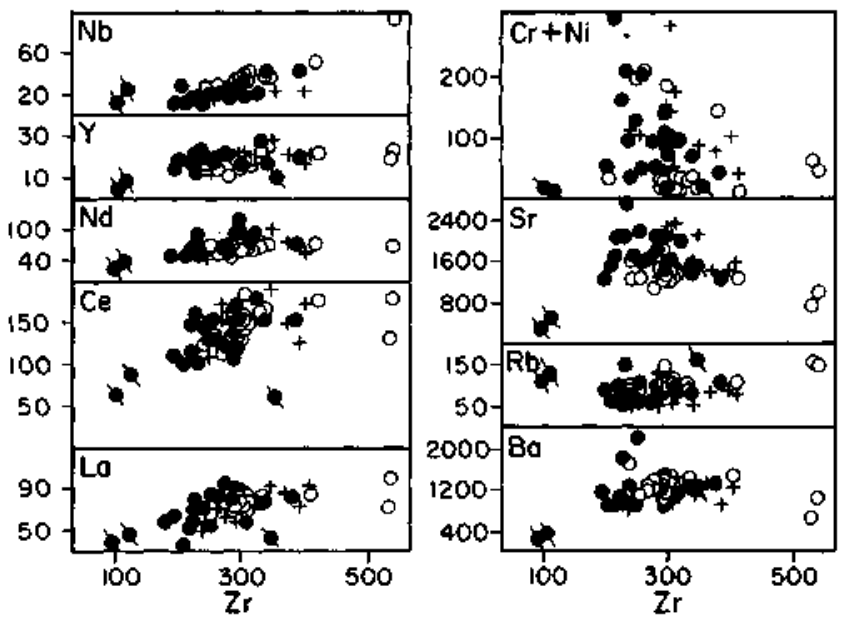

Figura 16 - Diagramas binários (La, Ce, $N d, Y, N b, B a, R b$, $\mathrm{Sr}$ e $\mathrm{Cr}+\mathrm{Ni}$ vs. $\mathrm{Zr}$, valores para os traços em ppm) para as rochas de Acahay. Símbolos como na figura 11

Figure 15 - Binary diagrams ( $\mathrm{La}, \mathrm{Ce}, \mathrm{Nd}, \mathrm{Y}, \mathrm{Nb}, \mathrm{Ba}, \mathrm{Rb}, \mathrm{Sr}$ and $\mathrm{Cr}+$ Ni vs. Zr, in ppm) for the Acahay rocks. Symbols as in figure 11

partir de uma fonte que sofreu grau de fusão diferente, por outro, o comportamento de alguns tracos conduz à especulação sobre fontes heterogêneas e seletivamente enriquecidas em elementos incompatíveis. Em geral, tem-se que estes magmas foram submetidos a processos de fracionamento cristalino com uma evolução, no sistema petrogenético residual (Hamilton \& Mackenzie 1965, Gittins 1979), tendendo ao mínimo fonolítico (Fig. 18).

CONSIDERAÇÕES FINAIS O maciço alcalmo de Acahay, intrusivo em arenitos silurianos e situado junto à porção meridional de um sistema de falhas verticais (Gráben Ypacaraí-Sapukai), apresenta características geológicas e morfológicas que permitem reconhecer: 1. Uma estrutura anelar com essexitos periféricos e gabros alcalinos no interior. 
Tabela 10 - Resultados do balanço de massa para o grupo extrusivo traquibasaltos-traquitos. Abreviações: ol. olivina; cpx. ctinopiroxênio; pi. plagioclâsio; mt. magnetita; bt. biotita; ne. nefelina; ap. apatita; rés soma dos quadrados do resíduo dos elementos maiores; $V$. fração líquida residual. As letras correspondem a algumas possíveis soluções obtidas

Table 10 - Mass balance calculations for the extrusive group trachybasalts-trachytes (abreviations: ol. oKvine; cpx. clinopyroxene; pl. plagioclase; mt. magnetite; bi. biotite; ne. nepheline; ap. apatite; res $^{2}$, sum of the squares of the major element residues; F. residual liquid fraction). Letters correspond to some possible solutions

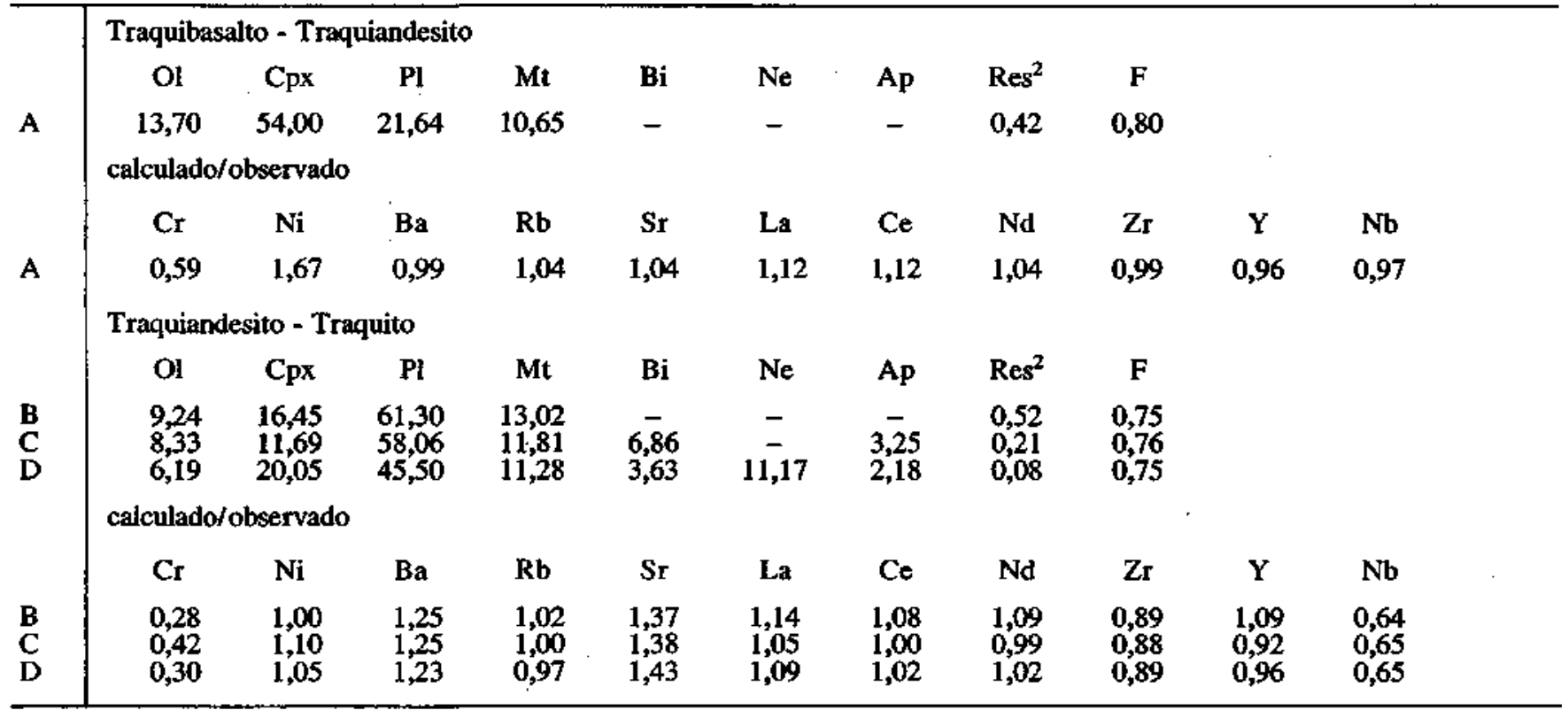

Tabela 11 - Resultados do balanço de massa para o grupo intrusivo gabros alcalinos-sienitos. Abreviaçöes, cono na tabela anterior, mais FA (feldspato alcalino)

Table 11 - Mass balance calculations for the intruaive group alkali gabbros-syenites. Abreviations as in the previous table plus FA (alkali feldspar)

\begin{tabular}{|c|c|c|c|c|c|c|c|c|c|c|c|}
\hline \multirow{5}{*}{$\begin{array}{l}\text { A } \\
\text { B }\end{array}$} & \multicolumn{11}{|c|}{ Gabro alcalino - Sienograbro } \\
\hline & Ol & $\mathrm{Cpx}$ & PI & $\mathbf{M t}$ & $\mathrm{Bi}$ & Anf & Ap & $\operatorname{Res}^{2}$ & $\mathbf{F}$ & & \\
\hline & $\begin{array}{l}8,05 \\
6,72\end{array}$ & $\begin{array}{l}48,19 \\
47,29\end{array}$ & $\begin{array}{l}31,03 \\
28,44\end{array}$ & $\begin{array}{l}12,74 \\
11,84\end{array}$ & $\overline{4,44}$ & $\begin{array}{l}- \\
-\end{array}$ & $\overline{1,27}$ & $\begin{array}{l}0,11 \\
0,01\end{array}$ & $\begin{array}{l}0,72 \\
0,72\end{array}$ & & \\
\hline & \multicolumn{11}{|c|}{ calculado/observado } \\
\hline & $\mathrm{Cr}$ & $\mathbf{N i}$ & $\mathbf{B a}$ & $\mathbf{R b}$ & $\mathbf{S r}$ & La & $\mathrm{Ce}$ & Nd & $\mathbf{Z r}$ & $\mathbf{Y}$ & $\mathbf{N b}$ \\
\hline $\begin{array}{l}\text { A } \\
\text { B }\end{array}$ & $\begin{array}{l}0,10 \\
0,10\end{array}$ & $\begin{array}{l}0,96 \\
0,94\end{array}$ & $\begin{array}{l}0,83 \\
0,79\end{array}$ & $\begin{array}{l}1,13 \\
1,09\end{array}$ & $\begin{array}{l}1,13 \\
1,13\end{array}$ & $\begin{array}{l}0,98 \\
0,94\end{array}$ & $\begin{array}{l}1,19 \\
1,14\end{array}$ & $\begin{array}{l}1,28 \\
1,23\end{array}$ & $\begin{array}{l}1,07 \\
1,06\end{array}$ & $\begin{array}{l}1,12 \\
1,03\end{array}$ & $\begin{array}{l}0,82 \\
0,82\end{array}$ \\
\hline
\end{tabular}

Sienogabro - Sienodiorito

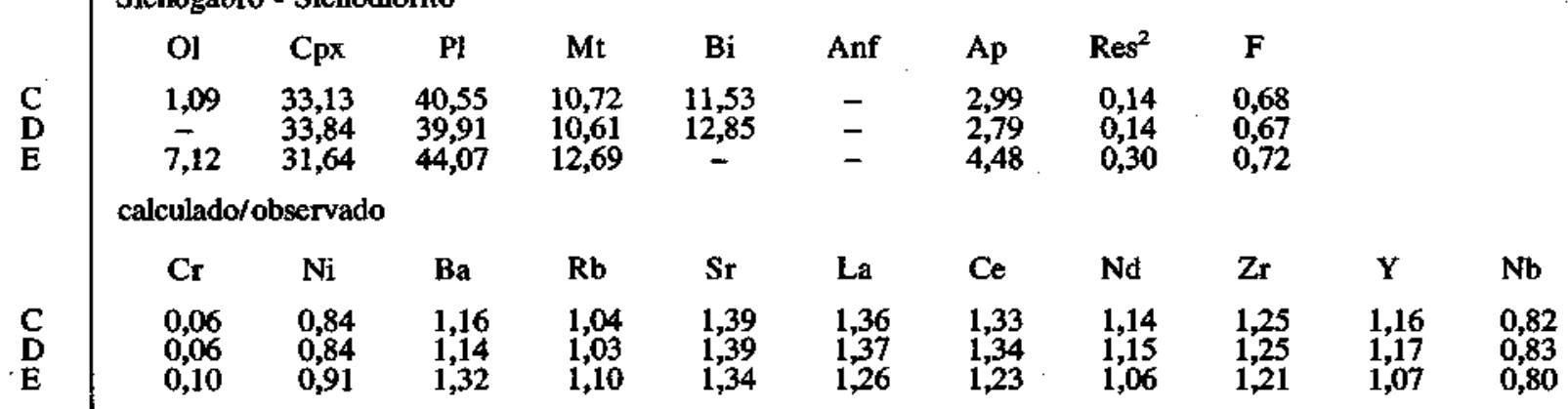

Sienodiorito - Sienito

$\begin{array}{lcccccccccc} & \text { Ol } & \text { Cpx } & \text { Pl } & \text { Mt } & \text { Bi } & \text { Anf } & \text { Ap } & \text { FA } & \text { Res }^{2} & \text { F } \\ \text { F } & \mathbf{0 , 7 5} & 1,60 & 24,54 & \mathbf{3 , 4 8} & - & 31,81 & 1,60 & 36,23 & \mathbf{0 , 0 1} & \mathbf{0 , 1 5} \\ \text { G } & 1,35 & \mathbf{3 , 7 3} & \mathbf{4 3 , 4 1} & \mathbf{4 , 8 5} & \mathbf{7 , 7 5} & 36,28 & \mathbf{2 , 6 4} & - & \mathbf{0 , 0 9} & \mathbf{0 , 4 5} \\ \text { H } & \mathbf{3 , 2 9} & \mathbf{1 8 , 5 2} & \mathbf{5 0 , 1 9} & \mathbf{6 , 5 7} & \mathbf{1 8 , 8 5} & - & \mathbf{2 , 5 8} & - & \mathbf{0 , 3 1} & \mathbf{0 , 4 4}\end{array}$

\begin{tabular}{|c|c|c|c|c|c|c|c|c|c|c|c|}
\hline \multicolumn{12}{|c|}{ calculado/observado } \\
\hline & $\mathrm{Cr}$ & $\mathbf{N i}$ & $\mathbf{B a}$ & $\mathbf{R} \mathbf{b}$ & $\mathbf{S r}$ & $\mathbf{L a}$ & $\mathrm{Ce}$ & Nd & $\mathbf{Z r}$ & $\mathbf{Y}$ & $\mathrm{Nb}$ \\
\hline $\begin{array}{l}F \\
G \\
H\end{array}$ & $\begin{array}{l}4,00 \\
1,00 \\
1,00\end{array}$ & $\begin{array}{l}5,50 \\
2,56 \\
0,94\end{array}$ & $\begin{array}{l}0,71 \\
4,39 \\
3,69\end{array}$ & $\begin{array}{l}2,59 \\
1,45 \\
1,27\end{array}$ & $\begin{array}{l}1,57 \\
5,65 \\
6,18\end{array}$ & $\begin{array}{l}5,75 \\
2,75 \\
2,93\end{array}$ & $\begin{array}{l}6,04 \\
2,75 \\
2,92\end{array}$ & $\begin{array}{l}6,45 \\
3,14 \\
3,57\end{array}$ & $\begin{array}{r}11,05 \\
4,77 \\
5,11\end{array}$ & $\begin{array}{l}6,43 \\
3,09 \\
3,36\end{array}$ & $\begin{array}{l}6,18 \\
2,75 \\
2,87\end{array}$ \\
\hline
\end{tabular}


Tabela 12 - Resultados do balanço de massa para o grupo intrusivo gabros essexíticos-essexitos e para as transições gabros alcalinos-essexíticos e gabros alcalinos-traquibasaltos

Table 12 - Mass balance calculations for die intrusive group essexitic gabbros-essexites and for the transitions alkali gabbros-essexitic gabbros and alkali gabbros-trachybasalts

\begin{tabular}{|c|c|c|c|c|c|c|c|c|c|c|c|}
\hline \multirow{5}{*}{$\begin{array}{l}\text { A } \\
\text { B }\end{array}$} & \multicolumn{11}{|c|}{ Gabro essexítico - Essexito } \\
\hline & Ol & Cpx & PI & $\mathbf{M t}$ & $\mathbf{B i}$ & Ap & $\mathbf{R e s}{ }^{2}$ & $\mathbf{F}$ & & & \\
\hline & $\begin{array}{l}8,24 \\
6,12\end{array}$ & $\begin{array}{l}44,19 \\
39,59\end{array}$ & $\begin{array}{l}36,68 \\
\mathbf{3 5}, 45\end{array}$ & $\begin{array}{r}10,89 \\
8,77\end{array}$ & $\overline{8,31}$ & $\overline{1,77}$ & $\begin{array}{l}0,40 \\
0,03\end{array}$ & $\begin{array}{l}0,67 \\
0,64\end{array}$ & & & \\
\hline & \multicolumn{11}{|c|}{ calculado/observado } \\
\hline & $\mathrm{Cr}$ & $\mathrm{Ni}$ & Ba & $\mathbf{R b}$ & $\mathrm{Sr}$ & La & $\mathrm{Ce}$ & Nd & $\mathbf{Z r}$ & $\mathbf{Y}$ & $\mathbf{N b}$ \\
\hline \multirow[t]{3}{*}{$\begin{array}{l}\mathbf{A} \\
\mathbf{B}\end{array}$} & $\begin{array}{l}0,07 \\
0,07\end{array}$ & $\begin{array}{l}0,90 \\
0,80\end{array}$ & $\begin{array}{l}1,16 \\
1,04\end{array}$ & $\begin{array}{l}1,03 \\
0,98\end{array}$ & $\begin{array}{l}1,28 \\
1,30\end{array}$ & $\begin{array}{l}1,25 \\
1,21\end{array}$ & $\begin{array}{l}1,39 \\
\mathbf{1 , 3 3}\end{array}$ & $\begin{array}{l}1,48 \\
1,42\end{array}$ & $\begin{array}{l}1,06 \\
1,10\end{array}$ & $\begin{array}{l}1,37 \\
1,22\end{array}$ & $\begin{array}{l}0,96 \\
1,00\end{array}$ \\
\hline & \multicolumn{11}{|c|}{ Gabro alcalino - Gabro essexítico } \\
\hline & ol & $\mathrm{Cpx}$ & PI & Mt & $\mathbf{B i}$ & Ap & $\operatorname{Res}^{2}$ & $\mathbf{F}$ & & & \\
\hline \multirow[t]{3}{*}{$\begin{array}{l}\mathbf{C} \\
\mathbf{D} \\
\mathbf{E}\end{array}$} & $\begin{array}{l}4,39 \\
1,90 \\
4,53\end{array}$ & $\begin{array}{l}50,48 \\
50,15 \\
50,32\end{array}$ & $\begin{array}{l}32,73 \\
30,86 \\
32,49\end{array}$ & $\begin{array}{l}12,40 \\
11,42 \\
12,36\end{array}$ & $\stackrel{5,66}{-}$ & $\begin{array}{l}- \\
\overline{0,29}\end{array}$ & $\begin{array}{l}0,10 \\
0,08 \\
0,10\end{array}$ & $\begin{array}{l}0,83 \\
0,82 \\
0,83\end{array}$ & & & \\
\hline & \multicolumn{11}{|c|}{ calculado/observado } \\
\hline & $\mathrm{Cr}$ & $\mathbf{N i}$ & $\mathbf{B a}$ & $\mathbf{R b}$ & $\mathbf{S r}$ & La & $\mathrm{Ce}$ & Nd & $\mathbf{Z r}$ & $\mathbf{Y}$ & $\mathbf{N b}$ \\
\hline \multirow[t]{3}{*}{$\begin{array}{l}\mathbf{C} \\
\mathbf{D} \\
\mathbf{E}\end{array}$} & $\begin{array}{l}0,22 \\
0,20 \\
0,23\end{array}$ & $\begin{array}{l}0,98 \\
0,96 \\
0,98\end{array}$ & $\begin{array}{l}0,94 \\
0,92 \\
0,94\end{array}$ & $\begin{array}{l}1,22 \\
1,20 \\
1,21\end{array}$ & $\begin{array}{l}1,16 \\
1,17 \\
1,16\end{array}$ & $\begin{array}{l}0,97 \\
0,98 \\
0,96\end{array}$ & $\begin{array}{l}1,02 \\
1,03 \\
1,01\end{array}$ & $\begin{array}{l}1,06 \\
1,07 \\
1,05\end{array}$ & $\begin{array}{l}0,91 \\
0,92 \\
0,91\end{array}$ & $\begin{array}{l}1,02 \\
1,02 \\
1,01\end{array}$ & $\begin{array}{l}0,67 \\
0,68 \\
0,67\end{array}$ \\
\hline & \multicolumn{11}{|c|}{ Gabro alcalino Traquibasalto } \\
\hline & Ol & Cpx & $\mathbf{P 1}$ & Mt & $\mathbf{B i}$ & Ap & $\operatorname{Res}^{2}$ & $\mathbf{F}$ & & & \\
\hline $\begin{array}{l}\mathbf{F} \\
\mathrm{G} \\
\mathbf{H}\end{array}$ & $\begin{array}{c}4,55 \\
- \\
-\end{array}$ & $\begin{array}{l}40,65 \\
40,52 \\
39,22\end{array}$ & $\begin{array}{l}40,51 \\
35,29 \\
33,20\end{array}$ & $\begin{array}{l}14,30 \\
11,72 \\
11,93\end{array}$ & $\begin{array}{c}-\overline{12,47} \\
12,99\end{array}$ & $\frac{-}{2,56}$ & $\begin{array}{l}1,22 \\
0,55 \\
0,15\end{array}$ & $\begin{array}{l}0,60 \\
0,56 \\
0,60\end{array}$ & & & \\
\hline & \multicolumn{11}{|c|}{ calculado/observado } \\
\hline & $\mathrm{Cr}$ & $\mathbf{N i}$ & $\mathbf{B a}$ & $\mathbf{R b}$ & $\mathrm{Sr}$ & La & $\mathrm{Ce}$ & Nd & $\mathbf{Z r}$ & $\mathbf{Y}$ & $\mathrm{Nb}$ \\
\hline $\begin{array}{l}\mathbf{F} \\
\mathrm{G} \\
\mathrm{H}\end{array}$ & $\begin{array}{l}0,01 \\
0,01 \\
0,01\end{array}$ & $\begin{array}{l}0,48 \\
0,40 \\
0,43\end{array}$ & $\begin{array}{l}1,14 \\
0,93 \\
0,91\end{array}$ & $\begin{array}{l}1,32 \\
1,18 \\
1,13\end{array}$ & $\begin{array}{l}1,90 \\
2,00 \\
1,43\end{array}$ & $\begin{array}{l}1,34 \\
1,42 \\
1,20\end{array}$ & $\begin{array}{l}1,55 \\
1,65 \\
1,37\end{array}$ & $\begin{array}{l}1,79 \\
1 ; 89 \\
1,57\end{array}$ & $\begin{array}{l}1,34 \\
1,39 \\
1,32\end{array}$ & $\begin{array}{l}\mathbf{1}, 79 \\
1,83 \\
1,38\end{array}$ & $\begin{array}{l}0,62 \\
0,65 \\
0,63\end{array}$ \\
\hline
\end{tabular}

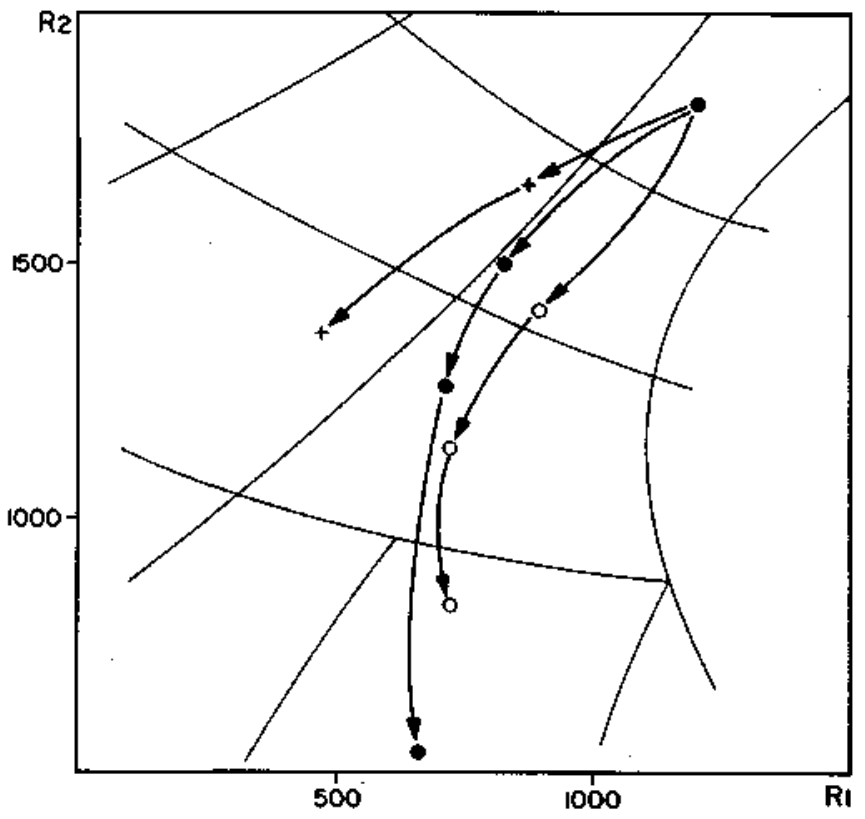

Figura 17 - Representação das unhas de evolução dos diferentes grupos titológicos no diagrama de classificação química de De La Roche et al. (1980). Símbolos como na figura 11 Figure 17 - Evolution lines for the different groups in the chemical classification diagram by De La Roche et al. (1980). Symbols as in figure 11

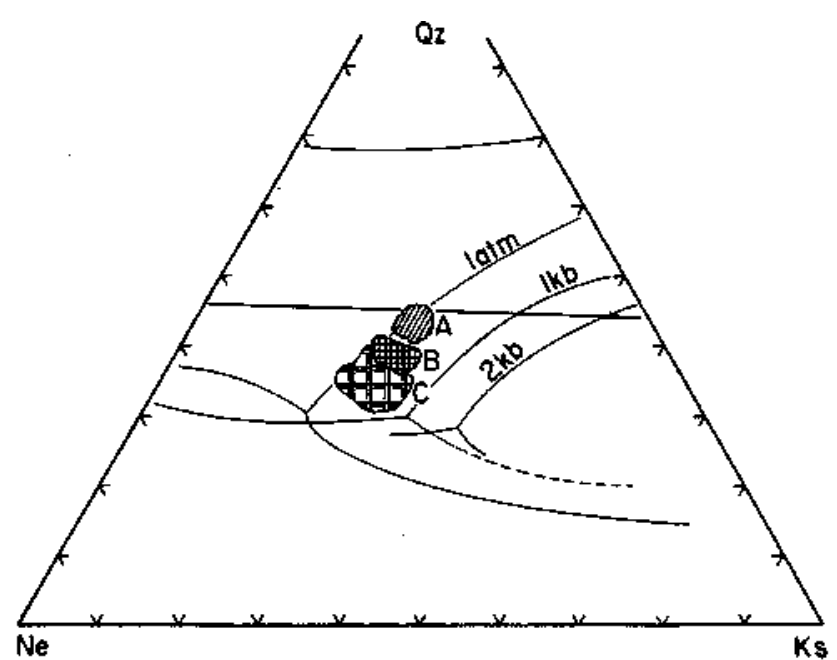

Figura 18 - Projeção das rochas de Acahay no sistema petrogenético residual $N e-K s-Q z$ (A. grupo extrusivo; B. grupo intrusivo gábrico; C. grupo intrusivo essexítico). Símbolos como na figura 11

Figure 18 - Plot of Acahay rocks in the residual Ne-Ks-Qz petrogenetic system (A. extrusive group; B. intrusive group, gabbric; C. intrusive group, essexitic). Symbols as in figure 11 
2. Rochas vulcânicas, que precederam a colocação das massas intrusivas, ocupando as partes altas do complexo.

Do ponto de vista petrográfico e petroquímico, três grupos, litológicos podem ser caracterizados:

1. Grupo extrusivo consistindo de traquibasaltos, traquiandesitos e traquitos.

2. Grupo intrusive representado por gabros alcalinos, sieno-, gabros, sienodioritos e sienitos.

3. Grupo intrusivo constituído de gabros essexíticos e essexitos.

Dentro de cada grupo, e com base em evidências químicas e cálculos numéricos, é possível derivar, por cristalização fracionada, os tipos mais evoluídos dos menos evoluídos. Por outro lado, a alcalinidade diversa exibida pelas litologias do maciço é compatível com a sua formação a partir de uma ou mais fontes de um manto com granada, submetida(s) a graus diferentes de fusão (4\%-7\%). Adicionalmente, dados isotópi-: cos para ${ }^{87} \mathrm{Sr} /{ }^{86} \mathrm{Sr}(\mathrm{R}=0,7073 \pm 0,0003$, idade $130 \mathrm{Ma}$, Bitschene 1987), quando confrontados com os referentes às rochas vulcânicas da Bacia do Paraná, encontradas em território paraguaio $\left(\mathrm{R}_{0}=0,7059\right.$, idade $130 \mathrm{Ma}$, Piccirillo et al. $1989 \mathrm{~b})$, e nefelinitos do vale de Ypacaraí $\left(\mathrm{R}_{0}=\right.$ 0,7036-0,7039, idade 57-38 Ma, Comin-Chiaramonti et al. 1989), são indicativos da natureza mais radiogênica da fonte mantélica mesozóica de tipo litosférico.

Agradecimentos Estes são devidos às agências brasileiras (FAPESP - Procs. 88/1214-0 e 88/0049-6; FINEP - Proc. 43.88.0690.00) e italianas (CNR e MPI) pelo apoio financeiro, bem como ao professor C. Garbarino (Universidade de $\mathrm{Ca}-$ gliari) e P. Da Roit (CNR, Pádua) pela assistência nos trabalhos de microssonda. Os autores agradecem também a R. Zettín (Universidade de Trieste), a A. Giaretta e a G. Mezzacasa (CNR, Pádua) pela valiosa colaboração técnica.

\section{REFERÊNCIAS BIBLIOGRÁFICAS}

ALMEIDA, F.F.M. 1983. Relacões tectônicas das rochas alcalinas mesozóicas da região meridional da plataforma sul-americana. Rev. Bras. Geoc., 13:139-158.

AMARAL, G.; BUSHEE, J.; CORDANI, U.G.; KAWASHITA, K.; REYNOLDS, J.H. 1967. Potassium-argon ages of alkaline rocks from southern Brazil. Geochim. Cosmochim. Acta., 31:117-142.

BELLIENI, G.; BROTZU, P.; COMIN-CHIARAMONTI, P.; ERNESTO, M.; MELFI, Ả.; PACCA, I.G.; PICCIRILLO, E.M.; STOLFA, D. 1983. Petrological and paleomagnetic data on the plateau basalt to rhyolite sequences of the Southern Paraná Basin (Brazil). An. Acad. brasil. Ciênc., 55:355-383.

BERBERT, C.O.1973. Rochas alcalinas do Centro-Oeste brasileiro. In: CONOR. BRAS. GEOL., 27, Aracaju, 1973. Anais... Aracaju, SBG. v.l, p. 469-473.

BERBERT C.O \& TRIGUIS, G 1973 Carbonatito de Pedro Juan Caballero, Paraguai. In: CONOR. BRAS. GEOL., 27, Aracaju, 1973.Resumos... Aracaju, SBG. v.1, p. 77-78.

BITSCHENE, P.R. 1987. Mesozoicher und Kanozoischer anorogener magmatisrnus in Ost Paraguay: arbeiten zur geologic und petrologie zweier alkaliprovinzen. Heidelberg. $317 \mathrm{p}$. (PhD Thesis, University of Heidelberg) (Inédito)

BITSCHENE, P.R. \& LIPPOLT, H. 1984. Geologic der Cordillera del Ybytyruzd in OstParaguay. Ein mesozoischer alkaliintrusiv-komplex am westrand des Parana-Beckens. 9. Geowiss. Lateinamerika-Koll., Marburg,Tag.-Hefte 33-34.

BUDDINGTON, A.F. \& LINDSLEY, D.H. 1964. Iron-titanium oxide minerals and synthetic equivalents. J. Petrol., 5:310-357.

CARMICHAEL, I.S.E. 1967. The iron-titanium oxide minerals of salic volcanic rocks and their associated ferro-magnesian silicates. Contrib. Mineral. Petrol., 14:36-54.

CENSI, P.; COMIN-CHIARAMONTI, P.; LONGINELLI, A.; ORUE, D.; DEMARCHI, G. 1989. Geochemistry and C-O isotopes of the Chiriguelo carbonatite (North-Eastern Paraguay). J. South Amer. Earth Set. (no prelo).

COMIN-CHIARAMONTI, P - CIVETTA, L; PICCIRILLO, E.M.; BELLIENI, G.; BITSCHENE, P.R.; DEMARCHI, G.; GOMES C.B.; PETRINI, R.; CASTILLO, A.M.C.; VELASQUEZ, J.C. 1989. Ultra-alkaline Tertiary magmatism in Eastern Paraguay: petrology and petrogenetic aspects. Lithos. (Submetido).

COMTE, D. \& HASUI, Y. 1971. Geochronology of Eastern Paraguay by the potassium-argon method. Rev. Bras. Geoc., 1:33-43

DE LA ROCHE, H.; LETERRIER, J.; GRANDCLAUDE, P.; MARCHAL, M. 1980. A classification of volcanic and plutonic rocks using R1-R2 diagram and major-element analyses: its relationships with current nomenclature. Chem. Geol., 29:183-210.

EBY, N.G. \& MARIANO, A.N. 1986. Geology and geochronology of carbonatites peripheral to the Paraná Basin. Brazil-Paraguay. In: CARBONATITES SYMPOSIUM, Ottawa, $1986.13 \mathrm{p}$.

ECKEL. E.B. 1959. Geology and mineral resources of Paraguay, a reconnaissance. U. S. Geol. Surv. Prof. Pap., (327): 1 1Op.

FRANZINI, M.; LEONI, L.; SAITTA, M. 1975. Revision! di una metodologia analítica per fluorescenza-X basata sulla correzione degli effeti di $m \& t t i c e$.Rend. Soe. Ital. Min. Petrol., 31:365-378.

GALLO, P. 1988. Studio petrografico delmassiccio alcalino diAcahay (Paraguay Orientate). Italia. 188p. (Tese de Graduação em Ciências Geológicas, Universidade de Palermo) (Inédito).

GITTINS, D.B. 1979. The feldspathoidal alkaline rocks. In: YODER, H.S. Jr. ed. The evolution of the igneous rocks. Princeton, Princeton University Press, p. 351-390.
GOMES, C B · BARBIERI, $\mathrm{M}$ - BECCALUVA, L · BROTZU, P CONTE, A.; GARBARINO, C.; MACCIOTTA, G.; MELLUSO, L.; MORBIDELLI, L.; RUBERTI, E.; SCHEIBE, L.F. TÄMURA, R.M.; TRÄVERSA, G. 1987. Petrological and geochemical studies of alkaline rocks from continental Brazil. 2. The Tunas massif, State of Parana. Geochim. Brasil., 1:201-234.

HAMILTON, D.L. \& MACKENZIE, W.S. 1965. Phase equilibrium studies in the system $\mathrm{NaAlSiO}_{4}-\mathrm{KAlSiO}_{\mathrm{a}}-\mathrm{SiO} 2-\mathrm{H}_{2} \mathrm{O}$. Mineral. Mag., 34:214-231.

HARRINGTON, H. 1950. Geologia del Paraguay Oriental. Buenos Aires, Fac. Ci. Exac. Fis. Nat. Contr. Cient. Ser. E. Geol. 1:1-88.

LEAKE, B.E. 1978. Nomenclature of amphiboles. Amer. Mineral., 63:1023-1052.

LEONI, L. \& SAITTA, M. 1976. X-ray fluorescence analysis of 29 trace elements in rock and mineral standard. Rend. Soe. Ital. Min. Petrol. 32:497-510.

LIVIERES, R.A. \& QUADE, H. 1987. Distribution regional y asentamiento tectónico de los complejos alcalinos del Paraguay. Zbl. Geol. Palaont., Teil I, H. 7/8:791-805.

MACDONALD, G.A. \& KATSURA, T. 1964. Chemical composition of Hawaiian lavas. J. Petrol., 5:82-133.

MATHEZ, E.A. 1973. Refinement of the Kudo-Weill plagipclase thermometer and its application to basaltic rocks. Contr. Mineral. Petrol., 41:61-72.

NORTHFLEET, A A · MEDEIROS, R A ; MULHMANN, H 1969. Reavaliação dos dados geológicos da Bacia do Paraná. Bol. Tec. Petrobrás, 12:291-346.

PALMIERI, J.H. 1973. El complejo alcalino de Sapukai (Paraguay Oriental) Espanha. (Tese, Universidad Salamanca) (Inédito).

PALMIERI, J.H. \& ARRIBAS, A. 1975. El complejo alcalino-potasico de Sapukai (Paraguay Oriental). In: CONOR. IBERO-AMER. GEOL. ECON., Buenos Aires, Anais... v.2, p. 267-300.

PALMIERI, J.H.; PFLUGFELDER, P.; CUEVAS, F. 1974 Contribución a la geologia regional del area de Nea - Cerro Sarambf. Rev. Soc. Cient. Paraguay, 14:62-66.

PAPIKE, J.J.; CAMERON, K.; BALDWIN, K. 1974. Amphiboles and pyroxenes: characterization of other than quadrilateral components and estimates of ferric iron from microprobe data. Bull. Geol. Soc. Amer., 6:1053-1054.

PETRI, S. \& FÚLFARO. V J. 1983. Geologia do Brasil. Fanerozóico. São Paulo; Editora USP. $63 \mathrm{lp}$.

PICCIRILLO, E.M.; COMIN-CHIARAMONTI, P.; MELFI, AJ.; STOLFA, D.; BELLIENI, G.; MARQUES, L.S.; GIARETTA A.; NARDY, AJ.R.; PINESE, J.P.P.; RAPOSO, M.I.B.; ROISENBERG, A 1989a. Petrochemistry of continental flood basalt-rhyolite suites and related intrusives from the Paraná basin (Brazil). In: PICCIRILLO, E.M. \& MELFI, A. J. eds. The mesozoic flood volcanism of the Paraná Basin: petrogenetic and geophysical aspects. IAG-USP (no prelo)

PICCIRILLO E.M. CIVETTA, L · PETRINI, R · LONGINELLI, A ; BELLIENI, G.; COMIN-CHIARAMONTI, P.; MARQUES, L.S. MELFI, A J. 1989b. Regional variationswithin the Paraná flood basalts (southern Brazil): evidence for subcontinental mantle het-

erogeneity and crustal contamination. Chem. Geol., 75:103-122.

POLDERVAART, A \& HESS, H.H. 1951. Pyroxenes in the crystallization of basaltic-magmas.J. Geol., 59:472-489.

POWELL, M. \& POWELL, R. 1977. Plagioclase-alkali feldspar geothermometry revisited. Mineral. Mag., 41:253-256.

PUTZER, H. 1962. Die geologic von Paraguay. Beitr.Reg. GeoL.Erde, 2:1-182. 
PUTZER, H. \& VAN DEN BOOM, G. 1962. Über einige Voikommen von Alkaligesteinen in Paraguay. Geol. $J b$., 79:423-444.

ROCK, N.M.S. 1982. Chemical mineralogy of the Monchique Alkaline Complex, Southern Portugal. Contrib. Mineral. Petrol, 81:64-78.

RUBERTI, E. 1984. Petrologia do maciço alcaUno doBanhadão, PR. São Paulo. 249p. (Tese de Doutoramento. Universidade de São Paulo) (Inédito).

SAGGERSON, E.P. \& WILLIAMS, L.A.J. 1964. Ngurumanite from South Kenia and its bearing on the origin of rocks in the northern Tanganyka alkaline district. J. Petrol., 5:40- 81.

SIMKIN, T. \& SMITH, J.V. 1970. Minor element distribution in olivine,J. Geol., 78:304-325.

SONOKI, I.K. \& GARDA, G.M. 1988. Idades K-Ar de rochas alcalinas do Brasil Meridional e Paraguai Oriental: compilação e adaptação às novas constantes de decaimento. Boi. IG-USP, 19 (Ser. Cient.) (no prelo).

STEIGER, R.H. \& JÃGER, E. 1978. Subcommission on Geochronology: convention on the use of decay constants in geochronology and cosmochronology. Contribution to the geologic time scale. Studies in Geology, 6:67-71.
STEPHENSON, D. 1974. Mn \& Ca enriched olivines from nepheline syenites of the South Qooroq centre. South Greenland. Lithos, 7:35-41.

STEPHENSON, D. \& UPTON, B.GJ. 1982. Ferromagnesian silicates from a differentiated alkaline complex. Kungnat Fjeld, South Greenland. Mineral. Mag., 46:283-300.

STORMER, J.C.: GOMES, C.B.; TORQUATO, R.F. 1975. Spinel Iherzolite nodules in basanite lavas from Asuncion, Paraguay. Rev. Bras. Geoc., 5:176-185.

VALENÇA, J.G. 1980. Geology, petrography and petrogenesis of some alkaline igneous complexes of Rio de Janeiro State. Brazil. Ontario. $284 \mathrm{p}$. (PhD Thesis, University of Western Ontario) (Inédito).

WRIGHT, T.L. \& DOHERTY, P.C. 1970. A linear programming and least squares computer method for solving petrologic mixing problems. Geol. Soc.Amer.Butt., 81:1995-2008

MANUSCRITO A616

Recebido em 16 de agosto de 1989

Revisão do autor em 10 de dezembro de 1989 Revisão aceita em 02 de março de 1990 